University of Louisville

ThinkIR: The University of Louisville's Institutional Repository

Electronic Theses and Dissertations

$5-2011$

\title{
How collaborative the collaboration? : assessing the collaboration of services for juvenile offenders.
}

James G. Dickerson

University of Louisville

Follow this and additional works at: https://ir.library.louisville.edu/etd

\section{Recommended Citation}

Dickerson, James G., "How collaborative the collaboration? : assessing the collaboration of services for juvenile offenders." (2011). Electronic Theses and Dissertations. Paper 343.

https://doi.org/10.18297/etd/343

This Doctoral Dissertation is brought to you for free and open access by ThinkIR: The University of Louisville's Institutional Repository. It has been accepted for inclusion in Electronic Theses and Dissertations by an authorized administrator of ThinkIR: The University of Louisville's Institutional Repository. This title appears here courtesy of the author, who has retained all other copyrights. For more information, please contact thinkir@louisville.edu. 
HOW COLLABORATIVE THE COLLABORATION?

ASSESSING THE COLLABORATION OF SERVICES FOR JUVENILE

OFFENDERS

By

James G. Dickerson

B.A. Indiana University, Bloomington, IN 2003

M.S.W. University of Southern Indiana, Evansville, IN 2007

\author{
A Dissertation \\ Submitted to the Faculty of the \\ Graduate School of the University of Louisville \\ In Partial Fulfillment of the Requirements \\ For the degree of
}

\title{
Doctor of Philosophy
}

\author{
Kent School of Social Work \\ University of Louisville \\ Louisville, Kentucky
}

May 2011 



\title{
HOW COLLABORATIVE THE COLLABORATION?
}

\section{ASSESSING THE COLLABORATION OF SERVICES FOR JUVENILE OFFENDERS}

\author{
By \\ James $\mathrm{G}$. Dickerson \\ B.A. Indiana University, Bloomington, IN 2003 \\ M.S.W. University of Southern Indiana, Evansville, IN 2007
}

A Dissertation Approved on

April 11, 2011

\begin{tabular}{c}
\hline Ruth Huber, Ph.D., Chair \\
\hline drystal Collins-Camargo, Ph.D. \\
\hline Karla Whashingtøn, Ph.D. \\
\hline Eli Karam, Ph.D. \\
Patty Cook-Craig, Ph.D.
\end{tabular}




\section{DEDICATION}

This dissertation is dedicated to Dr. Ruth Huber and my parents who have been unwavering in their support:

To Dr. Ruth Huber, who has always believed in my abilities and who continues to be a source of inspiration. You first told me that I must commit myself $100 \%$ to get everything I could from my doctoral education at the University of Louisville. If it had not been for you, my mentor, my teacher, my friend, the highs would not have been quite as high, and the lows would surely have been that much lower. Thank you, for being a role model and showing me what it means to be a true academic.

To my parents, Jim and Marilyn, who have always supported and encouraged my education. From my mother I learned the importance of an education; it is something I should always value and that it can never be taken away. From my father I learned about persistence and completing a project; if something is worth doing, it is worth doing well and correctly. Thank you both for everything that you have done and continue to do for me. 


\section{ACKNOWLEDGEMENTS}

I would like to thank Dr. Crystal Collins-Camargo. First, I would like to thank her for giving me an opportunity to work on her grant, and second for always being available to discuss my findings and the direction of the research.

Thank you, Dr. Karla Washington, for your mentoring, supervision, and support. She took on the arduous task of teaching me qualitative methodologies, and encouraged me to be innovative, as long as there is scholarship to support that innovation.

Thank you to my Committee members: Dr. Eli Karam, and Dr. Patti CookCraig. You are talented, busy people, and I appreciate your time and your expertise in guiding me through this process.

Thank you to the Office of the President: President Ramsey, Ms. Kathleen McDaniel-Smith, and Ms. Debbie Dougherty. You provided me with the means, a Graduate Assistantship with the President's Office, to participate in the doctoral program at the University of Louisville. I will be forever grateful.

Thank you to Emily Heineke. You taught me about Wraparound philosophies and how important it is for social support agencies to work in collaboration for the benefit of complex family systems.

Finally, I must thank the partners of the JETS Program. You allowed me access to your program and entrusted me with your unfiltered comments. 
Without you and your dedication to providing services to the juveniles and families of Jefferson County this research would not have been possible. 


\title{
ABSTRACT \\ HOW COLLABORATIVE THE COLLABORATION? ASSESSING THE COLLABORATION FOR SERVICES FOR JUVENILE OFFENDERS.
}

\author{
James G. Dickerson
}

April 11, 2011

Juvenile delinquency with co-occurring substance abuse and mental health disorders has become an increasing problem within the United States. In part this can be attributed to the excessive number of delinquent youth entering the juvenile justice system with untreated substance abuse and/or mental health disorders-thus requiring juvenile justice to become a default system for substance abuse and mental health intervention and treatment services. In an effort to combat this problem, governmental, mental health, social support agencies, and school systems have formed interagency collaborations to provide more effective treatment services. One such interagency collaboration is the JETS Program, a court diversion program that provides intervention and treatment services for juvenile offenders with co-occurring substance abuse and mental health disorders. This study identifies the relationship between shared meaning and collaboration as well as the relationship between collaboration and goal achievement among the nine agencies involved in the JETS Program during the first year of the program's inception. Utilizing a concurrent nested design and deductive content analysis, both qualitative and quantitative methodologies contributed to studying the phenomena of shared meaning and the impact that 
shared meaning can have on a juvenile interagency collaboration. In order to accomplish this task, 16 service providers (i.e., individuals who provide, or supervise the direct services to juveniles participating in the JETS Program) participated in semi-structured interviews and service provider surveys that focused on the individual's perceptions of collaboration within the JETS Program partnership. Findings indicate that although the JETS Program partners had shared meaning around the appropriate professionals being involved with the program and the goal of the program, a lack of shared meaning on partner roles, referral processes, and overall program structure contributed to negative program outcomes and a general sense of frustration among the service providers. 
TABLE OF CONTENTS

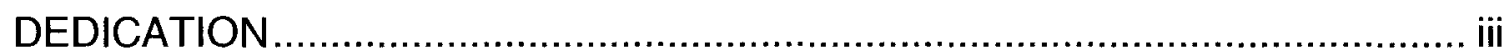

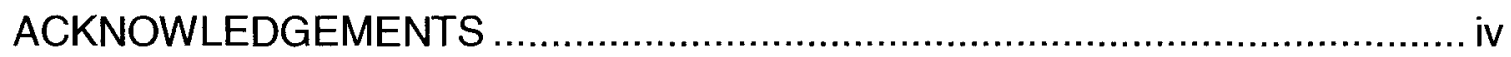

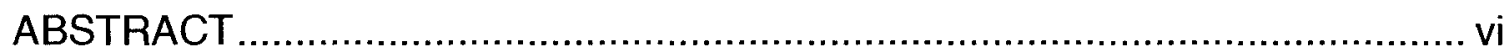

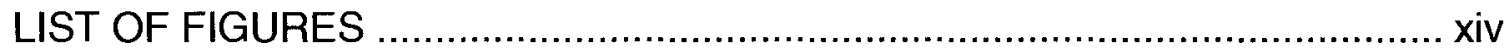

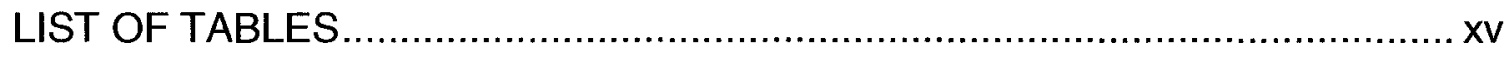

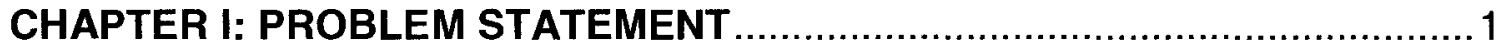

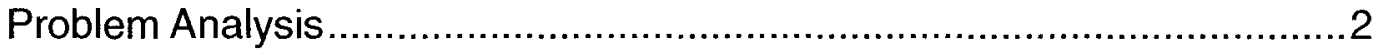

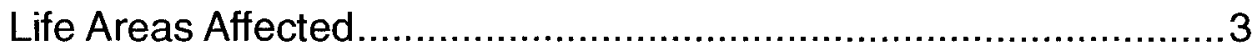

Social and Mental Health Factors............................................ 5

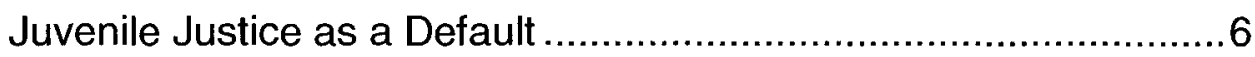

Juvenile Court Diversion Programs ....................................... 8

The $1^{\text {st }}$ Principle of the Wraparound Model:

Family Voice and Choice …......................................... 10

The $2^{\text {nd }}$ Principle of the Wraparound Model:

Team Based ……..................................................... 10

The $3^{\text {rd }}$ Principle of the Wraparound Model:

Natural Supports ............................................................ 10

The $4^{\text {th }}$ Principle of the Wraparound Model:

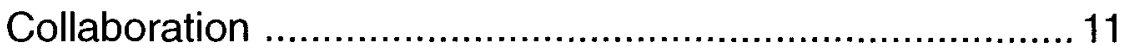


The $5^{\text {th }}$ Principle of the Wraparound Model:

Community Based

The $6^{\text {th }}$ Principle of the Wraparound Model:

Cultural Competency

The $7^{\text {th }}$ Principle of the Wraparound Model:

Customized Treatment Plan

The $8^{\text {th }}$ Principle of the Wraparound Model:

Strengths Based

The $9^{\text {th }}$ Principle of the Wraparound Model:

Persistence 12

The $10^{\text {th }}$ Principle of the Wraparound Model:

Measureable Outcomes 12

Louisville Network for Substance Abuse and co-occurring Treatment (LANScAT) ....................................................... 13

Purposes of the Research ..............................................14

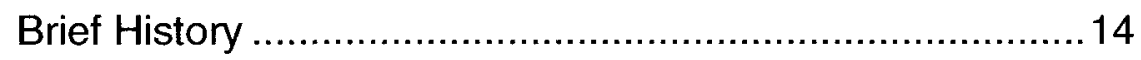

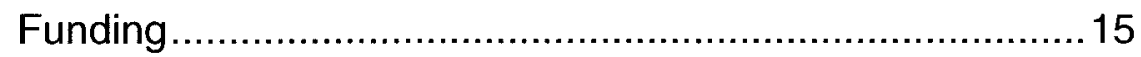

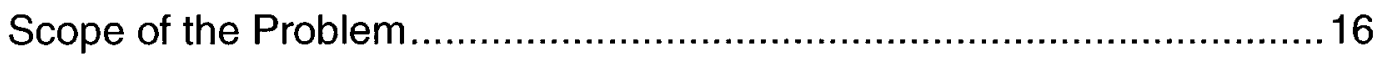

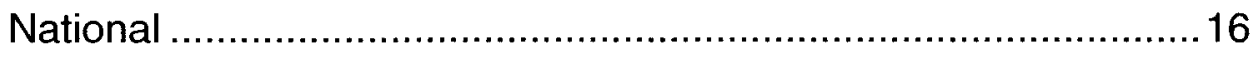

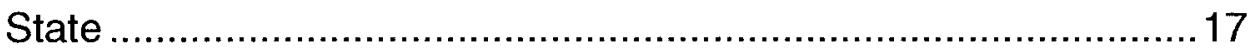

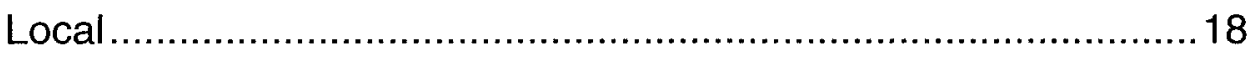

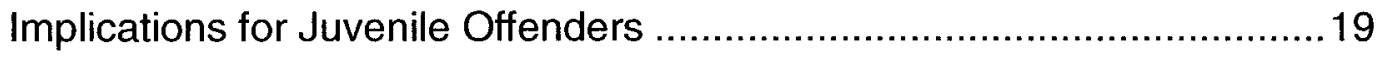

At the Macro System Level.......................................................20 
At the Mezzo System Level

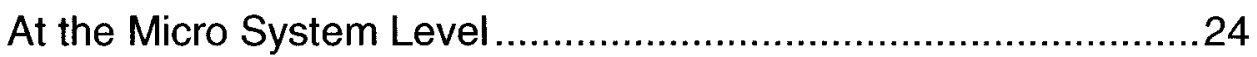

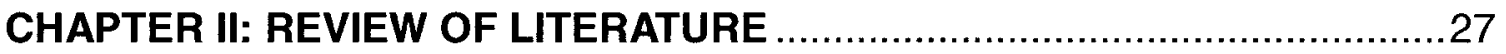

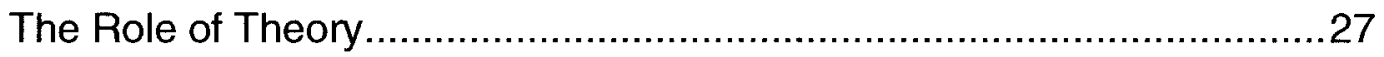

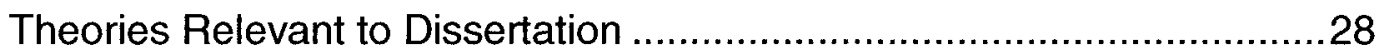

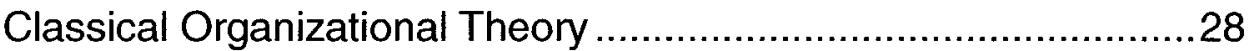

Rationale for Discarding Theory .......................................29

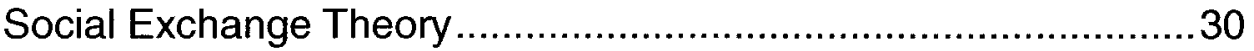

Rationale for Discarding Theory.........................................31

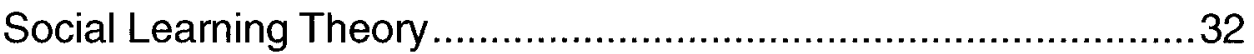

Rationale for Discarding Theory .......................................33

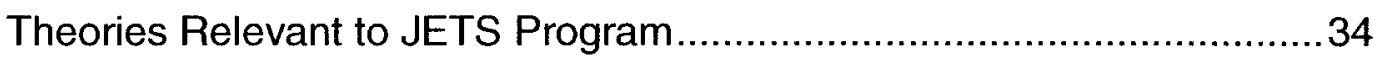

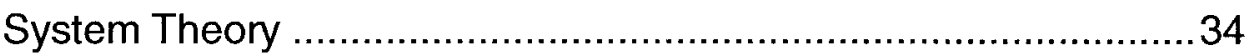

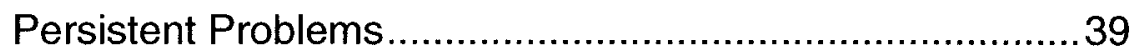

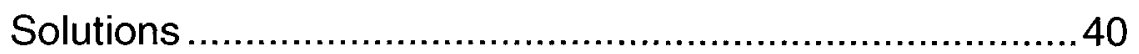

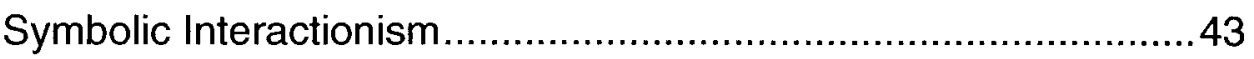

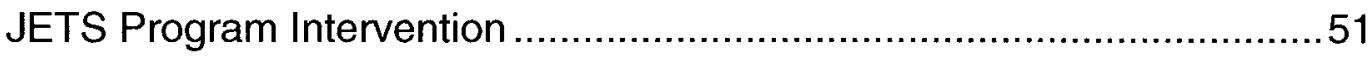

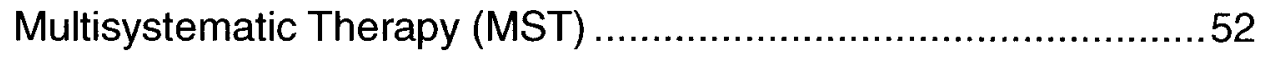

Drug and Mental Health Court Programs .............................................53

The Juvenile Counseling and Assessment Program (JCAP) .........54

The Weber Human Services Drug Court ......................................55

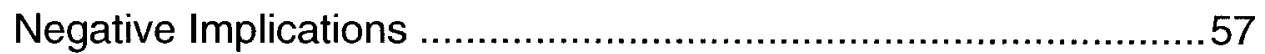

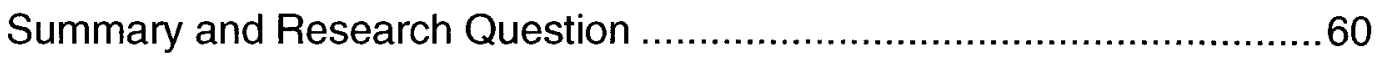




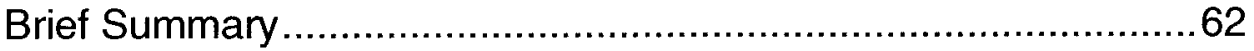

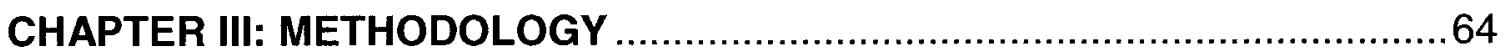

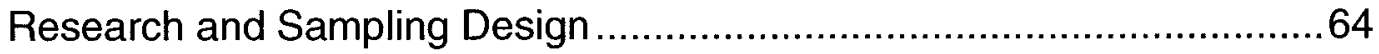

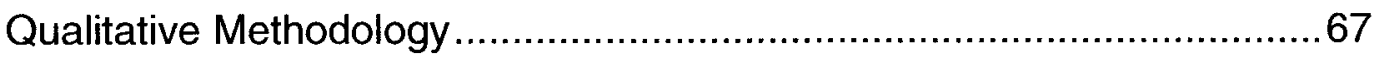

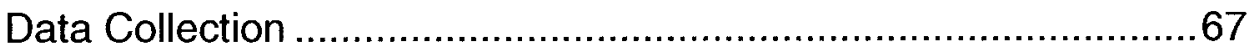

Operationalization of Synergy …..............................................

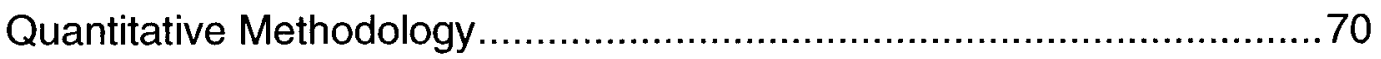

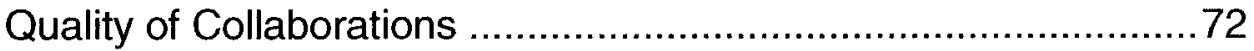

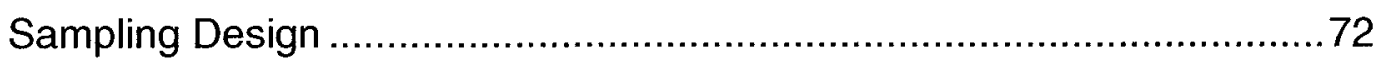

Institutional Review Board (IRB) Considerations ..........................73

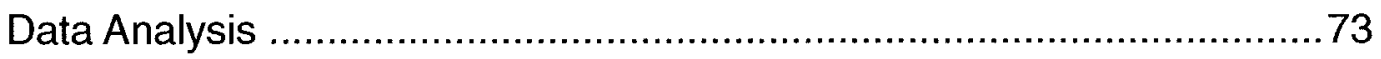

Qualitative Data Analysis.........................................................

Deductive Content Analysis ............................................ 75

Scientific Rigor ....................................................

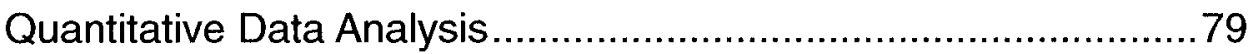

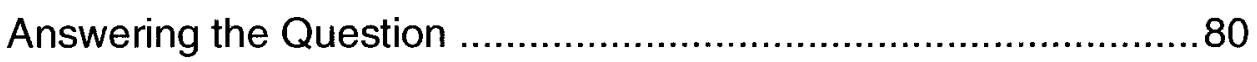

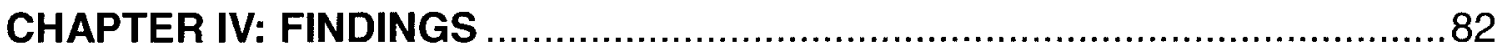

Constructs and Emergent Themes with High Degree of Shared

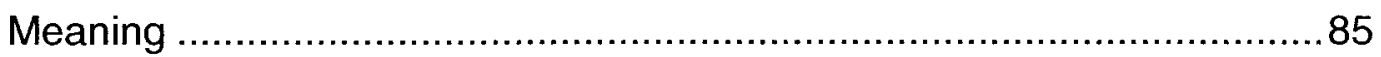

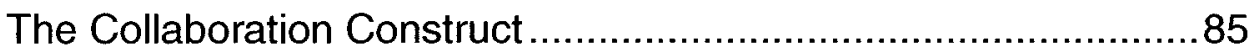

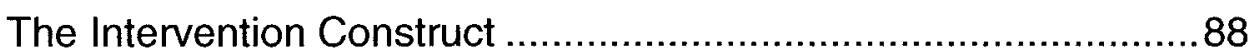

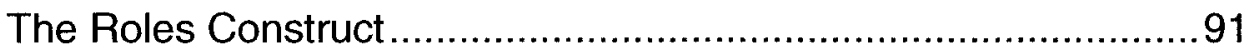

The Program Structure Construct...............................................93 
Constructs and Emergent Themes with Low Degree of Shared

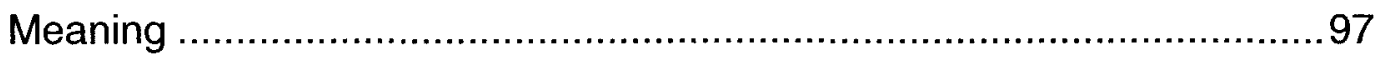

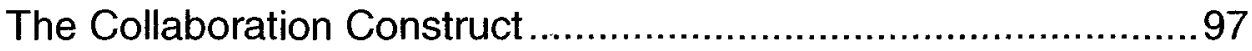

The Intervention Construct .......................................................100

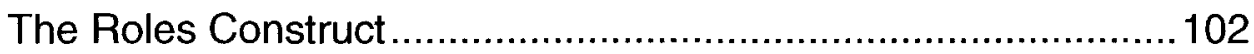

The Program Structure Construct..........................................104

The Referral Construct ........................................................107

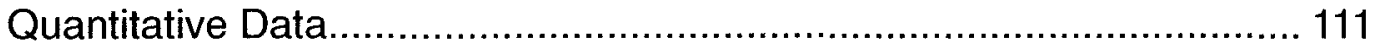

Service Provider Surveys .................................................... 111

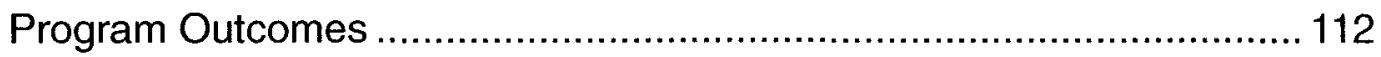

CHAPTER V: SUMMARY and RECOMMENDATIONS ............................116

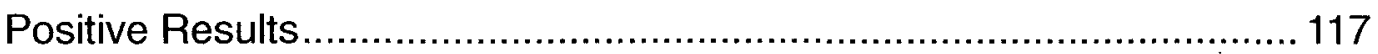

Appropriate Professionals at the Table .................................117

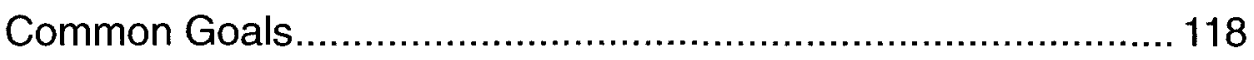

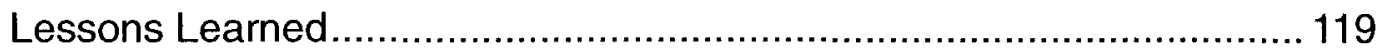

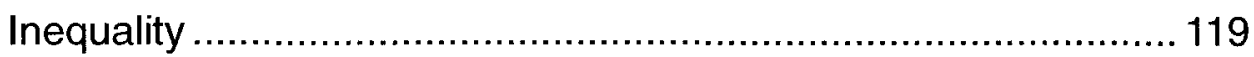

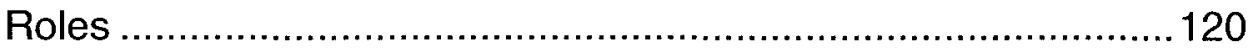

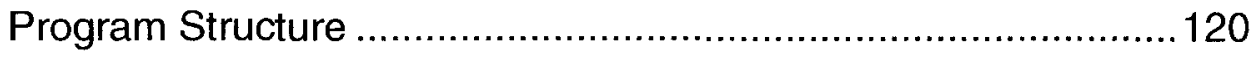

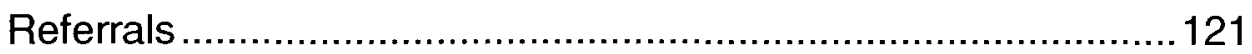

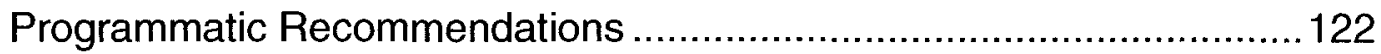

Effective Lines of Communication ..............................................122

Cross Training Team Members ................................................123

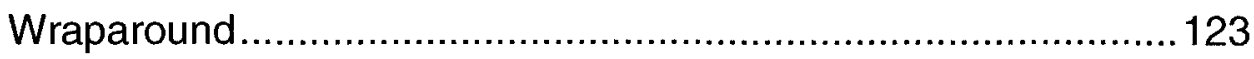


The $2^{\text {nd }}$ Principle of the Wraparound Model:

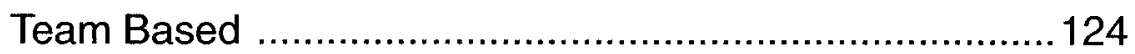

The $10^{\text {th }}$ Principle of the Wraparound Model:

Measureable Outcomes …........................................... 124

Recommendations for Research on Collaborations ............................125

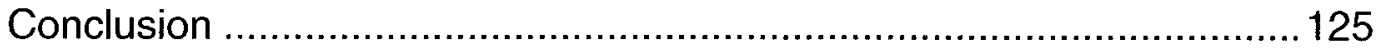

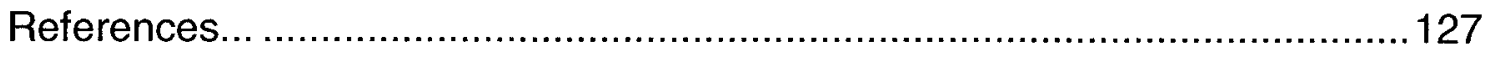

Appendix A: Service Provider Informed Consent ......................................148

Appendix B: Service Provider Survey and Questionnaire ............................152

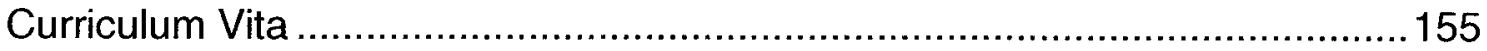




\section{LIST OF FIGURES}

1. Requested budgets for FY 2010 (national, state, \& local) ...........................21

2. Conceptual map of macro, mezzo, and micro systems for JETS Program .....35

3. Conceptual map of input, transformation and output for JETS Program .........37

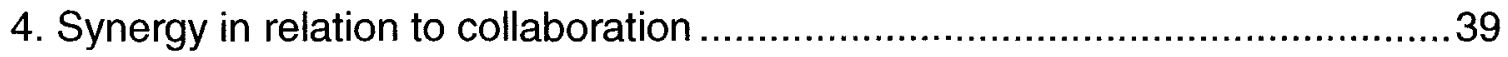

5. Conceptual map of feedback, entropy, and synergy ..................................40

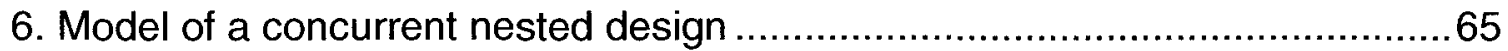

7. Deductive reasoning comparative analysis model ....................................74

8. Relationship between Shared Meaning, Collaboration, and Program

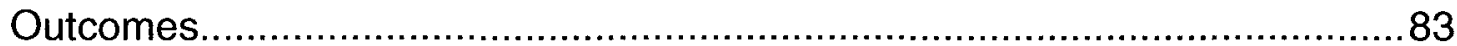




\section{LIST OF TABLES}

3.1. Semi structured Interview Questions for Service Providers .....................68

3.2. JETS Program: Synergy determinants operationalized...........................71

3.3. General Steps for analyzing/interpreting data from a concurrent nested

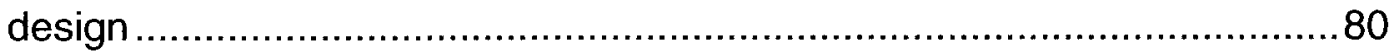

3.4. Specific Steps for analyzing/interpreting data from the JETS Program......81

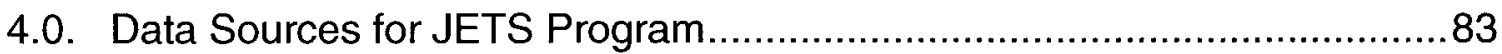

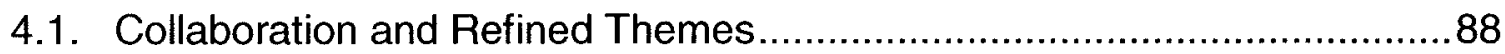

4.2. Content from Open-Ended Questions Relevant to Collaboration

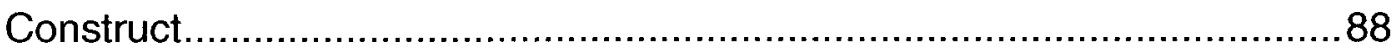

4.3. Intervention and Refined Themes ......................................................

4.4. Content from Open-Ended Questions Relevant to Intervention Construct.

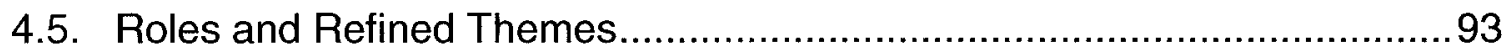

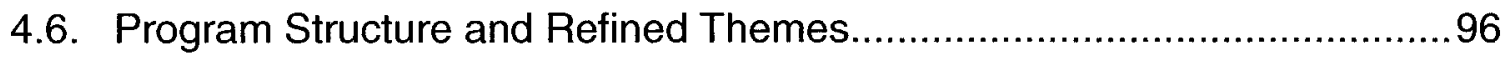

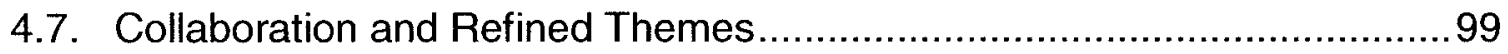

4.8. Content from Open-Ended Questions Relevant to Collaboration

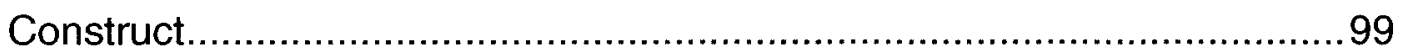

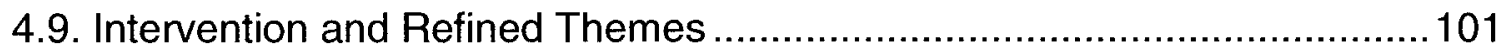

4.10. Content from Open-Ended Questions Relevant to Intervention 
Construct. 102

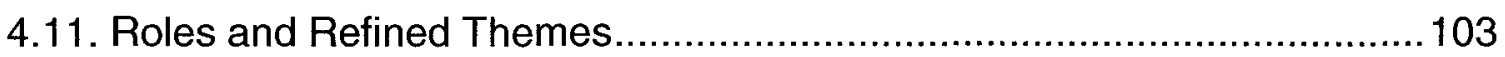

4.12. Content from Open-Ended Questions Relevant to Roles Construct ........104

4.13. Program Structure and Refined Themes........................................107

4.14. Content from Open-Ended Questions Relevant to Program Structure Construct 107

4.15. Referral and Refined Themes 108

4.16. Content from Open-Ended Questions Relevant to Referral Construct .....109

4.17. Summary of High and Low Levels of Shared Meaning with Constructs and Refined Themes 111

4.18. Findings from the Service Provider Surveys .....................................112

4.19. Program Evaluation Findings from July - September 2010 ..................113

4.20. Program Evaluation Findings from October - December 2010 ..............114 


\section{CHAPTER I}

\section{PROBLEM STATEMENT}

Juvenile delinquency with co-occurring substance abuse and mental health disorders has become an increasing problem within the United States. Due to the complex needs of these juveniles and the economic constraints of their communities, governmental, mental health, social support agencies, and school systems have formed interagency/community collaborations designed to provide more effective treatment services (Calhoun, Glaser, \& Bartolomucci, 2001; Flash, 2003; Hopkins, 2002; Nissen, 2007; Nissen, Merrigan, \& Kraft, 2005).

The purpose of this dissertation is to identify the relationship between shared meaning and collaboration as well as the relationship between collaboration and goal achievement among the nine agencies involved in the JETS Program. However, evaluating collaboration outside of the context of the purpose of the alliance itself lacks sufficient foundation for understanding the cooperative effort. Therefore, this chapter provides a clear picture of the juvenile offenders with co-occurring substance abuse and mental health disorders whom the partnership serves. Chapter II reviews relevant theories and the literature pertaining to collaborations per se, and the methodology is in Chapter III. 
To introduce the problem of juvenile delinquency with co-occurring substance abuse and mental health disorders, this chapter is divided into three main sections. The first section is a problem analysis that includes (a) an overview of the multiple life areas, (b) social and mental health factors, (c) the use of juvenile justice as a default treatment system for juveniles with cooccurring substance abuse and mental health disorders, (d) the use and structure of juvenile court diversion programs that were developed to address the increasing problems of these youth, and (e) a brief introduction to Louisville Adolescent Network for Substance Abuse \& co-occurring Treatment (LANScAT).

The second section is a discussion of the scope of the problem. This section outlines the economic outlook for providing treatment to these juvenile offenders at the national level in the United States, the state level for the Commonwealth of Kentucky, and the local level for the City of Louisville (Jefferson County), Kentucky

The third section is a review of the implications for juvenile offenders with co-occurring substance abuse and mental health disorders at the macro, mezzo, and micro system levels. Finally, this section introduces the literature on interagency/community collaboration in Chapter II.

\section{Problem Analysis}

Research has linked the occurrence of delinquent behaviors by juveniles with co-occurring substance abuse and mental health disorders (Hesse, Hesse, \& Lawrence, 2009; Robertson, Dill, Husain, \& Undesser, 2004). This link has shown that when juveniles are involved in substance abuse with co-occurring 
mental health disorders, there are ramifications for themselves, their families and their communities (Hamilton, Sullivan, Veysey, \& Grillo, 2007; Henderson, Rowe, Dakof, Hawes, \& Liddle, 2009; Ozechowski \& Liddle, 2000).

\section{Life Areas Affected}

Juveniles who abuse substances will often experience problems in one, or possibly multiple, life areas, including academics, health/mental health, peer relationships, and the legal system. Regarding academics, juveniles who are involved with substance use/abuse are more susceptible to declining grades, absenteeism from school and extracurricular activities, and have a higher rate of dropping out of school (Williams, Davis, Johnson, Williams, Saunders and Nebbitt, 2007). Cox, Zhang, Johnson, and Bender (2007) reported that there is a complex relationship between substance use/abuse and academic performance. These researchers believe the connection linking academic performance and substance abuse is not completely understood and that few studies have focused on the relationship between academic achievement and substance use. The causation or etiology of juvenile substance abuse and the resulting injuries of said use is more common.

Studies have also shown that juveniles who are involved with substance abuse are more prone to health and/or mental injuries due to accidents (e.g., auto), and sexually transmitted diseases (Plancherel, Bolognini, Stephan, Laget, Chinet, Bernard, \& Halfon, 2005; Rowe, Wang, Greenbaum, \& Liddle, 2008). To illustrate this point, Bingham and Shope (2004), found that automobile accidents are a leading cause of death in young drivers. Although these accidents usually 
involved substance use, and in particular, alcohol, other factors contribute to poor driving habits, including inexperience, anger and/or depression, poor decision making, thrill seeking, and/or personality factors.

Rowe, Wang, Greenbaum, and Liddle (2008) wrote that many juveniles with substance use/abuse problems engage in behaviors that place them at risk of contracting HIV/AIDS and other sexually transmitted diseases. These risky behaviors may include the use of needles for injecting substances or poor judgment and impulse control while experiencing the effects of the mood-altering substances. Although the rate of AIDS diagnoses has been relatively low among teenagers due to a long latency period, the Centers for Disease Control (2008) cautioned that many young adults can be infected with HIV in their early teens, which can lead to the continuing spread of the disease into young adulthood.

Research conducted at the National Center on Addiction and Substance Abuse (CASA) at Columbia University (2004), found that approximately $80 \%$ of the children and teens involved in the United States Juvenile Justice System were under the influence of alcohol and/or drugs when they committed their crimes, tested positive for drugs, were arrested for alcohol or drug offenses, admitted having substance abuse and addiction problems, or shared some combination of these characteristics. Wade and Pevalin (2005) also reported a link between substance abuse and delinquency. For many juveniles who abuse illicit substances, arrest, adjudication and intervention by the juvenile justice systems are inevitable. However, it is Wade and Pevalins's contention that one does not cause the other. In fact, their findings show that additional antecedents 
can contribute to behavior problems in children, including social and mental health factors.

\section{Social and Mental Health Factors}

Many juveniles are at high risk for delinquency and substance abuse given the quality of their neighborhoods. Often, their neighborhoods are disadvantaged, neglected, and are run amuck with crime, drug use, and drug selling (Fishbein \& Perez, 2000). However, not all juveniles fall victim to their environments. Fishbein and Perez (2000) found that juveniles who were more connected to positive peer and parental influences were more likely to adhere to the norms and values of society, while those youth who were connected to negative peer and parental influences were less likely to conform.

Parker and Benson (2004) also reported similar observations. They examined parental support and monitoring juveniles. It was hypothesized that greater levels of parental support and monitoring would be associated with higher self-esteem and less risky behavior, while conversely, lower levels of parental support and monitoring would be associated with lower self-esteem and higher degrees of risky behavior in adolescents. Their results confirmed that parents should be supportive of their adolescents and monitor their daily activities.

To this point the primary focus has been on adolescents, delinquency and substance abuse; another component of this ever-increasing problem falls in the mental illness realm. While an in-depth analysis of the Diagnostic and Statistical Manual for Mental Disorders ( $4^{\text {th }}$ Edition; DSM-IV) categories for juveniles is beyond the purpose and scope of this dissertation, mental health disorders 
among juveniles can include psychotic illnesses, major depression, AttentionDeficit and Hyperactivity Disorders (ADHD), and conduct disorders, to name a few. In 2000, the United States Surgeon General reported that approximately 1 in 5 children and adolescents will experience the signs and symptoms of a mental health disorder during the course of a year, and that about 1 in 10 children of this $20 \%$ will experience significant functional impairments as a result (Parens \& Johnston, 2008). Further, the National Center for Mental Health and Juvenile Justice (Shufelt \& Cocozza, 2006) found that $70 \%$ of youth involved in the juvenile justice system have or can be diagnosed with mental health disorders. In other words, of the approximately 106,000 adolescents who are held in juvenile detention facilities each year, two-thirds (approximately 60,066) of the boys and three-quarters (approximately 11,925 ) of the girls have at least one mental health disorder (Izquierdo, Healy, Rinderle, \& Matthews, 2005).

According to the Substance Abuse and Mental Health Services Administration (SAMHSA): Drug and Alcohol Services Information System (DASIS) Report (2005), individuals will have co-occurring disorders when there is more than one disorder (alcohol or mental health) existing at the same time. "A diagnosis of co-occurring disorders will occur when at least one disorder of each type can be established independent of the other and is not simply a cluster of symptoms resulting from the one individual disorder" (SAMHSA, p. 1).

\section{Juvenile Justice as a Default}

According to the United States Department of Justice, Office of Juvenile Justice and Delinquency Prevention (Skowyra \& Cocozza, 2006), the criminal 
justice system has become the default system of treatment for juveniles with cooccurring substance abuse and mental health disorders. Not only are many of these juveniles non-diagnosed, they are often detained in large correctional facilities in which the staff are not adequately trained in mental health or substance abuse treatment. Further, this lack of staff knowledge and training can increase the youth's risk of additional traumatic experiences and the development of more serious mental health issues related to detoxification.

Communities, governments, and families are experiencing an increasing amount of social and economic strain. This strain, in part, can be attributed to the excessive number of delinquent youth who have not received effective treatment for their substance abuse and/or co-occurring mental health disorders that contributed to their delinquent behaviors (Calhoun, Glaser, \& Bartolomucci, 2001; Flash, 2003; Hopkins, 2002; Nissen, 2007; Nissen, Merrigan, \& Kraft, 2005). Although many communities have social and rehabilitative services available to delinquent youth and their families, these services are often uncoordinated, i.e., miscommunications between the various services, miscommunications between the agencies, youth and/or families, duplication of services being provided to the youth and/or the families (Gyamfi, Keens-Douglas, \& Medin, 2007), and a lack of treatment of the substance abuse and/or mental health disorders that contributed to the juveniles' delinquency when providing social and rehabilitative efforts to youth and families (Evans, Armstrong, Beckstead, \& Lee, 2006). Thus, enter the juvenile court system. 


\section{Juvenile Court Diversion Programs}

One way in which juvenile courts are combating this problem is with the implementation of juvenile drug courts and diversion programs. The juvenile drug courts are designed as intensive treatment programs that provide specialized services for eligible drug involved juveniles and their families. These specialized services include an array of services such as substance abuse treatment, mental health service and family counseling, primary medical care, coordinated supervision of the juvenile and continued education (Office of Juvenile Justice and Delinquency Prevention, 2001).

The diversion component is intended to prevent juveniles with cooccurring mental health and substance abuse disorders from entering the criminal justice system; rather, to refer them into services that can positively impact their substance abuse and mental health problems. These programs have the potential to provide more services to at-risk juveniles. Additionally, the diversion program has the goal of reducing the juvenile's interaction with other, possibly more serious, deviant groups. By doing so, these juveniles will have less chance of encountering the labeling impact of courts and judges. This, in turn, will positively impact the juvenile's development of secondary deviance patterns by being labeled delinquent. Ultimately, another goal of the juvenile court diversion programs is to keep inappropriate juveniles out of the juvenile justice system and reduce the strain on the system (Patrick \& Marsh, 2005).

Unfortunately, this progressive approach does not always reduce recidivism, rehabilitate or deter continuing involvement with the juvenile justice 
system. However, when juvenile drug courts and court diversion programs are combined with intersystem collaborations and comprehensive service planning, they have been shown to positively impact multiple domains (e.g., individual, parent, family, and community) for the youth (Pullman, Kerbs, Koroloff, VeachWhite, Gaylor, \& Sieler, 2006).

Such collaborative approaches are often referred to as wraparound services-from the concept of a family wrapping its arms around an injured child, wraparound services organize and coordinate services for juveniles with complex needs. These juveniles are often involved with multiple service providers and the approach is based on developing plans that focus on the individual strengths and needs of each juvenile and their family. These individualized and unique plans are intended to center around the family and the community. Possible services in this approach are clinical therapy, substance abuse treatment, special education, medication dispersal, caregiver support, public assistance, employment training, housing support, medical health care, mentorship programs, transportation, and coordination of services with other community agencies such as juvenile justice and child welfare (Pullman, Kerbs, Koroloff, Veach-White, Gaylor, \&Sieler, 2006).

This service model emphasizes individualized service planning that is community-based and provided in the least restrictive environment. It is culturally competent, integrated, and comprehensive, and requires the full participation of the juveniles, their families, and the treatment team. There are 10 key principles in the wraparound-service model: family voice and choice, team based, natural supports, collaboration, community-based, culturally competent, individualized, 
strength-based, persistence, and outcome-based (Bruns, Walker, Adams, Miles, Osher, Rasher, \& VanDenBerg, 2004).

The $1^{\text {st }}$ Principle of the Wraparound Model: Family Voice and Choice The first principle posited by Bruns and colleagues (2004), family voice and choice, refers to the priority placed on the family's and child's perspectives. There is usually no better expert on what will work for that family than the family itself. The team provides options and choices that reflect the family values and preferences for treatment, monitoring, and support services.

\section{The $2^{\text {nd }}$ Principle of the Wraparound Model: Team Based}

Team based, the second principle, encompasses the notion that the treatment team will consist of agreed upon individuals (e.g., family members, friends, teachers, therapists, doctors, probation officers, and welfare workers). The intent is that these individuals will be committed to the best interests of the youth and their families in informal, formal, and community support relationships (Bruns, Walker, Adams, Miles, Osher, Rast, \& VanDenBerg, 2004).

\section{The $3^{\text {rd }}$ Principle of the Wraparound Model: Natural Supports}

The third principle encourages the involvement of the juveniles and their family's natural supports, identified as the family's interpersonal and community relationships including relatives, neighbors, sponsors, churches, and athletic groups. In turn, the treatment plan includes activities and interventions that draw on these sources of natural support (Bruns, Walker, Adams, Miles, Osher, Rasher, \& VanDenBerg, 2004). 


\section{The $4^{\text {th }}$ Principle of the Wraparound Model: Collaboration}

Collaboration means that the team members work together and share responsibility for the treatment plan. In turn, the treatment plan should reflect a blending of the team's perspectives, mandates, and resources (Bruns, Walker, Adams, Miles, Osher, Rasher, \& VanDenBerg, 2004).

\section{The $5^{\text {th }}$ Principle of the Wraparound Model: Community Based}

By being community-based, services can be provided in the most inclusive, responsive, accessible, and least restrictive setting as possible (Bruns, Walker, Adams, Miles, Osher, Rasher, \& VanDenBerg, 2004). This encourages the juvenile's safe reintegration into the family, home and community.

\section{The $6^{\text {th }}$ Principle of the Wraparound Model: Cultural Competency}

Cultural competency means that the team demonstrates respect for the youth and family's values, preferences, beliefs, culture, and identities, as well as those of their communities (Bruns, Walker, Adams, Miles, Osher, Rasher, \& VanDenBerg, 2004). Because of this and the fact that no two families are alike, the treatment plan must be individualized.

\section{The $7^{\text {th }}$ Principle of the Wraparound Model: Customized Treatment Plan}

The team must develop and implement a customized set of strategies, supports and services (Bruns, Walker, Adams, Miles, Osher, Rasher, \& VanDenBerg, 2004). If the same plan or constellation of services worked equally well for all juveniles and their families, there would be no need to customization, but this is not the case. Just as juveniles and their families are each unique, so must be interventions. 


\section{The $8^{\text {th }}$ Principle of the Wraparound Model: Strengths Based}

The treatment plan must identify, build on, and enhance the capabilities, knowledge, skills, and assets of the child, family, community and team members. Identifying the strengths of troubled families may be one of the more difficult of the team's tasks (Bruns, Walker, Adams, Miles, Osher, Rasher, \& VanDenBerg, 2004). However difficult, all families have strengths that treatment plans can be built upon such as personal talents and skills, religious or spiritual ideology, relatives, friends, neighbors, housing, health, and/or something as innate as a love for each other.

\section{The $9^{\text {th }}$ Principle of the Wraparound Model: Persistence}

Persistence means that the team works together toward the identified goals until there is mutual agreement among team members, including the juvenile and family, that the team's services and processes are no longer needed (Bruns, Walker, Adams, Miles, Osher, Rasher, \& VanDenBerg, 2004). Persistence does not mean staying with service plans that are not working; rather, it means changing and updating the plan until it works.

\section{The $10^{\text {th }}$ Principle of the Wraparound Model: Measureable Outcomes}

The final principle is that the process is outcome based; goals and/or objectives must have measureable indicators of success. When necessary, the treatment plan should be revised or updated to reflect the goals of the team (Bruns, Walker, Adams, Miles, Osher, Rasher, \& VanDenBerg, 2004). One such treatment team has been developed by the Louisville Adolescent Network for 
Substance Abuse \& co-occurring Treatment (LANScAT) - the team behind the collaborative program on which this dissertation is based.

\section{Louisville Adolescent Network for Substance Abuse and Co-occurring Treatment (LANScAT)}

In Louisville, KY, the Administrative Offices of the Juvenile Court, Seven Counties Mental Health and Substance Abuse Center, along with various other local social support agencies (both public and private), have joined efforts to produce Louisville Adolescent Network for Substance Abuse \& co-occurring Treatment (LANScAT). Based on a collaborative approach, one goal of LANScAT is to identify the at-risk population of mental illness/co-occurring disorder youth as early as possible and to provide evidence-based intervention and treatment services to gain positive outcomes for the identified youth and their families. This is accomplished through the Juvenile Enhanced Treatment Service, or JETS. In the development of the JETS program, the Executive Committee of LANSCAT determined that the services for youth with mental illnesses or co-occurring mental health and substance use disorders require more deliberate coordination to eliminate service fragmentation and improve the effectiveness of the system's response. Furthermore, the services provided by the JETS program should not only include mental health and substance abuse treatment, but also provide other supportive services such as educational, vocational, leisure time/recreation, mentoring, and other family support services. 


\section{Purposes of the Research}

The Juvenile Enhanced Treatment Service (JETS) program in Jefferson County, KY (Louisville, KY), is a partnership of various judicial, governmental, educational, and substance abuse/mental health agencies that work with juvenile offenders and their families. Before stating the purposes of this interagency/community collaboration evaluation, a brief history of the origins of the Louisville Adolescent Network for Substance Abuse and co-occurring treatment (LANSCAT) and the subsequent JETS Program is provided.

\section{Brief History}

LANScAT was established in 2002 by Seven Counties Services, Inc. through a Center for Substance Abuse Treatment grant called Strengthening Communities: Youth (SCY). The intent of the grant is to identify at-risk juveniles with co-occurring substance abuse and mental health disorders while increasing the treatment capacity within the community to better serve these juveniles and their families. LANSCAT is a network of both private and public agencies that provide services to such juveniles and is based on an interagency/community collaborative approach. In an attempt to further assist identified juvenile offenders with co-occurring substance abuse and mental health disorders, their families, and their communities the LANSCAT Executive Committee developed the JETS Program.

JETS is a diversionary program-juveniles are under court orders to be incarcerated or are on probation of some form, and JETS has the potential to be an extraordinary and positive option for them. One of the primary goals of 
LANScAT is to identify the at-risk population of youth with co-occurring substance abuse and mental health disorders as early as possible, and to provide evidence based intervention and treatment services to gain positive outcomes for the juveniles and their families-keeping juveniles in their communities instead of incarcerating them farther away from their families and support systems. This is the goal of the JETS Program.

The JETS Program is an interagency/community collaboration of representatives from the Jefferson County Juvenile Court Judicial Branch and the Administrative Offices of the Court, Law Enforcement, Prosecutor's Office, Public Defender's Office, Child Protective Services, Department of Juvenile Justice, Juvenile Detention Services, Substance Abuse/Mental Health Agencies, Jefferson County Public School System, and community volunteers. Funding for the JETS Program was established through a Federal grant.

\section{Funding}

The JETS Program is funded by a Federal grant awarded to the Jefferson County Administrative Office of the Courts by the Bureau of Justice $(\$ 350,000$ over a 2.5 year timeframe). A stipulation of the grant is that annual evaluations be completed by an outside evaluator and the Principal Investigator is Crystal Collins-Camargo, Ph.D., Kent School of Social Work, University of Louisville, The funding for the JETS Program evaluation component is $\$ 40,000$ per year $(\$ 80,000)$, with an additional $\$ 20,000$ for the half year at the end for final evaluation. This dissertation draws from interviews with the collaborators from the participating agencies to learn their perspectives of how well the collaboration 
is working and, therefore, contributing to the effectiveness of services to the youth and their families. Federally funded juvenile court diversion programs, such as the JETS Program, have been initiated in hopes of lessening the impact of juvenile delinquency with co-occurring substance abuse and mental health disorders on national, state and local levels.

\section{Scope of the Problem}

\section{National}

During any 12-month period in the United States, an estimated 10 million people have at least one mental health and one substance abuse disorder (SAMHSA, 2008). Unfortunately, the outlook for juveniles within this group with co-occurring disorders in the juvenile justice system is no better. Skowyra and Cocozza (2001), in their most recent findings for the Office of Juvenile Justice and Delinquency Prevention, estimate that two-thirds (approximately 71,000 ) of these juvenile detainees have one or more alcohol drug and mental disorders. Nationwide, this figure translates to more than 670,000 youth (individuals under the age of 18) each year, who are processed through the juvenile justice system and require mental health and/or substance abuse treatment.

Research conducted at the National Center on Addiction and Substance Abuse (CASA) at Columbia University (2004), indicated that approximately $80 \%$ of the children and teens involved in the United States Juvenile Justice System are under the influence of alcohol and/or drugs while committing their crimes, or test positive for drugs after their arrests. Additionally, these teens are arrested for committing alcohol or drug offenses, and/or admit to having substance abuse 
and/or addiction problems. The problem of juvenile delinquency with co-occurring substance abuse and/or mental health disorders is just as pronounced in the Commonwealth of Kentucky as in the national findings.

\section{State}

The Commonwealth of Kentucky, Office of Juvenile Justice and Delinquency Prevention (Kentucky Justice \& Public Safety Cabinet, 2008) reported that 3,397 juveniles were arrested in the Commonwealth during 2008; of these juveniles 729 (21.5\%) were arrested for alcohol and/or drug offenses. Further, the Kentucky Division of Substance Abuse (2004) reported that of the 38,587 adolescents assessed, 3,389 (approximately $9 \%$ ) were referred to early intervention programs and 1,753 (approximately $5 \%$ ) were made to publicly funded treatment programs. In 1998 and 2005, the University of Kentucky conducted the Household Survey of Adolescents. This survey, in addition to determining levels of drug use, estimated the percentage of adolescents needing treatment based on an abuse or dependency diagnosis per the DSM-IV, as well as the number of adolescents who had actually received treatment. Using 2000 census data, it is estimated that 32,500 Kentucky adolescents or about $10 \%$ of the12-17 year old population, needed treatment, but that only about 4,700 of the 32,500 who needed treatment received treatment-about $15 \%$, or 1 of every 7 adolescents. Of the 4,700 youth who received treatment in 2001 , about 1,800 (slightly more than one-third) received services in a publicly funded Community Mental Health Center. The remaining two-thirds were seen in privately funded 
programs (Wolf, Gibson, Watson, \& Leukefeld, 2005). Juvenile substance abuse offenses have been just as prevalent in Jefferson County/Louisville, KY.

\section{Local}

From January 2000 through December 2004, 3,581 juvenile arrests were made in Louisville/Jefferson County for drug and alcohol related offenses. Charges include possession of illegal drugs, controlled substances, prescription drugs, prescription violations, drug paraphernalia, selling to minors, selling near a school, and public intoxication. Results from the Louisville and Jefferson County, Drug, Alcohol and Violent Crime Database Report shows that 1,790 juveniles were arrested between January 2004 and December 2005 (834 in 2004 and 956 in 2005). These offenses included possession of drug paraphernalia, trafficking, possession, cultivating and manufacturing, and other offenses. Some of the offenses included in the other category were selling drugs near a school and public intoxication (Louisville Metro Police Department, 2005). However, these numbers do not reflect the juveniles who have been arrested for other law violations and assessed for substance use and or mental health disorders. The Crime in Kentucky Report indicated that in 2009 there were 445 juveniles arrested for substance and alcohol related offenses: 389 for Narcotic Drug Law violations, 11 for Driving Under the Influence (DUI), 22 for Liquor Law violations, and 23 for Public Drunkenness (Kentucky State Police, 2009). The implications for the staggering numbers of juvenile delinquency with co-occurring substance abuse and/or mental health disorders can be felt at macro (local, state and 
federal governments), mezzo (communities and contributing or participating agencies), and micro (youth and their families) levels.

\section{Implications for Juvenile Offenders}

The direct and indirect cost of juvenile delinquency with co-occurring substance abuse and mental health disorders to government, communities, families and individuals is difficult to calculate. Although estimating the unique costs to juvenile delinquency and substance abuse is difficult, they can be assumed to be substantial. Some costs of crime, such as the government's direct cost of fighting juvenile delinquency, can be readily estimated (Cohen, \& Quinn, 2009; Fass, Chung-Ron, 2002; McCollister, French, Sheidow, Henggeler, Halliday-Boykins, 2009). These costs are associated with the costs for police, prosecution, courts, probation, and incarceration or treatment. Other costs cannot be easily measured. For example, many crimes go unreported or even undetected and thus their costs to society are not available. Furthermore, some costs are transferred by manufacturers and retailers to consumers to cover their costs for crime prevention activities or losses from the crime. Additionally, the cost associated with juvenile delinquency can also include a decrease in quality of life, shortened life expectancy, increased financial obligations for property damage and/or peer alienation (leSage \& deRuyter, 2008), and a disconnection in the supportive relationship between the parent and child (Caldwell, Home, Davidson, \& Quinn, 2007; Church, MacNeil, Martin, \& Nelson-Gardell, 2009; Dembo \& Walters, 2003). The basic tenets of social work (i.e., Human Behavior in the Social Environment), and the ideas surrounding macro, mezzo, and micro 
systems can further enlighten the implications of juvenile delinquency with cooccurring substance abuse and mental health disorders.

\section{At the Macro System Level}

From a social work perspective and for purposes of this work, macro level entities include State and Federal Legislators, Federal and State Funding Sources, the Office of Kentucky Chief Administrative Judge, the Commonwealth of Kentucky Administrative Office of the Courts, the Commonwealth of Kentucky Department of Juvenile Justice, and the Commonwealth of Kentucky Department of Child Services. Juvenile delinquency is estimated to cost the government approximately $\$ 14.4$ billion annually for the federal, state and local juvenile justice systems. This figure includes the costs of law enforcement and the courts, detention, residential placement, incarceration, and substance abuse treatment. However, it does not include the costs of probation, physical and mental health care services, child welfare and family services, school costs and the costs to victims. When these factors are taken into consideration the combined spending on juvenile justice could exceed $\$ 28.8$ billion (National Center on Addiction and Substance Abuse, Columbia University, 2004). This translates to approximately $\$ 960,000,000(10 \%)$ of the National Budget for Juvenile Justice being spent on substance abuse treatment for juvenile offenders.

The Commonwealth of Kentucky Operating Budget indicates that for the Fiscal Year 2010, Juvenile Justice will cost the Commonwealth $\$ 108,347,100$ (approximately $12 \%$ ) of the $\$ 891,903,316$ allocated monies for correctional services. This amounts to approximately $\$ 10,834,719(10 \%)$ for the treatment of 
substance abuse in juvenile offenders. For fiscal year (FY) 2011 the

Commonwealth is requesting $\$ 116,716,600$ (approximately $11.5 \%$ ) of the proposed $\$ 1,010,615,600$ budgeted for Juvenile Justice. For FY 2012, Juvenile Justice is requesting $\$ 126,836,500$ (approximately $12 \%$ ) of a $\$ 1,046,948,900$ budget (Office of State Budget Director, 2010). To provide treatment for juvenile delinquents with substance abuse disorders would cost the Commonwealth of Kentucky $\$ 12,683,650$ (approximately 10\%) of the Juvenile Justice Budget for FY 2011 (Figure 1).
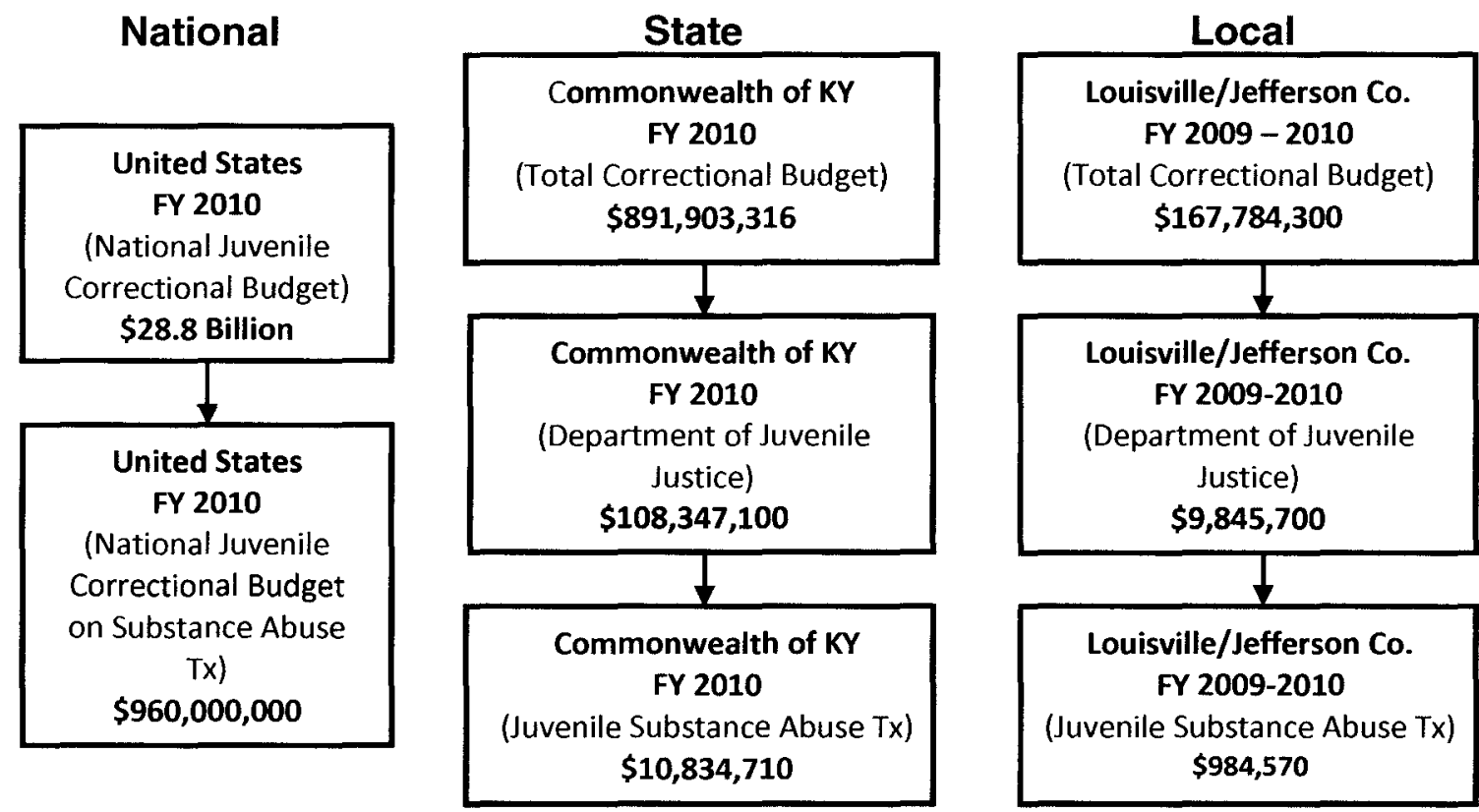

Figure 1. Requested budgets for FY 2010 (national, state, \& local). Costs incurred and projected for Louisville/Jefferson County are just as significant. The actual cost incurred in FY 2007-2008 for Juvenile Justice in Louisville was $\$ 9,700,300$ (approximately $6 \%$ ) of a $\$ 162,722,000$ total correctional budget. There was a slight increase for FY 2008-2009 with $\$ 9,712,200$ (approximately $6 \%$ ) allocated from a $\$ 167,182,100$ total correctional 
budget. Again, slightly increasing, Louisville/Jefferson County Department of Juvenile Justice is requesting $\$ 9,845,700$ (approximately $6 \%$ ) from a total correctional budget of $\$ 167,784,300$ (Metro Louisville Approved Operating Budget, 2009-2010). This translates to $\$ 984,570$ (approximately $10 \%$ ) allocated for the treatment of substance abuse in juvenile offenders from the Louisville/Jefferson County Department of Juvenile Justice's Budget. This leads into the mezzo implications for juvenile delinquents with co-occurring substance abuse and/or mental health disorders.

\section{At the Mezzo Level}

The mezzo level includes the Administrative Office of the Courts (Jefferson County), Department of Juvenile Justice (Jefferson County), Department of Child Services (Jefferson County), Jefferson County Public School System, Seven Counties Substance Abuse and Mental Health Services, The Morton Center, other local social support and judicial agencies, as well as the surrounding community. There are several implications for Louisville/Jefferson County, Kentucky schools, medical agencies, legal and judicial agencies, social support agencies and local communities when addressing the ongoing problem of juvenile delinquency with co-occurring substance abuse and/or mental health disorders. The implication for local schools is that unaddressed juvenile delinquency will contribute to declining grades, truancy, and other negative activities. There will also be an increased risk of juveniles dropping out and/or exhibiting behavioral problems while attending school. This will contribute to poor academic performances for the juveniles and a disruption in learning for their 
classmates. One way in which educators and administrators can begin to address this problem is to encourage juveniles' involvement in afterschool activities and/or programs, provide additional learning resources such as tutoring or peer mentoring, and advocate for additional community resources for juveniles and their families (Cox, Zhang, Johnson, \& Bender, 2007).

Further, there are multiple implications for local medical agencies. Juveniles who are experiencing these types of problems have an increased probability of health-related consequences (e.g., accidental injuries, physical disabilities and diseases, overdoses, and suicides and/or homicides). In turn, an increased number of drug/mental health-related hospital emergency episodes and drug/mental health-related emergency department visits for the juvenile and/or victim(s) within the community could be expected. There is also the potential risk of contracting Human Immunodeficiency Virus (HIV) and other sexually transmitted disease, thereby increasing the risk for transmission to other unsuspecting individuals in their neighborhoods (Centers for Disease Control, 2008). Local health professionals who provide services to juveniles and their families have a responsibility to be aware of possible complications, issues, and changes in their clients and make appropriate referrals addressing the problem(s). This may require Louisville/Jefferson County, Kentucky health practitioners to become more involved or aware of the services and resources available within the community, such as interagency/community collaborations similar to LANScAT and the Juvenile Enhanced Treatment Services (JETS) Program. 
Juvenile delinquency with co-occurring substance abuse and/or mental health disorders give way to implications for Louisville/Jefferson County, Kentucky law enforcement, judicial and social support agencies. Unaddressed, juveniles with substance abuse or mental health issues can contribute to an increase in substance-related traffic fatalities or injuries, increased time and/or resources expended by law enforcement, prosecutors, probation officers, and court personnel within the community. There is also the opportunity for law enforcement caseloads, judicial and social support agencies to be overloaded and a greater financial burden placed upon the community for funding and financial support. High economic and social costs result from the monetary expenditures and emotional distress related to substance-related crimes (Skowyra \& Cocozza, 2001). To address these economic and social costs, law enforcement, and local judicial and social support agencies must secure alternative, more cost-effective programs and methods of distributing services, such as the JETS Program. Another method would be to seek additional federal, state, or local funding sources, or innovative best-practice service designs to form additional interagency/community collaborations. However, these innovative and more cost-effective programs will not address all of the problems associated with juvenile delinquency, substance abuse and/or mental health disorders without the active participation of juveniles and their families.

\section{At the Micro Level}

Micro level social work occurs at the point of connection with clients. As mentioned above, juvenile delinquency with co-occurring substance abuse 
and/or mental health disorders has implications for governments and communities. Aside from these implications and the more personal/individual implications for the juvenile's negative behavior (e.g., decrease in quality of life, shortened life expectancy, increased financial obligations for property damage and/or peer alienation) there are also relationship implications for juveniles and their families. One such implication is a disconnection in the supportive relationship between the parent and child (Caldwell, Home, Davidson, \& Quinn, 2007). For example, parents may experience feelings of frustration with the negative behaviors exhibited by their children and the children's refusal to follow household rules or reasonable expectations. The parents may then come to believe that the attempts at corrective parenting are futile. In essence, parents discontinue or stop parenting and allow their children to experience the consequences of their actions (Church, MacNeil, Martin, \& Nelson-Gardell, 2009). Youths, on the other hand, may perceive this disconnection as parental rejection and assume that their parents do not want relationships or involvement with them. This assumption by juveniles and a lack of parenting skills can lead to an increase in the youths' criminality, substance abuse, and contribute to discipline issues at home, at school and within the community (Dembo \& Walters, 2003; leSage, \& deRuyter, 2008).

Additionally, there is always the possibility that the family does not have sufficient access to emotional supports, financial resources or knowledge of available community resources to treat the youth's behavioral, substance abuse and/or mental health issues. Another contributing factor could be that various 
support agencies are involved, but are not meeting the needs of juveniles and their families. This can occur when the youth and family are not included in the treatment planning process or have different or even opposite goals from the service providers. Although the juvenile and family may be receiving assistance from multiple social support agencies, this does not always lead to a reduction in the problem behaviors (e.g., delinquency, substance abuse, and/or mental health) exhibited by the youth and experienced by the family and community (Austin, Macgowan, \& Wagner, 2005; Kumpfer, Alvarado, \& Whiteside, 2003; Ozechowski \& Liddle, 2000; Waldron \& Turner, 2008;).

In part, this inability to reduce the juvenile's problematic behavior can develop due to ineffective and fragmented interagency/community collaborations, a lack of communication between these various agencies, and a duplication of services provided to the juveniles and their families. The purpose of this research is to evaluate the interagency/community collaboration of the JETS Program and provide feedback on how the collaboration can administer more effective treatment and support services to juvenile offenders with co-occurring substance abuse and/or mental health disorders. A literature review of relevant theories and interagency/community collaboration follows in the next chapter. 


\section{CHAPTER II}

\section{REVIEW OF THE LITERATURE}

This chapter is first about the role of theories in social work, then the specific theories relevant to this dissertation. Next is a discussion about what is known about the effectiveness of community collaborations, and the chapter concludes with a summary, research questions, and the hypotheses.

\section{The Role of Theory}

A theory is a cohesive set of ideas about why a problem exists and/or how change can be created to correct the problem. Additionally, a theory can assist in explaining how individuals relate to others and how effective treatment or rehabilitative programs can be designed (Bengston \& Roberts, 1991; Malysiak, 1998; Munro, 2002; Payne, 1997; Thyer, 2002). If a theory is based on research and the experience of other social movements it can support and expand the knowledge base of our profession and validate our actions to others, including potential funders, legislators, media representatives, and our communities. For these reasons, it is important and relevant for social work treatment and prevention programs, program evaluations, and scientific research to be grounded in theory (Aymer \& Okitikpi, 2000; Crotty, 1998; Dean \& Fenby, 1989; Holmes, 1986; Tooley, 2007). To accomplish this task a social researcher must examine the theories related to the phenomena under study-embracing those 
that inform and discarding those that do not provide insight or address the issues at hand (Austin, 1983; Gambrill, 1999; Gergen, 1999; Gibbs, 2003; Haworth, 1991; Roberts, 2000; Saleebey, 1991; Weick, 1991). Immediately following is a discussion of relevant theories that were considered to inform the current work (classical organizational theory, social exchange theory, and social learning theory), but were set aside; the rationale for doing so is provided for each. Next, the two theories that were more specifically relevant to the JETS program, systems theory and symbolic interactionism, are discussed.

\section{Theories Relevant to Dissertation}

\section{Classical Organizational Theory}

Classical organizational theory incorporates a merger of scientific management theory (Taylor, 1911), bureaucratic theory (Weber, 1947), and administrative theory (Mooney \& Reiley, 1931). There are four inherent principles to classical organizational theory: (a) find the one best way to perform each task, (b) carefully match each worker to each task, (c) closely supervise workers and use reward and punishment as motivators, and (d) embrace the concept that the task of management is planning and control. Further, classical organizational theory stresses the need to reduce diversity and ambiguity in organizations by establishing clear lines of authority and control. The emphasis is placed on a hierarchical structures of power and formal sets of rules that will ensure stability and uniformity (Blau \& Scott, 1962). Although classical organizational theory recognizes organizational behavior as a network of human interactions, it 
stresses conformity and rigidity, while downplaying creativity, individual growth, and motivation (Jones, 2009).

\section{Rationale for Discarding}

There are two important reasons for setting aside classical organizational theory as the theoretical foundation of the interagency/community collaboration for the JETS Program. First, the theory does not emphasize teamwork or worker empowerment. Classical organizational theory's purpose is to increase production while decreasing manufacturing time. To accomplish this, workers are expected to be subordinate, passive, and dependent on their supervisors and managers for direction. There is no concern for human needs (Jones, 2009). In contrast, the JETS Program is based on the idea that participants from multiple agencies will cooperate at all levels (i.e., administrators, managers, workers, and clients). These separate levels must operate cohesively in order to establish lasting change for clients, their families, and their communities. Further, team members must be empowered by the LANScAT Executive Committee to make suggestions and/or decisions regarding services, treatment, and courses of action for their clients. Otherwise, the legal, rehabilitative, and treatment agencies will continue to be plagued by excessive caseloads and a fragmentation of services.

The second reason for discarding classical organizational theory as a theoretical foundation of the JETS Program interagency/community collaboration is that it operates from the notion that all organizations are similar or somehow alike. It does not take into consideration that organizations have differences in 
organizational structure, paradigms, and communication patterns (Jones, 2009). The JETS Program is composed of judicial agencies, law enforcement, and rehabilitative agencies, as well as substance abuse and mental health agencies. Additionally, these agencies often have different purposes or goals. To not recognize the fact that these agencies are dissimilar would be shortsighted and provide an opportunity for more misunderstandings or miscommunications to occur. This leads into the next theory of social exchange and the expected interactions between individuals.

\section{Social Exchange Theory}

Social exchange theory was first proposed by Malinowski (1922) to set apart social from the already established economic exchange theory. He believed that social behavior is prompted by psychological rather than economic needs. However, Levi-Strauss (1963), an anthropologist, saw exchange as a social process that had symbolic, normative, and dynamic underpinnings. Although both theorists were concerned with the relationship between the individual and society, Levi-Strauss was most concerned with the structural integration of exchange in the larger society.

Another noted theorist and behavioral sociologist, Homans (1958, 1961), further expanded on social exchange theory by basing his ideas on the animal models of operant conditioning rather than on symbolic human behavior that had been previously suggested. Similar to Skinner (1974), Homans proposed that an individual's actions increase with rewards and decrease with punishment or the absence of rewards. Further, he hypothesized that these actions are based on 
the individual's perception of greater rewards. However, if the individual perceives an unexpected withholding or granting of rewards, then anger or pleasure can result. Homans also posited that human behavior involves distributive justice - a notion that rewards and costs should be distributed fairly among the individuals involved. However, if an individual perceives a disadvantage (i.e., lower rewards and/or higher costs) the individual will experience anger. Cook and Emerson (1978), both sociologists, disagreed and held that social exchange theory is not a theory but a frame of reference. This leads to the criticisms and the reasoning behind social learning theory being discarded as the theoretical foundation in the interagency/community collaboration of the JETS Program.

\section{Rationale for Discarding}

The first criticism is that social exchange theory is not testable and therefore, is not capable of being proven false; an important criterion for a theory. Therefore, the central concept of costs and rewards is not clearly defined, thus making it impossible to pose an operational distinction between what people value, what they perceive as rewarding, and how they behave. Further, it is impossible to find an instance when an individual does not act in ways so as to obtain rewards (Sabatelli \& Shehan, 1993), although such awards may be altruistic in nature. A second criticism is that social exchange theory views people as rational calculators of costs and rewards in their everyday lives. Additionally, there is disagreement that people actually consider costs and rewards before engaging in particular behaviors or that they have varying levels of cognitive 
awareness and activity. Some people may be more self-aware than others and there may be individual differences that affect how they process information (Berger \& Roloff, 1980). For the purposes of the JETS Program, it is crucial to have measures that are clearly defined and testable due to the nature of the funding (federal grant) and the requirements for reporting the outcomes of the program. This brings into question social learning theory as the theoretical foundation for the interagency/community collaboration. Social learning theory clearly defines, measures, and is testable, two of the features lacking in social exchange theory.

\section{Social Learning Theory}

Social Learning Theory presumes that people learn new behaviors through reinforcement, punishment, and/or observing others within their social environments. If people observe positive, desired outcomes for observed behaviors, they are more likely to model, imitate, and adopt those behavior themselves (Robbins, Chatterjee, \& Canda, 2006).

Combining both internal and external processes, social learning theory originated from the work of several theorists such as Clark Hull. Hull $(1929,1930$, 1937, and 1943) believed that conditioned reflexes could be used to explain thought processes and behaviors-simply put, they are a sequence of stimulus and responses. Further expanding on these ideas, Rotter $(1966,1975)$ focused on motivation, suggesting that people like to avoid negative consequences, while seeking positive results or effects. Further, he hypothesized that people are motivated to exhibit a behavior if they think there is a high probability of a positive 
outcome associated. Additionally, when this behavior is positively reinforced, the behavior is likely to be repeated. Thus, behavior is influenced by environmental, as well as psychological factors.

Bandura (1977) continued to build upon Rotter's ideas of social learning theory and incorporated aspects of both behavioral and cognitive learning. Bandura believed that environmental influences can elicit a behavior, but that cognitive learning will influence how a particular behavior is exhibited. Bandura asserted that there are three requirements for people to learn and model social behavior: attention/retention (being aware of the environment and remembering what is observed), reproduction (having the ability of reproducing the specific behavior), and motivation (rewards are associated with the behavior).

\section{Rationale for Discarding}

Although social learning theory increases the understanding of social behavior it does not necessarily provide the needed theoretical foundation for interagency/community collaborations. More specifically, the theory advocates that individuals, especially children, imitate or copy modeled behavior from personally observing others, the environment, and the mass media. If the object of this study was to simply examine actual juvenile delinquency with co-occurring substance abuse and/or mental health disorders, social learning theory would be appropriate. However, the focus of this research is to identify the relationship between shared meaning and collaboration. Hence, social learning theory is discarded in favor of two theories that are more applicable in the development of these collaborations: systems theory and symbolic interactionism. 


\section{Theories Relevant to the JETS Program}

This section focuses on two theories that converge to inform the hypotheses. First, the role of systems theory is explained, including a view from Lasker's framework for Partnership Synergy. This is followed by the fit of symbolic interactionism to the interagency/community collaboration of the JETS Program. Then relevant intervention models are discussed, concluding with the rationale for the JETS program's designers' choice of the Multisystemic Therapy (MST).

\section{Systems Theory}

Systems theory can inform the development and understanding of interagency/community collaborations. The idea of systems was originated by Ludwig von Bertalanffy as a biological theory (general systems theory). He proposed that all organisms are systems that are composed of subsystems, and that each system lives within its super-system (Payne, 1997).

When applied to social work, Pincus and Minahan (1973) postulated that people depend on various types of systems in their immediate social environments for satisfactory and productive lives, and posed three kinds of systems that can support individuals. The first is Macro, a societal system of support systems that include various state and national governmental agencies (Anderson, Carter, \& Lowe, 1999). Mezzo is the second type of system-it is formal and includes various local governmental agencies, schools, medical and mental health agencies, social support agencies, and community/neighborhood groups including churches, sport/team affiliations, and exercise facilities 
(Anderson, Carter, \& Lowe, 1999; Fellin, 2001). The third is Micro and includes informal or natural systems, including an individual's family, friends, and peers and/or neighbors (Broderick, 1993; Zastrow \& Kirst-Ashman, 2010). Figure 2 is a conceptual map of macro, mezzo, and micro systems in relationship to the JETS Program.

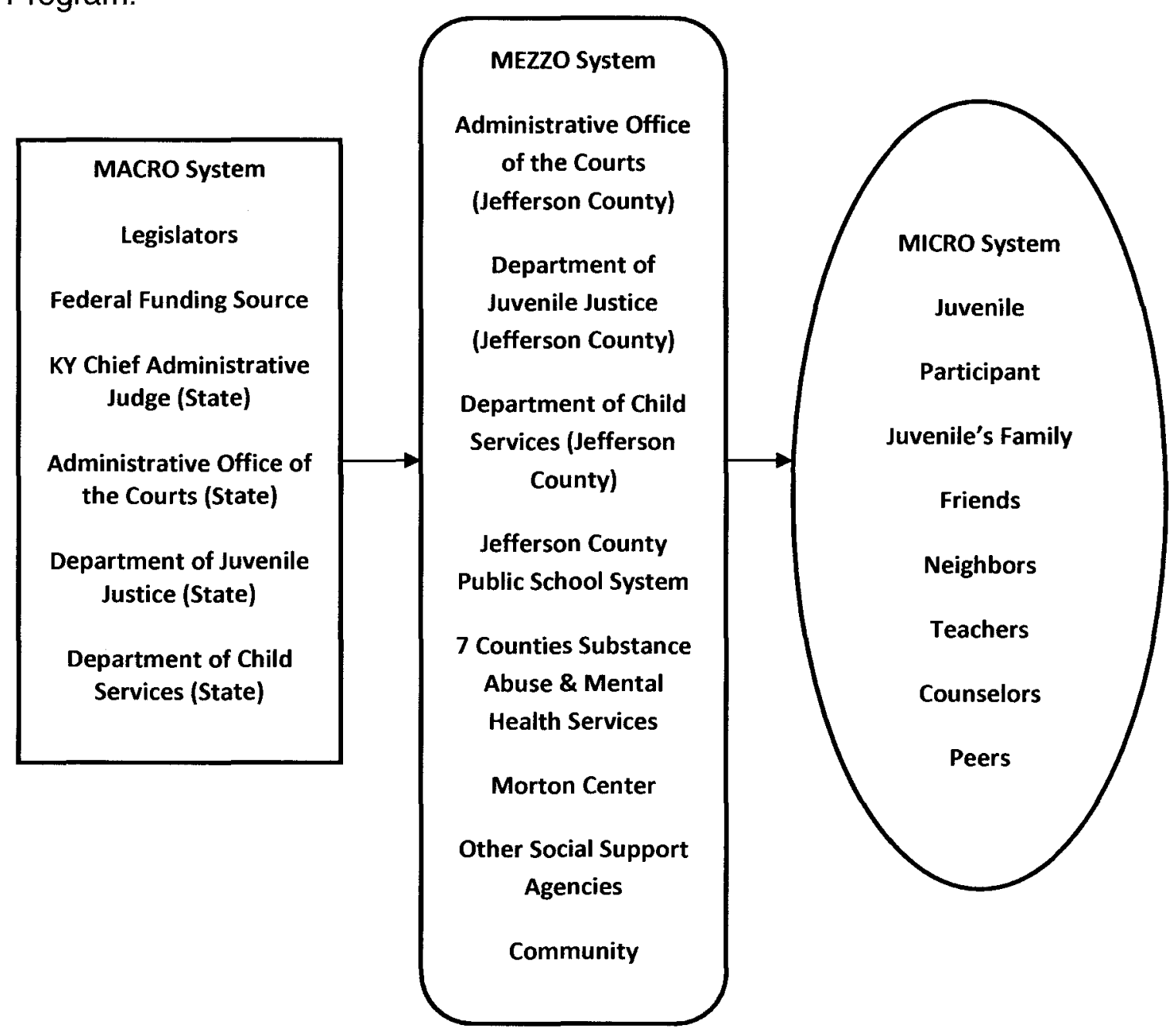

Figure 2. Conceptual map of macro, mezzo, and micro systems for the JETS Program.

Input, transformation, and outcome are also important concepts in understanding systems theory as it pertains to the JETS Program. Input includes 
the energy, information, and communication flow received from other systems. In the transformation stage, the processes can be described as changing inputs into the desired outcomes. Outcome is the result of the transformation process (Anderson, Carter, \& Lowe, 1999; Zastrow \& Kirst-Ashman, 2010). For example, a school of social work functions as a system with (a) inputs of students and resources, and (b) teaching transforming future social workers into (c) knowledgeable social workers (outcome).

As shown in the conceptual map in Figure 3, juvenile offenders are evaluated with the Global Appraisal of Individual Needs-Quick (GAIN-Q) instrument for participation in the JETS Program during the input stage. This evaluation is completed by a trained Jefferson County Court Designated Worker, Department of Juvenile Justice Worker, or Mental Health Specialist who screens juveniles to determine whether they are appropriate for community based treatment and have needs in multiple domains of functioning. The second stage is transformation and attempts to address the multiple needs of juveniles and their families (e.g., substance abuse, mental health, rehabilitation. education, and social support), through the interagency/community collaborations that have been formed by the JETS Program. Output, the third stage, is the determination of whether the appropriate treatment and support services have been identified and implemented effectively for juveniles and their families. The success of the program is determined by reduced recidivism (e.g. no new law violations or continued substance use). 


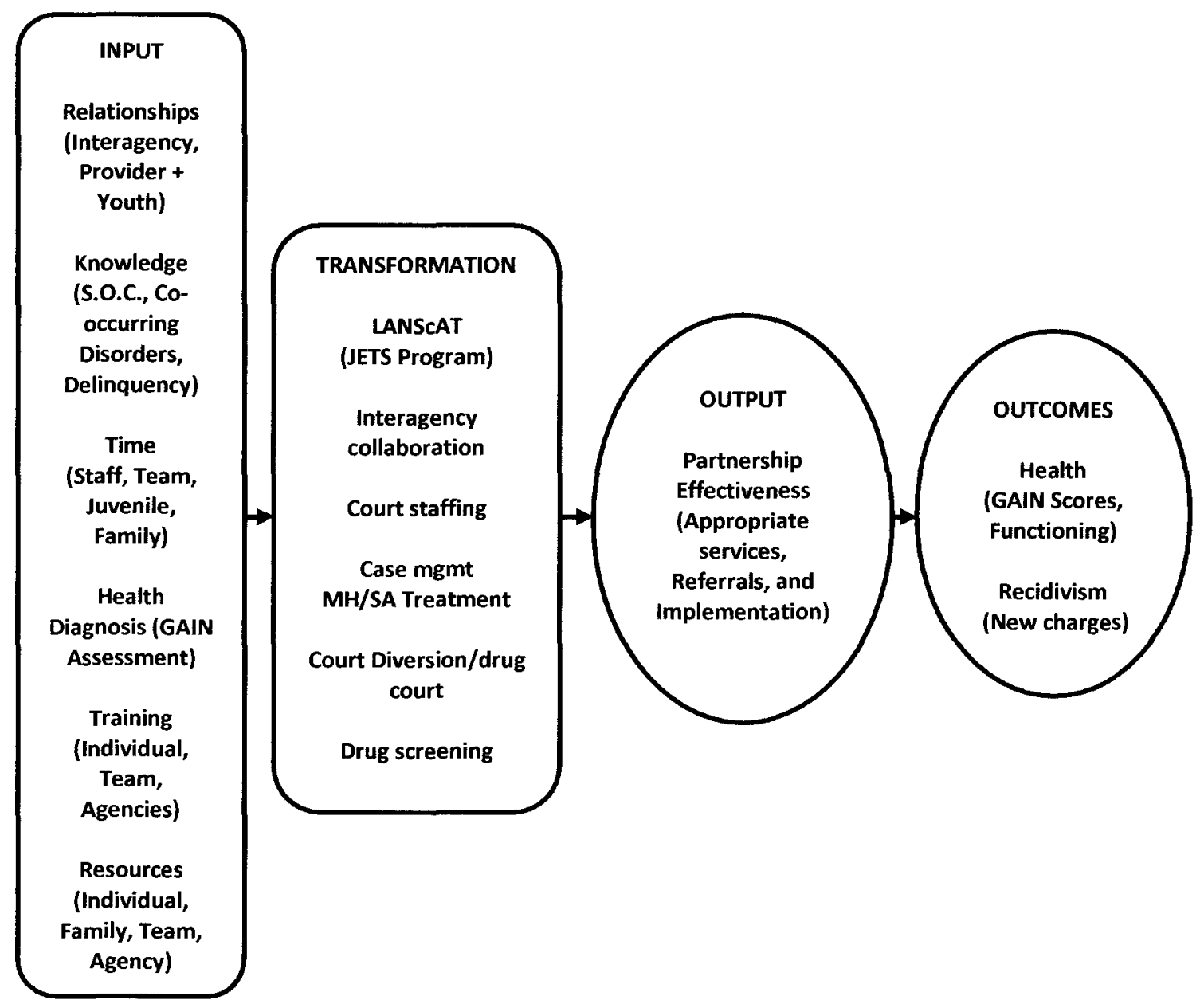

Figure 3. Conceptual map of input, transformation and output for JETS

\section{Program.}

Systems theory provides additional concepts such as feedback (both negative and positive), synergy, and entropy that can be applied to the conceptualization of the JETS Program. Feedback is a form of input in which the system receives information regarding its own performance. Negative Feedback gives an indication of problematic functioning within the system and allows the system to make corrections to deviations or mistakes and return to a more balanced state (Anderson, Carter, \& Lowe, 1999; Zastrow \& Kirst-Ashman, 
2010). In relation to the JETS Program, examples of negative feedback may include low enrollment, high recidivism, and/or a decrease in interagency/community partners. In support, Lasker and colleagues (2001) stated that diverse partnerships, such as the JETS Program, can be rife with tension and conflict, and exact a heavy toll on the leadership, coordination, and management skills of a partnership. If corrections are not made, entropy occurs. Entropy is the tendency for a system to progress toward disorganization, depletion, and death, often due to the system's inability or unwillingness to make corrections (Anderson, Carter, \& Lowe, 1999; Zastrow \& Kirst-Ashman). For the JETS Program this could include a decrease in funding or the cancelation of the entire program.

Positive feedback, on the other hand, involves the system receiving information about what it is doing correctly to maintain itself and thrive (Anderson, Carter, \& Lowe, 1999; Zastrow \& Kirst-Ashman, 2010). Examples of positive feedback for the JETS Program include high enrollment, low recidivism, an increase or betterment in participant functioning, and/or an increase in interagency/community partners. The opposite of entropy is synergy (negative entropy, or a healthy state) and is a direct result of positive feedback (Anderson, Carter, \& Lowe, 1999; Zastrow \& Kirst-Ashman, 2010).

To further elaborate on synergy, Gray (1989) as well as Lasker and colleagues (2001) see collaboration as a process in which individuals who have differing or opposing perspectives can constructively explore those differences and discover solutions together that were once unavailable or unconsidered. This 
ability, for a group of individuals, or an organization, to combine differing perspectives, resources, and skills is a form of synergy that can result in partnership effectiveness (depicted in Figure 4; Fried \& Rundall, 1994; Lasker, \& Committee on Medicine and Public Health, 1997; Lasker, Weiss, \& Miller, 2001; Mayo, 1997; Richardson \& Allegrante, 2000; Taylor-Powell, Rossing, \& Geran, 1998). This is the process by which a system proceeds toward growth and development (Anderson, Carter, \& Lowe, 1999; Zastrow \& Kirst-Ashman, 2010) and in relation to the JETS Program can include continued or additional funding. Figure 5 is a conceptual map of how feedback, entropy, and synergy relate to the JETS Program.

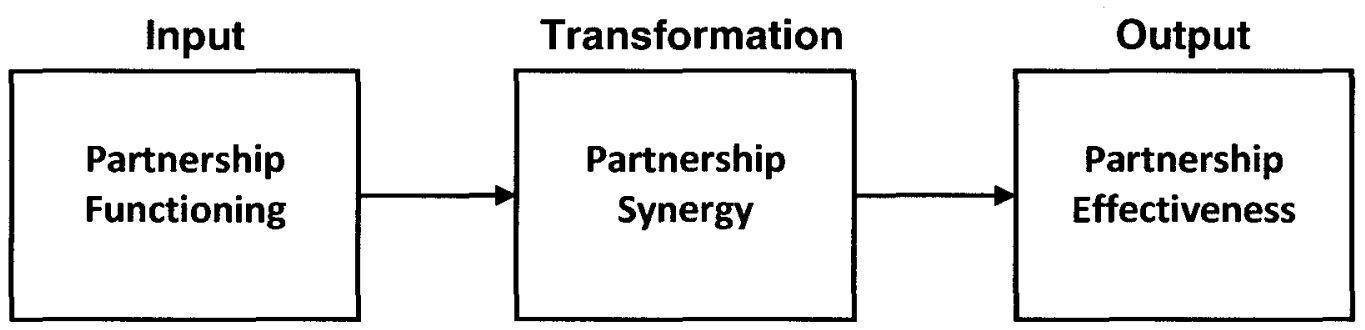

Figure 4. Synergy in relation to collaboration (Lasker, Weiss, \& Miller, 2001).

\section{Persistent Problems}

Despite the number of caring parents, the number of committed community members, and the various professionals in juvenile justice and mental health/substance abuse agencies, these systems of support continue to have difficulty in positively intervening in the lives of these juveniles and their families (Nissen, Merrigan, \& Kraft, 2005). These scholars reported a lack of coordination and even negative collaboration that has hindered the ability of these systems to support juvenile offenders with co-occurring substance abuse and mental health 


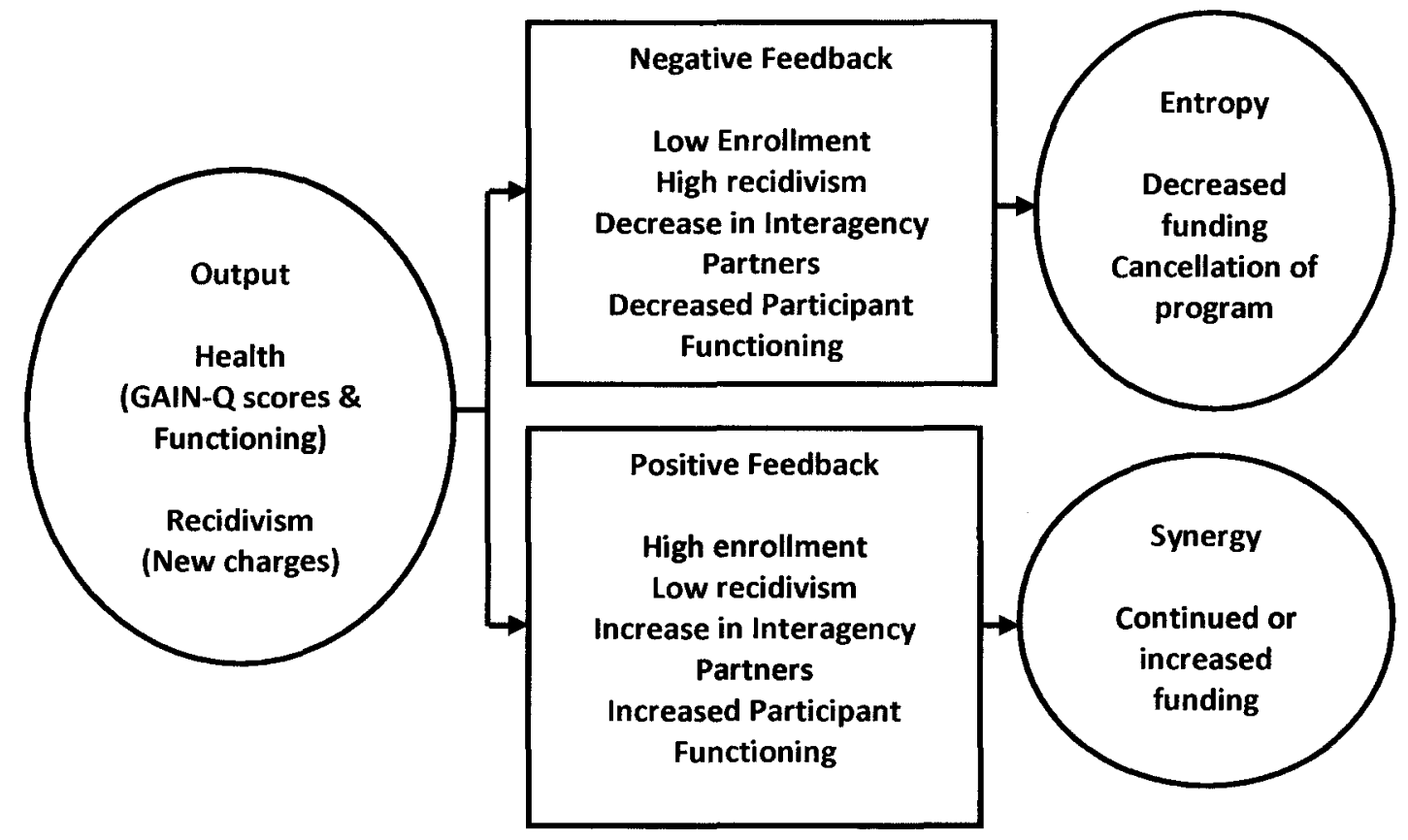

Figure 5. Conceptual map of feedback, entropy, and synergy.

disorders. Further, one of the difficulties is that the various systems operate under different, even conflicting, mandates, priorities, timelines, and definitions of the primary client; each system has different goals and definitions of success. These differences have lead to discussions on how best to meet the needs of juveniles, and their families and local communities (Green, Rockhill, \& Burrus, 2008).

\section{Solutions}

One solution to these problems is an increase in the collaboration between the child welfare system, the judicial system, the substance abuse/mental health treatment system and the families of juvenile offenders with co-occurring substance abuse and mental health disorders. Coordinated efforts within these systems are thought to be the key to timely access to appropriate 
treatment services, client participation, and quality follow-up and support. Interagency/community collaborations can help agencies communicate more effectively and ensure that families are not overwhelmed with requirements and demands (Green, Rockhill, \& Burrus, 2008).

Nissen (2007) described an integrated care network, or interagency/community collaboration that was piloted in the early 1990 s for the juvenile justice system. These networks/collaborations involved court personnel and treatment programs who established new agreements and arrangements for identifying and processing certain drug-related cases; they focused on linking the youth with treatment and community resources. This type of collaboration demonstrated that separate systems could be improved in terms of their ability to work across conflicting agency boundaries. Nissen also reported that individual agencies could work more effectively as a united team in the provision of services and that systematic change would yield improved outcomes for the youths and their families.

Some substance abuse and mental health delivery systems have established interagency/community collaborations. Barreira and colleagues (2000) demonstrated that successful collaborative approaches must be composed of all stakeholders from multiple system levels, including individuals or clients, family members, community supports, and mental health and governmental agencies as well as policy makers. The success of interagency/community collaborations is achieved by establishing effective lines of communication, setting common goals, and cross-training team members. By 
taking these steps, the substance abuse and mental health agencies were able to successfully integrate their services and establish a continuity of care for clients and their families. Further, the collaboration provided more comprehensive services and improved the quality of care within the communities.

Mental health, social service, and judicial agencies are no strangers to the varying degrees of teamwork needed to impact the lives of their clients and the communities they serve. To establish these collaborative teams, varying types of integration between the participating agencies are essential. For example, a loose-knit network may work in parallel according to their own priorities, while a fully vetted and recognized team has policies of collective accountability and agreed upon objectives.

Sheehan, Robertson, and Ormond (2007), provide examples of three different types of teams, the first of which is the interagency/community team. This type of team usually consists of professionals who work within particular scopes of practice and interact formally. Interdisciplinary teams, the second type, have greater overlap in professional roles. This kind of team utilizes formal and informal communication and shares problem solving for the greater good of clients. In the third type, trans-disciplinary teams, roles are not fixed and are often blurred.

It is usually the interagency/community teams, consisting of mental health, social service, and judicial agencies that collaborate more frequently to serve children and their families. Unfortunately, this type of interagency/community collaboration often results in a fragmentation in services and can present a major 
problem in the treatment of children and adolescents with co-occurring substance abuse and mental health disorders (Lee, Morrissey, Thomas, Carter, \& Ellis, 2006). This is due, in part, to children's needs to be treated for multiple health issues and the need for their participation in two or more specialized programs (i.e., out/in-patient therapy, probation, and foster care). It has been suggested that in order to reduce recidivism among these clients, multiple types of treatment must be provided concurrently via the linkage of these various agencies that provide the services. However, within these linkages are conflicts in paradigms, communication patterns, organization and cognitive development (Duncker, 2001). Symbolic interactionism is a perspective that attempts to make sense of this phenomenon.

\section{Symbolic Interactionism}

The foundation for symbolic interactionism began with German sociologist and economist Max Weber $(1947,1948)$ and American philosopher George H. Mead (1934) both of whom emphasized the subjective meaning of human behavior, the social process, and pragmatism (e.g. the function of thought guides the action). Weber's primary focus was on the subjective meanings that individuals attach to their actions. He proposed four major types of social action (Johnson, 2008; Weber, 1947).

The first type of social action is purposeful or goal-oriented rational action. In this action an individual rationally chooses both the goal and the means to achieve the goal (i.e., taking the appropriate steps toward a goal). Value-oriented rational action, the second type, is striving for a substantive goal that within itself, 
may not be rational, but that is nonetheless pursued (e.g., the end justifies the means, or actions leading to a goal without sufficient thought to its consequences). A third type of social action, emotional or affective motivation action is anchored in the emotional state of the individual rather than rationally weighing the means and ends (e.g., emotional actions, expressing emotions). Finally, there is traditional action that is guided by customary habits of thought, by reliance on the eternal yesterday (e.g., actions carried out by tradition, culture, habit, or custom). Weber, whose primary concern was Western society, believed that modern behavior had become dominated by goal-oriented rationality, instead of tradition, affect, or value-oriented rationality (Coser, 1971; Johnson, 2008; Weber, 1947). As mentioned previously, Mead was also interested in how social actions are developed and interpreted.

Mead (1934) believed that the human mind is rational, conscious, and reflective; it is in a constant search for meaning. He postulated that human nature is universal and is composed of both social (i.e., cooperative) and antisocial (i.e., uncooperative) impulses; both being necessary for social organization. Likewise, Mead concluded that highly developed societies have multiple relationships that are intricately connected and that many of these relationships are formed through the common interests of the society and its members. However, even with common interests there will also be conflict due to the innate differences among groups, individuals, and individuals.

If one individual's actions elicited the same response in others, Mead (1934) was confident that the meaning of symbols would no longer be private but 
a behavioral reality. Further, he asserted that humans are actors who continually adjust their behaviors in response to the actions of other actors. This ability to adjust behavior to the action is due to the interpretive ability of humans (i.e., the ability to denote an action with a symbol and then treat the action and those who perform them as symbolic objects) — a process that is further aided by an individual's ability to think about and react to themselves and their actions as symbolic objects (Mead, 1934). To elaborate, Mead discussed three main components to his theoretical perspective: mind, self, and society.

First, the mind, "is a social phenomenon-arising and developing within the social process within the empirical matrix of social interactions" (Mead, 1934, p. 133). In this definition the mind is formed through interactions with others and self-conversation. Self, the second component, is also developed through a social process, is an object unto itself, and possesses a social structure. This implies that individuals develop their own identities that, in turn, form a consciousness of self.

The development of self occurs through a process of imitation (infants), play-acting (children), and generalized other (adult). During the process of generalized other there is an emergence of two dimensions for self that are continuously formed and reformed. In this, the first dimension considers the identity that is formed in response to the attitudes of others and the definitions of the particular situation. The second dimension is composed of the rules for the actual response. Hence, Mead (1934) employed the concepts of the individual, or I, and the social, or Me. 
According to Mead (1934) the Me is a cognitive object and is only known in retrospect or upon reflection. If an individual behaves in a habitual manner, that person is not usually self-conscious of the particular behavior and these actions are considered to be on a non-reflective level. However, when the generalized other is considered, the individual is cognizant of the behaviors and forms a self in relationship to the system of behaviors that complete the generalized other (i.e., defining oneself from the perspective of the many-sided sets of behaviors that constitute the system of operation).

On the other hand, the $I$ is composed of the novel reactions of the individual and cannot be predicted nor are they predetermined. These reactions or actions of the individual are always somewhat different from previous reactions or actions and can be in response to others or self-initiated (Mead, 1934). According to Mead, the / contributes to a sense of freedom, or initiative when the situation allows for a self-conscious behavior. The / responses are nonreflective, however once the actions of the / have become objectified and known, they become a Me.

The third component, society, occurs when the individual, through social interaction, incorporates the generalized social attitudes of the greater environment. This incorporation of the attitudes of the greater environment is beyond the scope of personal relationships, intimate groups, or communities, and is considered a common response (Mead, 1934). It is Mead's contention that self and society are divided and that the self is tempered by the wishes, rules, and 
roles of others. Herbert Blumer expanded on the foundation that had been set forth by Weber and Mead.

Blumer (1969), who studied with Mead at the University of Chicago, is responsible for the term symbolic interactionism. He is also responsible for developing the most prominent version of symbolic interactionism that concentrates on the sociological and social psychological implications of Mead's ideas on pragmatism. A central goal for Blumer was to develop accurate descriptions for the occurrence of the social processes that are formed through social action. He believed that individual and collective actions were ongoing and that individuals used symbols to represent themselves, their actions, and others.

Additionally, Blumer (1969) coined the term acting unit to describe human behavior and believed that it could encompass solitary acts of the individual to collective events (i.e., interactions between two or more people, including international relations). His emphasis on an individual's experiences and their subsequent behaviors led him to hypothesize about the relationship between structure and process, change and persistence, thought and action, individual and society, as well as the interrelationships between individual and community life. Blumer had particular interest with the changes in an individual's behavior for the purpose of social existence.

Blumer (1969) believed that individuals' social reality was dependent upon their engagement within the world, and their meaningful participation. Further, he concluded that this social reality is ongoing, and that individuals have the ability 
to appropriately adjust to the situation at hand—dependent on the relationships between people and their attached symbols.

Symbolic interactionism, according to Blumer (1969), is a perspective that attempts to make sense of conflicts in paradigms and communication patterns and employs three basic premises:

$\ldots 1$ ) individuals act toward things on the basis of the meanings they ascribe to those things ...2) the meanings of things is derived from, or arises out of, the social interaction that one has with others and the society ... 3) meanings are handled in, and modified through, an interpretative process used by the individual in dealing with the things he/she encounters. (Blumer, 1969, p. 2-6)

Further, he asserted that an individual's response to an action is not because of the action itself, but the meaning that is attached to the action.

Symbolic interactionism is a perspective about human social interaction and the meanings that individuals connect to those interactions. Brunier (2005) described these meanings as definitions that have been attached to physical, social, cultural, and political objects within an individual's life. Further, she believes that these definitions are developed through social interaction with others and that the process is ongoing, fluid, and refined as individuals attempt to make sense of their environments and their social situations.

Morrione (1988) asserted that individuals are active interpreters of the world and the situations they experience. As active interpreters, individuals act upon the definitions assigned to the persons, objects, and events within each 
situation. Because life experiences and perceptions vary between individuals and groups, each will believe a different aspect of the situation to be more relevant than another, which can lead to miscommunication and/or misinterpretation. Additionally, Morrione believes that situations are always embedded in and shaped by larger contexts of meaning (i.e., culture, political, economic, and social). This can be a problem when multiple systems form collaborative partnerships and there are conflicts in paradigms, communication patterns, organizations, and cognitive development. In effect, a common language and a common ground are needed.

To find a common language Frost, Robinson, and Anning (2005) believed that the traditional claims to professional expertise (i.e., expertise in a specific professional field) versus joined-up thinking (i.e., the ability to mediate, liaise, and negotiate with other professional fields) need to be addressed. If not, interagency/community team members can experience discomfort, anxiety, and anger as they encounter an end to professional identities before new identities can be developed. This is due to the rapid pace in which collaborative teams often move from strategic planning to operational implementation.

Team members are expected to justify conceptual bases for their actions or interactions-something that many may have never experienced, especially while working within single agency settings. Further, their implicit knowledge needs to be made explicit and may include discarding their profession/field's specialized vocabularies (Frost, Robinson, \& Anning, 2005). Many of the individuals involved will see this as a painful process of steps. However, they are 
necessary for tasks to be redefined and redistributed so that their common goals can be pursued and eventually achieved.

Doyle (2008) believes that interagency/community collaborations and services are an effective way of delivering a high standard of care to children and their families. She found that when interagency/community collaborations are implemented effectively there will be an improvement in service provision and a better standard of care. Additionally, the implementation of effective interagency/community teams can lower the levels of stress for parents and create higher job satisfaction for staff. Such a team has the potential to facilitate better communication between agencies and combine the skills, resources, and mutual support for team members, children, and their families.

To successfully work together, several key factors need to be addressed by the interagency/community team including a dedication of time, resources and a commitment for good communication and information sharing between agencies. Team members should have the ability, desire, and commitment to network with each other and use collaborative efforts to effect change for clients and their families. Additionally, Doyle 2008 conceptualized that in addition to the line-level workers there must be effective leadership and management systems within the various agencies. Also, a recognized partnership with the children and their families must be established.

For the above mentioned factors to be implemented it is necessary for key workers to be identified, a co-location to be established, a continued commitment to interagency/community training by the participating agencies and an 
awareness by team members and their agencies of the benefits associated with effective joint working relationships. Additionally, Doyle (2008) conceptualized two other requirements that are sometimes unaddressed by interagency/community collaborations: shared/universal records, and an awareness or appreciation for the roles of the other professionals included on the team. Once these factors have been addressed and the requirements satisfied, interagency/community teams become a more desirable means to deliver holistic and individualized services to children and their families. There are several interventions that utilize interagency/community collaborations in treating juvenile delinquency with co-occurring substance abuse and mental health disorders.

\section{JETS Program Intervention}

Therapeutic interventions at the micro system level, when based in theory, are approaches that effectively assist individuals to identify, motivate, and change problematic behavior. The JETS Program intervention is based on systems theory and symbolic interactionism. Systems theory provides a conceptual perspective on how individuals view the world while symbolic interactionism provides insight into how these perspectives are shared and/or communicated among individuals, groups and communities. As theoretical foundations, systems theory and symbolic interactionism provide insight into a therapeutic intervention that might be of assistance in the development of interagency collaborations for the treatment of delinquent youth. Following is a discussion of Multisystemic Therapy the intervention implemented by the JETS Program 


\section{Mutisystemic Therapy (MST)}

This intervention of choice for the JETS Program is a comprehensive, individualized, home-based therapy that is child-focused and family-centered. This approach was developed in an effort to treat adolescent antisocial behavior (i.e., conduct disorder, delinquency, and substance abuse). Based in system and social-ecological theories, MST holds that youth develop antisocial behaviors as a result of individual, peer, family, community, and school factors. To assist adolescents and their families, MST combines several techniques including strategic family therapy, structural family therapy, behavioral parent training, and cognitive behavior therapy (Henggeler, Schowenwald, Bourdin, Rowland, \& Cunningham, 1998).

Addressing complex problems in a comprehensive, intense, and individualized manner is a key element to MST. Because the treatment is individualized, the families and therapists work together to target problem areas and select appropriate intervention strategies. This is accomplished through the utilization of a strengths perspective and the continuous engagement of the adolescent, their families and their identified social support networks. Additionally, therapists assist adolescents and their families in identifying resources and/or supports that are available within their communities (Brown, Henggeler, Schoenwald, Brondino, \& Pickrel, 1999).

The service delivery model associated with MST was developed with a focus on increasing accessibility and engagement while decreasing treatment attrition for youth and their families. Several treatment components of MST assist 
in meeting this goal: (a) services are provided in home and community-based settings to facilitate cooperation, engagement, and retention in treatment, (b) low caseloads enable therapists to be available 24 hours a day, 7 days a week to meet the diverse needs of the youth and their families, (c) treatment meetings are scheduled according to the needs of the youth and family, including evening and weekend sessions, and (d) responsibility for youth and family engagement and treatment outcome is assumed by all members of the treatment team and treatment strategies are modified as needed to meet the changing needs of youth and their families (Brown, Henggeler, Schoenwald, Brondino, \& Pickrel, 1999).

Henggeler, Schowenwald, Bourdin, Rowland, and Cunningham (1998), examined several outcomes for treatment retention, drug and alcohol use, criminal activity, and out-of-home placements with the use of MST. Findings indicate that adolescents who were treated with MST had statistically significant decreases in reported drug and alcohol use immediately following treatment. However, these decreases were not maintained at the 6-month follow-up. As mentioned previously the JETS Program utilizes the MST intervention in concurrence with a Juvenile Substance Abuse/Mental Health Court Diversion Model.

\section{Drug and Mental Health Court Programs}

The JETS Program, as well as many other drug and mental health court programs, is based on the Treatment Drug Court Model introduced in Miami, Dade County Florida, in 1989. These collaborative programs were established in 
an effort to develop a more efficient and cost effective means of breaking the cycle between delinquent behavior, substance abuse, and/or mental health disorders. Those offenders, who enter drug court programs are required to participate in treatment and counseling, undergo sanctions, are given incentives for pro-social or positive behaviors, and are required to participate in frequent court appearances (Bureau of Justice Assistance, 1994; Office of Justice Programs, 1997).

This is a comprehensive therapeutic experience for the offender; the treatment experience begins in the courtroom and continues throughout the involvement of the drug court. Because the problem of drugs and crime is so complex for a single agency to combat, drug courts rely upon the cooperation and effective communication of judges, court personnel, probation officers, treatment providers, support groups and the community (Bureau of Justice Assistance, 1994; Office of Justice Programs, 1997).

The Juvenile Counseling and Assessment Program (JCAP)

An example of this type of juvenile court diversion program, with similarities to the JETS Program, can be seen in the Juvenile Counseling and Assessment Program (JCAP). JCAP is an interagency/community collaboration between the local Juvenile Court, the State Department of Juvenile Justice, a Regional Youth Detention Center, the Department of Counseling in the College of Education, and the local community (Calhoun, Glaser, \& Bartolomucci, 2001). This type of court diversion program identifies several variables for the 
conceptualization of juvenile delinquency and provides an alternative intervention to incarceration.

The characteristic of the juvenile is one of the first variables to be addressed in the possible causes of juvenile delinquency and includes heredity, gender, personality or intelligence, social skills, and cognitive processing ability. A second variable to be evaluated is the environment or ecological context in which the juvenile resides. Taken into consideration are the juvenile's family, peers, school and community. The third relevant variable is how these variables interact with each other in determining the juvenile's propensity for delinquency (Calhoun, Glaser, \& Bartolomucci, 2001). Because of the complex interactions between the variables, the JCAP incorporates several strategies in the intervention and prevention of juvenile delinquency. These include individual counseling, group counseling, academic interventions, family consultations, employment training/counseling and the incorporation of community support (Calhoun, Glaser, \& Bartolomucci, 2001). However, there is a second type of juvenile court diversion model which more closely resembles the JETS Program-discussed next.

\section{The Weber Human Services Drug Court}

The Weber Model drug court diversion program was originally developed for adult offenders in Weber, Utah but has expanded to include juvenile offenders who qualify for diversion services due to substance abuse issues (Department of Human Services Division of Substance Abuse, 2001).The drug court is an interagency/community collaboration between the Utah justice, mental health, 
and treatment agencies. However, in this model the drug offenders, whether adult or juvenile, follow the same legal process as other defendants within the judicial system (i.e., arrest, prosecution, conviction, incarceration, release) but receive treatment for substance abuse and mental health disorders while incarcerated and after release.

From an examination of recidivism rates, urinalysis results, employment statistics, survey, and monthly reports, Egbert, Church, and Byrnes (2006) concluded that there is a greater risk for repetition of this cycle (i.e., arrest, prosecution, conviction, incarceration, and release) when the offenders are released without the proper supports in place in the community. Results indicated that a collaborative knowledge from the participating partners is needed for the offender's success and a reduction in recidivism.

This collaborative knowledge comes from those who have an understanding of effective treatment measures for substance abuse (i.e., substance abuse therapists), those who have an understanding of psycho-social functioning (e.g., mental health workers), those who have an understanding of and the authority within the judicial system (i.e., judges, prosecutors, attorneys), and those who have an understanding of available community and governmental supports (i.e., social support agencies, local, state, and federal legislators) (Egbert, Church, \& Byrnes, 2006). Results also suggest that within these collaborative partnerships there is a need for effective regular communication in the form of individual and group counseling sessions with the offenders, written and oral evaluative reports between treatment specialist and court personnel, 
and written and oral evaluative reports between the program administrators and the program's funding sources (Egbert, Church, \& Byrnes, 2006). Although there is support for interagency/community collaborations to combat the increasing problem of juvenile offenders with co-occurring substance abuse and mental health disorders, there are also negative implications and questions regarding the effectiveness of such interagency/community collaborations.

\section{Negative Implications}

Due to the increasing problem of substance abuse, the federal government continues to provide support (e.g., financial and technical) for interagency/community collaborations (Halfors, Hyunsan, Livert, \& Kadushin, 2002). There are several reasons for this continued support including the attractiveness of bringing the community together to address local problems and the possibility of community support agencies having an opportunity to access additional funding streams for their treatment services. However, there is some question as to whether these collaborations are actually effective in reducing substance abuse (Halfors, Hyunsan, Livert, \& Kadushin, 2002).

In a comparison study of several large-scale interagency/community collaborations for substance abuse treatment and chronic disease prevention programs the results were not positive for the substance abuse treatment collaborations (Halfors, Hyunsan, Livert, \& Kadushin, 2002). These scholars reported that interagency/community collaborations for substance abuse treatment can have multiple adverse effects, including decreasing the political strength of existing treatment programs, increasing conflicts between existing 
treatment programs and the new collaborative partners, and attracting new treatment and/or support programs that are more harmful than helpful to the clients, as well as to the communities (Halfors, Hyunsan, Livert, \& Kadushin, 2002). This brings into question the treatment strategies of collaborative partnerships.

By bringing broad treatment and/or support services together there is the possibility of less effectiveness. This can be attributed to members of the collaboration yielding to the various political demands of the more powerful members, which can result in a less cohesive and targeted program. Additionally, there is empirical support that interagency/community collaborations require more work and effort by the partners with little awareness and acknowledgement from the community being served. Successful public awareness campaigns require leadership, consistency, repetition, power, and money, all of which are usually in short supply for newly formed collaborations (Halfors, Hyunsan, Livert, \& Kadushin, 2002). Although there is literature that advocates for interagency/community collaborations and highlights their achievements, the evidence can be unconvincing of their success (Berkowitz, 2001; Foster-Fishman, Berkowitz, Lounsbury, Jacobson, \& Allen, 2001; Kadushin, Lindholm, Ryan, Brodsky, \& Saxe, 2005; Wandersman \& Florin, 2003).

Kadushin and colleagues (2005) outlined six reasons why most community or interagency collaborations are unsuccessful. First, the majority of these collaborations and their structures have been poorly defined from their 
inception (e.g., there is no consensus on what constitutes a coalition or collaboration). Second, the term community is not always well defined and is not always applicable to the current political and/or social climate (e.g., the term community can have different meanings to the individuals involved within the partnership). Additionally, local organizations have difficulty addressing complex problems that originate at the state, regional, or national levels (e.g., grassroot organizations have no control over funding or policy issues at higher jurisdictional levels). Third, there are ethnic, racial, and class divisions within collaborations and communities that can complicate the intervention efforts and the cooperation of the partners (e.g., partners do not have equitable power and/or authority within the collaboration or the community). Fourth, a history of past interventions that have occurred within communities can affect perceptions for current interventions (e.g., past successes or failures of interventions can affect how the collaborating partners and the community will embrace the new intervention and the new partnership). Fifth, most interventions occur at an organizational level, when these organizations are brought together the differences in organizational forms and habits make working within the coalition difficult (e.g., individual organizations within the collaboration have different missions, values, philosophies and structures that create numerous challenges and make collaborations difficult). Sixth, the structure of interagency/community collaborations often leads to non-rational decision making by the coalition (e.g., collaborations have many problems, solutions, and decision opportunities; however, logic and rational thought are often not considered when linking a 
solution to a problem). Often, the solution or even the collaboration just seemed like a good idea and was implemented. This makes understanding the experiences and successes of interagency/community collaboration difficult.

Wolf (2001) wrote that although communities have learned an increasing amount about interagency/community collaborations, their successes and failures have gone largely unwritten. Unfortunately, this knowledge tends to be communicated orally within the community; thereby not contributing to the knowledge base and sharing the experiences that could make the difference between successful collaborations and those that are a waste of time and result in disorganization and confusion. The evaluation and examination of the interagency/community collaboration with the JETS Program is an opportunity to add to that knowledge base.

\section{Summary and Research Question}

Theories provide cohesive sets of ideas about why a problem exists and/or how change can be created to correct problems. Theory also assists in explaining how individuals relate to others and how treatment or rehabilitative programs can ensure that services are being provided in an effective manner. Keeping this in mind, systems theory and symbolic interactionism provide the theoretical foundation for an evaluation of the interagency/community collaboration in the JETS Program that was developed to reduce the recidivism of juvenile offenders with co-occurring substance abuse and/or mental health disorders. Systems theory provides the foundational tenet that juvenile offenders with co-occurring disorders need support from various systems working in 
collaboration with each other, while symbolic interactionism gives evidence for the development of a common language between these systems.

Several therapeutic interventions based in systems theory have been developed to treat adolescent delinquency with co-occurring substance abuse and/or mental health disorders. The LANScAT Executive Committee decided to use Multisystemic Therapy (MST) in conjunction with a court diversion model for the newly developed JETS Program. Although MST and the court diversion models have shown promise in treating juvenile offenders with co-occurring substance and mental health disorders, there is conflicting literature on how the quality of the interagency/community collaboration influences the effectiveness of a juvenile court diversion program.

This discrepancy may be attributed, in part, to the constrictive paradigms (i.e., purest qualitative and purest quantitative) of researchers when conceptualizing their studies. Crabtree and Miller (1992) believed that by combining the positive attributes of both qualitative and quantitative methodologies researchers can become more "empowered " and develop an "emancipated consciousness" by not limiting the study to a process of "historical review" and/or "interpretive inquiry" (p.11-12). Additionally, it is their contention that the determination of the research aim, specific research question, and appropriate mode of engagement should inform the research methodology. This includes the use of deductive reasoning in a mixed methodology study that is primarily qualitative in nature. 
Other researchers agree that change is needed when considering the traditional methodologies of qualitative and quantitative. Hyde (2000) argued that formal deductive procedures can represent an important step for assuring conviction in qualitative research findings. Further, he believes that deductive reasoning can occur in qualitative research when the concepts to be studied are obvious from the outset and hypothesized relationships between these concepts can be stated before data gathering commences.

Poggenpoel, Myburgh, and van der Linde (2001) believe that qualitative and quantitative research methods are not in opposition to each other but are complimentary in the search for truth and in the solution of research methodology problems. Their contention is that qualitative strategies should not be synonymous with inductive reasoning and quantitative strategies synonymous with deductive reasoning. Moreover, both qualitative and quantitative reasoning strategies can be used, depending on the problem statement and aims of the research.

\section{Brief Summary}

Briefly stated, there are mixed findings regarding the effectiveness of collaborations; some say yes, they are effective, others say they are not. It appears that we are missing the underlying reasons for ineffectiveness and disagreements about effectiveness. Instead of just looking at outcomes without examining the reasons for ineffectiveness, i.e., people coming from different disciplines, philosophies and service models, missions, funding sources, and even professional parlance, symbolic interactionism encourages a deeper look at 
the how and why—or the real collaborativeness—of collaborations. Thus, the research question is posed: What is the relationship between shared meaning and collaboration among the partners of the JETS Program? The following chapter explains the mixed methodology used to answer this question. 


\section{CHAPTER III}

\section{METHODOLOGY}

This chapter describes the mixed methodology (research utilizing both qualitative and quantitative methods) used to evaluate the perceived effectiveness of the interagency/community collaboration of the JETS Program. This is organized into six sections: (a) research and sampling designs for evaluating the perceived effectiveness of the interagency/community collaboration, (b) qualitative methodology, (c) quantitative methodology, (d) sampling design, and (e) data analysis.

\section{Research and Sampling Design}

Mixed methods research occurs when the researcher collects, analyzes, and integrates qualitative research and quamtitative research methods to study a problem (Plano Clark, 2010). Ultimately, the goal of any research project is to answer a question. Tashakkori and Teddlie (2003) asserted that mixed methods research is superior to single approach designs when the mixed methods approach (a) can answer questions the other methodologies cannot, (b) provides stronger conclusions than the other methodologies, and (c) offers more diverse views than either methodology can alone. Plano Clark agreed and cited the exponential increase in the use of mixed methodologies for graduate projects and dissertations between 1997 and 2008. Further, she stated that in these 
mixed methodologies the qualitative methods and data were associated with exploratory and descriptive types of research aims. Often these studies described the experiences of individuals participating in the studies. Additionally, using a mixed methodology approach with an emphasis on qualitative design allows for multiple views to be examined and a consideration of the social realities of the respondents under study (Hesse-Biber, 2010). However, although there has been an increase in the use of mixed methodologies, there is no real consensus on what constitutes a mixed methodology in scientific research (Morse, 2003).

In response to this conundrum, Morse (2010) described a mixed method design as "consisting of a complete method or core component, either qualitative or quantitative, plus one (or more) incomplete method(s) that cannot be published alone, within a single study" (p. 483-484). The concurrent nested design is an example of one such mixed method design (Figure 6).

Plano Clark and Creswell (2008) further described methodology, stating that a nested design has a primary method (i.e., qualitative or quantitative) that

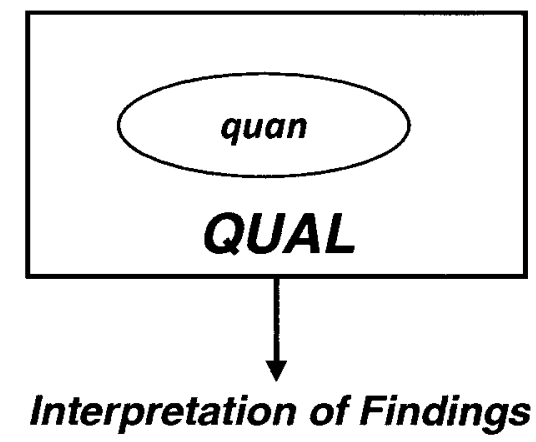

Figure 6. Model of a concurrent nested design. 
directs the project. Given less importance, another method is embedded, or nested, within the dominant method. The nested method may address a question different from that addressed by the dominant method, or seek information from different levels. Further, in a concurrent nested the data (i.e., both qualitative and quantitative) are collected at the same time-as opposed to a sequential design where one type of data (either qualitative or quantitative) are collected, followed by the data collection of the other type. Integrating the collected data occurs in data analysis. Another important factor is that this design may or may not have a theoretical perspective that guides the process.

There are several incentives for using the concurrent nested design. The first is that the researcher can examine broader perspectives from multiple methods as opposed to relying on a single method (Plano Clark \& Creswell, 2008). A second incentive, as noted by Morse (1991) is that quantitative data can be nested, or embedded, within a primarily qualitative design to enrich the description of the participants. The third is that a concurrent nested design can be utilized when there is a need to study different groups or levels within a design (Plano Clark \& Creswell, 2008). Mixed methodologies also have inherent strengths and limitations.

Strengths of the concurrent nested design are that data can be collected simultaneously and having both qualitative and quantitative data can yield enriched, deeper, or more meaningful information. An additional strength is that new or different perspectives may be evaluated (Plano Clark \& Creswell, 2008). 
As with most methodologies, there are also limitations to mixed method designs. First, there is limited scholarship regarding mixed methods which limits the opportunity for guidance during the process. Second, because there is limited scholarship there are also few recommendations on how to resolve discrepancies between the two types of data. Third, due to the inequality between the priorities of the methods, there is also an opportunity for unequal evidence and this can be a disadvantage when interpreting the results (Plano Clark \& Creswell, 2008).

The purpose of the concurrent nested design, in reference to the evaluation of the interagency/community collaboration of the JETS Program, is to use quantitative data to assist and enhance the interpretation of qualitative data. The qualitative methods are first described here, followed by the quantitative methodology.

\section{Qualitative Methodology}

\section{Data Collection}

There are three points of qualitative data collection. The first draws from notes taken during actual drug court proceedings. These notes log (a) the attendance of the service providers, (b) their discussion of service delivery and progress for each of the participating juveniles and their families, and (c) discussion of juveniles who have been referred to the program for acceptance, including the rationale for acceptance or rejection. Additionally, the notes detail the actual court proceedings with the juveniles and their families. Qualitative observational methods were used because they are an effective means of 
detailing social processes and phenomena. Further, these notes allowed access to and development of an understanding of what the social and occupational world looks like for those who work in juvenile justice and substance abuse (Clarke, 2009; Denzin \& Lincoln, 2008). The context and organization of social settings as well as phenomena of particular interest was captured as fully as possible.

The second data collection point was semi-structured interviews of the service providers via six broad, open-ended questions (Table 3.1) that were designed to encourage participants to share their own unique perceptions while targeting the content area of the inquiry (Hatch, 2002; Lincoln \& Guba, 1985, Patton, 1990). The purpose of the semi-structured interview was to gain insight into the interagency/community collaboration from the perspectives of the service providers. A qualitative semi-structured interview guide was developed using symbolic interactionism as a framework. The guide was refined with the addition

\section{Table 3.1}

\section{Semi-structured Interview Questions for Service Providers}

\begin{tabular}{|r|l|}
\hline 1 & Tell be about the JETS Program. \\
\hline 2 & How did you become involved with the JETS Program? \\
\hline 3 & Tell be about your role in the JETS Program. \\
\hline 4 & Tell me about the other partners in the JETS Program and their roles. \\
\hline 5 & Tell me about how the partners of the JETS Program work together. \\
\hline 6 & $\begin{array}{l}\text { Tell me how you feel the JETS Program is going. What are the program's } \\
\text { strengths and weaknesses? }\end{array}$ \\
\hline
\end{tabular}


of a question regarding philosophy, after the pilot interviews and participant observation notes were taken during the drug court proceedings.

These interviews occurred after discussing the process to date and receiving feedback from my committee chair and another committee member who serves as the qualitative methodologist. New prompts were also added to the interview guide; however, the basic questions presented on the participant version of the interview guide remained the same. Questions remained sufficiently broad, allowing participants to construct and communicate their own meaning of lived experiences (Creswell, 2007).

Interviews were conducted primarily at participants' places of employment, with additional locations including public establishments and the researcher's office. The location and time of each interview was negotiated based on participant convenience. All interviews were digitally audio-recorded and transcribed verbatim by an outside medical transcription service (MediVoxx) prior to analysis. Notes and memos were taken after participant observations and the interviews regarding theoretical insights, or concepts, to return to or build upon in future participant interviews. Upon completion of interview transcription, the interviews were provided, in writing, to each participant for review. Participants were offered the opportunity to engage in a follow-up interview or to provide comments concerning any information they may wish to add, correct, or clarify.

The third data collection point was the result of the three open-ended questions on the Service Provider Survey Questionnaire (Appendix A). Openended questions encourage respondents to provide individualized answers to the 
questions (Rubin \& Babbie, 2005). The purpose of the three open-ended questions was to evaluate the effectiveness of the JETS Program and the interagency/community collaboration from the service providers' perspectives. These questions were developed by the principal investigator of the evaluation team, as required by the federal grant that was awarded to LANScAT for the development of the JETS Program. These were presented to all service providers in March 2010, and October through December 2010.

\section{Operationalization of Synergy}

Previously mentioned research (Fried \& Rundall, 1994; Lasker \& Committee on Medicine and Public Health, 1997; Lasker, Weiss, \& Miller 2001; Mayo, 1997; Richardson \& Allegrante, 2000; and Taylor-Powell, Rossing, \&

Geran, 1998) has suggested that partnership synergy can be precisely measured by the partners' ability to conceptualize the collaboration's goals, actions, and relationships. Synergy determinants for the JETS Program's interagency/community collaboration are operationalized in Table 3.2 .

\section{Quantitative Methodology}

There are two points of quantitative data collection. The first is from the program evaluations that were compiled and submitted to the Administrative Office of the Court, and required by the guidelines of the federal grant that funds the JETS Program. These evaluations described the specific program outcomes that were agreed upon by the JETS Program and the Bureau of Justice. Further, the evaluations provided feedback to the funding source, program partners, and communities on whether these agreed upon goals were met. Weiss (1998) 
Table 3.2

JETS Program: Synergy Determinants Operationalized (Lasker, Weiss, \& Miller, 2001)

\begin{tabular}{|l|l|}
\hline Resources & $\begin{array}{l}\text { Funding } \\
\text { Skills, and expertise } \\
\text { Information } \\
\text { Connection to people, organizations, groups } \\
\text { Endorsements } \\
\text { Convening power }\end{array}$ \\
\hline Partner characteristics & $\begin{array}{l}\text { Diverseness } \\
\text { Level of involvement }\end{array}$ \\
\hline Relationship among partners & $\begin{array}{l}\text { Trust } \\
\text { Respect } \\
\text { Conflict } \\
\text { Power differentials }\end{array}$ \\
\hline Partnership characteristics & $\begin{array}{l}\text { Leadership } \\
\text { Administration and management } \\
\text { Governance } \\
\text { Efficiency }\end{array}$ \\
\hline External environment & $\begin{array}{l}\text { Community characteristics } \\
\text { Public and organizational policies }\end{array}$ \\
\hline
\end{tabular}

defines evaluation as "the systematic assessment of the operation and/or the outcomes of a program or policy, compared to a set of explicit or implicit standards, as a means of contributing to the improvement of the program or policy" (p. 4). Additionally, Weiss provides many purposes for evaluating programs and policies, including determining how clients are faring, making midcourse corrections in the programs, choosing the best alternatives, and providing feedback to staff. 
The second data collection point is the survey administered to service providers. These are the individuals who refer juveniles to the JETS Program or provide services that are a part of the program. This survey was adapted from Wisconsin's Collaborative Systems of Care's Service Provider Evaluation which was developed by Dan Naylor, White Pine Consulting (Wisconsin Collaborative, 2008). The reliability and validity of this instrument were not available when this research was conducted. The Service Provider Survey provided the partners with an additional opportunity to describe their perceptions of the collaboration among the partners and enhance the scientific rigor of the study.

\section{Quality of Collaborations}

The quality of collaborations is determined by the service providers' responses on 12 Likert scale (Likert, 1932) questions of the Service Provider Survey (Appendix A). The questions focus on providers' perceptions of overall service coordination, participant input, service delivery, and how conflicts and crises are resolved. This instrument was administered to service providers during their individual interviews between October 2010 and December 2010.

\section{Sampling Design}

A purposive sample of the total number of service providers participating was attempted. All JETS Program service providers participating between 2009 and 2010 were included—approximately 18 service providers. However, 2 service providers declined to participate in this study, resulting in 16 service providers participating in the individual interviews and 12 who returned their service provider surveys to be included in the study. 


\section{Institutional Review Board (IRB) Considerations}

The protection of human subjects is important and includes numerous ethical considerations including respect for persons, individual autonomy, and self-determination (e.g., providing an opportunity for assent and permission with informed consent), beneficence (whether the participants were treated with respect), and justice (e.g., the potential risks of the research should be carried equally by members of the society who are likely to benefit and the research

does not systematically select specific classes or types of individuals simply because of their availability or their compromised positions) (Levine, 1988).

The JETS Program evaluation did not solicit information from the juvenile participants in the course of data collection. However, data were collected from the service providers in the form of surveys and semi-structured interviews. Informed consent, per IRB procedures, was obtained before any data were collected (Appendix B). The procedures and instruments meet the ethical requirements outlined by the IRB for providing respect for persons, individual autonomy and self-determination, beneficence and justice. This evaluation was considered to be minimal risk by the IRB (Category 1) and given exemptexpedited review status.

\section{Data Analysis}

Recall the research question, What is the relationship between shared meaning and collaboration among the partners of the JETS Program? The following data analysis procedures were conducted. 


\section{Qualitative Data Analysis}

The quality of collaborations is determined by analyzing the descriptive information from drug court notes, service provider semi-structured interviews, and the service provider survey. This was accomplished by identifying themes/categories and looking for interconnectedness among the emerging categories/themes. Interpretation of qualitative data was achieved through particularization (contextualizing), larger sense-making, personal interpretation and asking questions of the respondents (Tashakkori \& Teddlie, 2003). The study was conceptualized through systems theory and symbolic interactionism lens. It was then narrowed into a specific research question that was answered with a mixed method approach that led to a confirmation of the original theoretical foundation of the study (Figure 7). This was accomplished through a process of deductive comparative analysis.

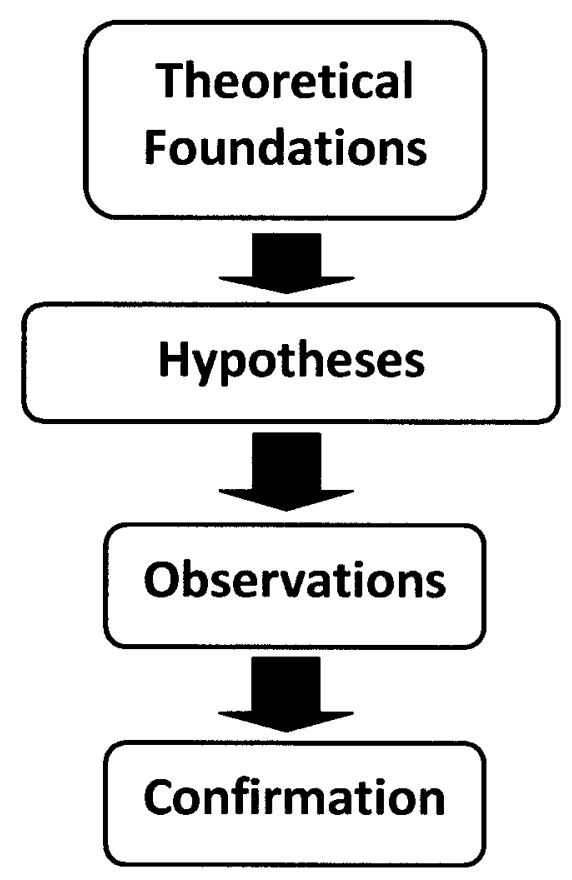

Figure 7. Deductive reasoning comparative analysis model. 


\section{Deductive Content Analysis}

Content analysis is a method for analyzing written, verbal, or visual communication messages (Cole, 1988). Researchers describe content analysis as a systematic and objective means for describing and quantifying phenomena (Downe-Wamboldt, 1992; Krippendorf, 1980; Sandelowski, 1995). This kind of qualitative methodology allows for testing theoretical issues to enhance the understanding of the data. Additionally, content analysis allows words, phrases, and comments to be deconstructed into fewer content related themes-with the assumption that they share the same meaning (Cavanagh, 1997). The focus is to develop a deconstructed and broad description of the phenomenon. One form of content analysis is deductive content analysis.

Deductive content analysis is used when the structure of analysis is operationalized on the basis of previous knowledge and the purpose of the study is theory testing. This approach is based on previously developed theory or models and moves from the general to the more specific (Burns \& Grove, 2005; Elo \& Kyngas, 2008).

The goal of deductive content analysis is to classify words or text into much smaller content categories. Unfortunately, there are no systematic rules for analyzing data (Weber, 1990). Despite a lack of systematic rules, Cavanagh (1997) described three main phases of deductive content analysis: preparation, organizing, and reporting. During the preparation phase, the researcher must decide on what to analyze, in what detail, and the sampling parameters. Organizing, phase two, is about becoming immersed in the data, making sense 
of the data, and attempting to obtain a better understanding of what is happening (e.g., who is telling, when did it happen, what is happening, and why is it happening). Phase three, reporting, concerns itself with analyzing the data. For the purposes of the JETS Program evaluation and this research, a deductive reasoning approach was utilized—using systems theory and symbolic interactionism to inform the research.

To efficiently complete these three phases, NVivo 8 qualitative software for analyzing unstructured data was utilized. The first step was the initial coding of each transcribed interview. This coding is the process whereby data are disassembled and there is a delineation of concepts to stand for blocks of raw data (Corbin \& Strauss, 2008). This was accomplished within a relatively short amount of time, approximately 4 to 6 weeks, and allowed for a comparative analysis between the transcribed interviews. The relatively fast turnaround between participant interview and open coding enabled the researcher to use information from early interviews to enhance upcoming interviews. For example, more appropriate prompts for future interviews were gleaned from previous interviews, thereby resulting in a better foundation for later analyses.

Corbin and Strauss (2008) referred to this process as developing more appropriate constructs. This research used the constructs based on symbolic interactionism (i.e., communication, values, history, professional experience, and philosophy) and Lasker, Weiss, and Miller's (2001) model for Partnership Synergy (i.e., resources, partner characteristics, relationship among partners, partnership characteristics, and the external environment) as a starting point for 
understanding the content of the data. At this point data began diverting from the Lasker, Weiss, and Miller model for Partnership Synergy and areas of shared meaning began to develop that were more indicative of the JETS Program including Collaboration, Intervention, Roles, Program Structure, Participant and Parents, Referrals, Assessment, and Academics. Each of the areas of shared meaning codes were then placed within a category of high or low levels of shared meaning. These categories of high or low levels of shared meaning codes were then given more specificity and coded into refined themes. Quantitative data from the Service Provider Surveys were then analyzed and compared to the qualitative data. These steps are discussed more fully in the Answering the Question section. This leads to the discussion of scientific rigor in qualitative research, and the methods used for this study.

\section{Scientific Rigor}

Scientific rigor is an important issue when discussing qualitative research. In part, this importance is attributed to the abstract and subjective nature of qualitative inquiry. Another is the desire to establish the integrity of the research. A variety of approaches have been identified to judge the credibility of qualitative studies-addressing the issue of consistency between respondents' views and the researcher's representation of them (Schwandt, 1996). These approaches can include member checking, audit trails, and triangulation.

Of these various approaches member checking is one of the most popular methods of assuring credibility in qualitative research and involves the participants' views on the honesty and consistency of the research findings. For 
example, once a researcher has paraphrased, or summarized the participant's words, the subject is then asked if the interpretations are an accurate interpretation of what was meant, said, or experienced (Crabtree \& Miller, 1992). Member checking is one method utilized in this study to enhance the scientific rigor. Service providers were asked to review their transcribed interviews and were encouraged to edit, delete, or clarify any of their comments from the transcribed document. Of the 16 service provider interviews, 4 partners made changes to their documents. However, none of the changes reflected the content or meaning from the interview. All of the edits and/or deletions were efforts to enhance grammar or correct the misspelling of words. The remaining 12 service providers verified that the transcribed interviews were accurate descriptions of what was said, and what was meant.

Providing an audit trail is also important to establishing scientific rigor in qualitative research. Audit ability provides defensibility of the findings and refers to the ability to follow the interpretative efforts of the researcher (Guba \& Lincoln, 1989). In essence, it is the responsibility of the researcher to show that the research was logical, traceable, and clearly documented.

This was accomplished for the JETS Program by detailing and outlining the decisions that lead to the findings contained within this study-including how each step of the process was followed, the underlying methodology, and the thoroughness in collecting and analyzing the data. Additionally, evidence can be provided on the process of collecting data for the study including the raw data 
(i.e., service provider transcripts, service provider surveys), and the trail of documentation for data collection (i.e., E-mails, and court notes).

A third approach that can increase the scientific rigor of qualitative research is triangulation. Triangulation is the combination of two or more theories, data sources, methods, or investigators in one study of a single phenomenon. This approach to enhancing scientific rigor is useful in assisting the researcher to ensure the completeness and the confirmation of the findings (Denzin, 1989). Additionally, utilizing a combination of methods can give a more accurate picture of the phenomena under study (Annels, 2006).

In relation to the JETS Program, triangulation is accomplished through the use of both qualitative (i.e., service provider interviews) and quantitative (i.e., service provider surveys and program evaluations) methodologies. Additionally, observational notes were taken during 25 court proceedings to document actions and comments of the JETS Program partners. This leads to the discussion of the quantitative data analysis used to evaluate the collaboration of the JETS Program partners, and the relationship with program outcomes.

\section{Quantitative Data Analysis}

Quantitative analysis of the quality of collaborations was limited to descriptive statistics of the 12 Likert scale items of the Service Provider Survey and Questionnaire ( $n=12$, Appendix A). These items were used as indicators of the quality of the interagency/community collaborations as perceived by the service providers. 


\section{Answering the Question}

Researchers Tashakkori and Teddlie (2003) provided five general steps for mixed methodology analyses (Table 3.3) and Table 3.4 summarizes how data were analyzed and interpreted to answer the research question.

Table 3.3

General Steps for Analyzing/interpreting Data from a Concurrent Nested Design (Tashakkori \& Teddlie, 2003)

\begin{tabular}{|l|l|}
\hline Step 1 & Code the qualitative data. \\
\hline Step 2 & $\begin{array}{l}\text { Analyze the quantitative data from questionnaires. These findings then } \\
\text { become themes. Compare these themes to the themes analyzed from } \\
\text { qualitative data. }\end{array}$ \\
\hline Step 3 & $\begin{array}{l}\text { Comparing results: Directly compare the results from qualitative data } \\
\text { collection to the results from quantitative data collection. Support } \\
\text { statistical trends by qualitative themes or vice versa. }\end{array}$ \\
\hline Step 4 & $\begin{array}{l}\text { Consolidating data: Combine qualitative and quantitative data to form } \\
\text { new variables. Compare original quantitative variables to qualitative } \\
\text { themes to form new quantitative variables. }\end{array}$ \\
\hline Step 5 & Interpret the combined data for answers to the research question. \\
\hline
\end{tabular}


Table 3.4

Specific Steps for Analyzing/Interpreting Data from the JETS Program

\begin{tabular}{|c|c|}
\hline Step 1 & $\begin{array}{l}\text { Upload: Service provider interviews, drug court notes, partner } \\
\text { discussions, and observations were uploaded into NVIVO8 (qualitative } \\
\text { software). }\end{array}$ \\
\hline Step 2 & $\begin{array}{l}\text { Source code: Uploaded service provider interviews, drug court notes, } \\
\text { participant discussions, and observations were coded for their particular } \\
\text { source (i.e., specific name of the service provider interviewed, dates of } \\
\text { drug court notes and observations, specific names of partners involved in } \\
\text { discussions. }\end{array}$ \\
\hline Step 3 & $\begin{array}{l}\text { General Construct Code: Comments, phrases, individual notes and } \\
\text { discussions from the source coded service provider interviews, drug court } \\
\text { notes, participant discussions, and observations were then coded into the } \\
\text { following constructs that were developed from Lasker, Weiss, and Miller's } \\
\text { (2001) Synergy Determinants (Table 2): Relationship Among Partners, } \\
\text { Program Foundation, Participant Characteristics, Services, and } \\
\text { Outcomes. }\end{array}$ \\
\hline Step 4 & $\begin{array}{l}\text { Area of Shared Meaning Code: The previously coded constructs were } \\
\text { then deconstructed further and coded for the specific area of shared } \\
\text { meaning of which they spoke: Collaboration, Intervention, Roles, Program } \\
\text { Structure, Participant and Parents, Referrals, Assessment, and } \\
\text { Academics. }\end{array}$ \\
\hline Step 5 & $\begin{array}{l}\text { High or Low Level of Shared Meaning Code: Each of the Areas of } \\
\text { Shared Meaning codes were then placed within a category of High or Low } \\
\text { Level of Shared Meaning. }\end{array}$ \\
\hline Step 6 & $\begin{array}{l}\text { Refined Themes Code: Area of Shared Meaning codes were then given } \\
\text { further specificity and coded into refined themes. }\end{array}$ \\
\hline Step 7 & $\begin{array}{l}\text { Quantitative Analysis of data obtained from service provider } \\
\text { surveys: Frequency distributions, and univariate statistics were used in } \\
\text { analyzing data due to the small sample size. }\end{array}$ \\
\hline Step 8 & $\begin{array}{l}\text { Comparison of the findings from qualitative and quantitative analysis, } \\
\text { and the program evaluations. }\end{array}$ \\
\hline Step 9 & $\begin{array}{l}\text { Interpretation of the findings from the qualitative and quantitative data } \\
\text { and program evaluations. }\end{array}$ \\
\hline Step 10 & $\bar{R}$ \\
\hline
\end{tabular}




\section{CHAPTER IV}

\section{FINDINGS}

Recall that the purpose of this study is to determine the relationship between shared meaning and collaboration within a partnership of service providers for juvenile offenders with co-occurring substance abuse and/or mental health disorders. The effectiveness of individual services is sometimes more easily documented than the work of teams; consider the notion that the whole is greater than the sum of its parts. Too often, however, collaborating sounds like a really good idea-assemble a team of experts and generate that outcome that is greater than the sum of individual efforts. For this outcome to actually come to pass, however, requires real, deep, and consistent collaboration. This is the purpose of this work-to learn to what extent there is truly shared meaning among the providers of the JETS program. The findings of this study suggest that the relationship between shared meaning and collaboration is cyclic, not linear, and that there is a relationship between shared meaning, collaboration, and program outcomes (Figure 8), thereby supporting the hypothesis: if shared meaning does not occur among the members of the partnership, their collaborative behaviors will be negatively affected, as well as the agreed upon program outcomes.

This chapter presents the results of the 16 service provider interviews and surveys, drug court notes, and observations of the JETS Program in the first year 
(Table 4.0). The results are presented in four major sections: (a) from qualitative data, high levels of shared meaning on themes derived from the major constructs (i.e., resources, partner characteristics, relationships among partners,

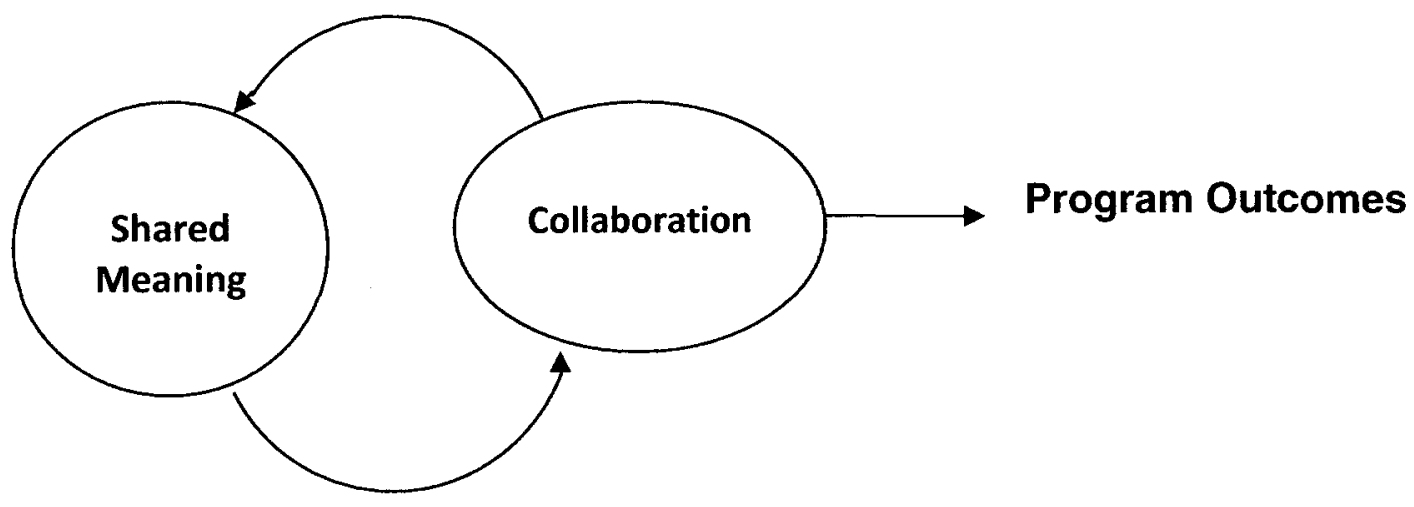

Figure 8. Relationship between Shared Meaning, Collaboration, and Program Outcomes.

partnership characteristics, and external environment), and (b) low levels of shared meaning likewise (see Table 2 in Chapter III), (c) quantitative data from service provider surveys, and (d) program outcomes.

Table 4.0

Data Sources for JETS Program

\begin{tabular}{|l|l|}
\hline \multicolumn{1}{|c|}{ Data Source } & \multicolumn{1}{c|}{ Collection Dates } \\
\hline Service Provider Interviews & October through December 2010 \\
\hline Service Provider Surveys & $\begin{array}{l}\text { March 2010 } \\
\text { October through December 2010 }\end{array}$ \\
\hline Drug Court Observations \& Notes & July through December 2010 \\
\hline
\end{tabular}

The service provider surveys were administered in March 2010 and October through December 2010, 1 year into the implementation of the JETS 
Program. The JETS Program partners who received this survey included representatives from Seven Counties, Administrative Office of the Court, Department of Juvenile Justice, Louisville Metro Youth Detention Center, The Morton Center, and the Department of Community Based Services. Of the 16 service provider surveys distributed, 12 surveys were completed and returned.

While Table 3.2 reflected the foundation for this work, a modified model (4.17) originating from the data will be presented later in this chapter. The modified model begins with the most prevalent constructs and refined themes for which there were high levels of shared meaning among the partners of the JETS Program. This is followed by the constructs and themes for which there were low levels of agreement. For the purposes of this study the term construct (capitalized herein) will serve the same function of as a concept. While a refined theme (italicized herein) is a breakdown of the construct into more specific or distinct qualities, or characteristics. Additionally, when applicable, comments from the open ended questions obtained from the service provider surveys will be summarized at the end of each appropriate construct.

The third section presents the quantitative results from the service provider survey data collected concurrently, and program evaluations that were submitted quarterly. It is here that program outcomes are discussed. These two sources, surveys and program evaluations, along with the interviews, begin to connect the ideas of shared meaning, collaboration, and program outcomes. 


\section{Constructs and Refined Themes with Highest Degree of Shared Meanings The Collaboration Construct}

The construct with the highest number of references on which there was a high level of shared meaning among the partners is that of Collaboration ${ }^{1}$ itself. These comments were assigned to this particular construct because they spoke of the partners' agreement that the appropriate professionals were involved in the collaboration, and their interactions. This construct, along with the refined themes, describes the ways in which shared meaning is achieved by the partners of the collaboration, and how information is shared about the progress of the JETS program participants and their families.

In concert with qualitative researchers who posited similar constructs and themes as those under study here and called for providing examples that most closely represented refined components (Lasker, Weiss, \& Miller, 2001; Mattessich, Murray-Close, Monsey, \& Wilder Research Center, 2001), it is not surprising that the very idea of collaboration is difficult to imagine without good communication. In the following comments the shared meanings are evident as team members recalled the importance and value added to the program from their discussions. ${ }^{2}$

The entire team met last Wednesday, and we discussed what was going on in the past year and what could change.

There is a lot of sharing of information that typically would not occur without this program. When we come together on Wednesdays, we discuss recommendations for the child, whether it be sanctions or incentives.

\footnotetext{
1 For clarity, the names of Constructs are capitalized and themes are italicized.

2 The narrative data are paraphrased to protect respondents' confidentiality.
} 
There is a lot of good input from eight different people because once you get a lot of people together in one room you are going to have different ideas, you are going to have different thoughts from each person, so we work very well together.

I would say between the Emails, telephone calls, and text messages, everybody works really well at making sure that we are all included in conversations about what is going on with each person, who fits in the program and then coming together weekly and each having a voice in making decisions.

I think we try and educate each other on a weekly basis in drug court because I don't know resources that are available. We are all kind of in our own little areas and there are lots of things that I don't have regular access to so part of it is just that discussion when the team is together.

We are also looking at how we can train together.

Additionally, service provider comments reflected a high level of shared meaning and collaboration regarding having the appropriate professionals participating in the partnership. The refined theme of the appropriate professionals participating within the collaboration attests that most, if not all of the partners, were in agreement that the individuals involved make the collaboration stronger, and can address the multiple needs of the complex families served. Following are examples of the comments echoing this theme.

We have got the right people at the table to be able to do it.

There are the right people there, or the right agencies there.

We're on the same team when we're in the JETS Program together.

They really are in it for their concerns for the kids.

Everyone has come to the table earnestly and honestly and wanting to make a difference in impacting this population's resources in the community.

A lot of people that are in the programs, or the partners at the table, already knew each other.

Service provider comments also reflected a high level of shared meaning and collaboration in terms of the partners having shared responsibility and equality within the JETS Program. The refined theme of equality indicates that many of the partners view the JETS Program as a true collaboration among the 
participating individuals and agencies. Although many of the partners share this

viewpoint on equality, there are others who distinctly disagree and their

comments are discussed later. Examples of the comments for partner agreement

on the theme of equality follow.

Absolutely, everybody has their opportunity to voice their opinion.

Collaboration and joint-ownership of program with equal responsibilities and ownership is stressed, as well as equal input from each of the partners at the meetings with equal ownership.

It is a collaborative and we all have equal say in what happens.

Service provider comments also support the theme of strengths in relation to the construct of collaboration. This theme indicated that many of the partners have shared meaning of the collaboration being a positive conduit for service delivery to the community (examples of partner comments supporting this theme follow).

I think the strength is in all fairness it has a good grounding purpose and you have people that want to see that succeed. You have good people in there that have knowledge, have the desire to see kids succeed and they want to see kids do better and are willing to put the time and energy into coming and showing up and being there. I think that is a huge strength of the program.

A strength is the communication between all of the agencies, all of the team members, you know and the ability to share that information quickly and get kids hooked up in services quickly as opposed to waiting the normal routes which takes a long time. I think that every member who is on the team seems to work well together, everybody kind of brings their own opinion but it is good to have those differing opinions there. You know, I think.

Every single one of the team members has the best interest of the child at heart so that is a benefit for the kids.

I think a big strength is that we have such good communication between agencies, getting appointments for, you know, for counseling or making referrals to other agencies has been really good. The fact that there is somebody represented from each agency in court every week I think has been really beneficial.

So that collaboration, the coordination, the relationships, those strengths, building our knowledge of what is in the community and what we can tap into and how we can use it, that has been a strength, having the school system involved in such a way that they help us, that has been a tremendous strength. 
The strength would be that you do have people from a lot of different disciplines that can give different information, different expertise and there is more of a wraparound kind of mentality to address a lot of the issues going on and I think that is very positive.

So we are sitting in there and I counted the room. It was two kids and 15 adults. 15 adults who came back every week because they cared about this initiative and wanted to make a difference just in two kids' lives. I mean, you don't see that anywhere. That's a lot of positive can-do attitude about a population that most people write off or find ways to give ultimatums to and run them off.

The resulting themes and their frequency are shown in the first building block of the new model (Table 4.1), and Table 4.2 provides supporting comments from the providers in response to open-ended questions on the service provider surveys.

\section{Table 4.1}

Collaboration and Refined Themes

\begin{tabular}{|l|l|}
\hline $\begin{array}{l}\text { High levels of shared meaning } \\
\text { on this construct ... }\end{array}$ & ... were refined into these themes \\
\hline Collaboration & $\begin{array}{l}\text { Communication } \\
\text { Appropriate professionals } \\
\text { Equality } \\
\text { Strengths }\end{array}$ \\
\hline
\end{tabular}

Table 4.2

Content from Open-Ended Questions Relevant to Collaboration Construct

\begin{tabular}{|l|l|}
\hline \multicolumn{1}{|c|}{ Content from March, 2010 } & \multicolumn{1}{c|}{ Content from October-December, 2010 } \\
\hline $\begin{array}{l}\text { Having all the social support agencies } \\
\text { involved, and the resources they bring }\end{array}$ & Number of resources available \\
$\begin{array}{l}\text { Fast response time, and assessment for } \\
\text { services }\end{array}$ & Accessibility of services, and faster treatment \\
$\begin{array}{l}\text { Increased accountability for juveniles and } \\
\text { their parents }\end{array}$ & Team approach, and committed individuals \\
& Collaboration between the community partners \\
& Aggressive and assertive monitoring of cases \\
\hline
\end{tabular}

\section{The Intervention Construct}

Intervention is another construct on which there were high levels of shared meaning among the partners. These comments were assigned to this construct 
because they spoke of the interventions that were discussed, and employed by the partners as well as the shared meaning on the outcomes of the interventions on the participants' behaviors and/or substance abuse. The theme of discussions is an indication of how the partners developed shared meaning on the possible interventions available, and their appropriateness to address the specific needs of the juvenile (examples follow).

Partners discussed whether to keep participant in program and what leverage the program has over his treatment.

Partners discussed additional services such as group and treatment (i.e., individual and family) $1 \times$ per week.

Partners discussed sanctions that will be given since violating his court requirements.

Partners asked about giving incentives to parents for their progress.

Partners suggested house arrest, adding community service hours, as well as making appointments for Individual, family and group treatment services within 24 hours.

Seven Counties representative led discussion on Medicaid eligibility for client. Partners inquired about availability of couple therapy for parents.

Partners were updated on participant's progress (i.e., completion of community service, following up with psychiatrist, getting medications straightened out, getting set up with appointments to see child/adolescent psychiatrist).

Decisions by the partners regarding intervention and treatment strategies constitute another theme that emerged from the Collaboration construct. Intervention decisions were observable behaviors that reflected shared meaning on the treatment strategies that would be employed for addressing the substance abuse, mental health, and/or behavioral needs of the participant (examples follow).

Partners agreed that detention would not serve a purpose at this point; partners agreed for him to focus on school assignments and continue with individual counseling.

She is starting treatment group this week. Partners voted to leave participant as status quo. 
Judge will continue with status quo and inquired about parent's participation in services. Partners reported no difficulties and parents are compliant with services and treatment.

Participant asked about Healing Place, an adult substance abuse rehabilitation and treatment agency, partners and parents agreed this was not an appropriate community service placement.

Partners in agreement that participant needs to be seen at least weekly for individual counseling.

JETS has definitely used home incarceration, which means the youth is identified as needing some type of more restrictive supervision than just the parent. When court ordered, the participant is placed on home incarceration, which means they come over here and we slap a bracelet on their ankle. They will have releases for their therapeutic appointments and school only. Other than that, we would be monitoring them on our phones. If the kid goes out or leaves the home or leaves an authorized place, we also have a device in our vehicles so that we can drive by a school and check and it will tell us if that ankle transmitter is in the school, so we know if the kid is there.

Positive outcomes for the intervention decisions emerged as another theme from the Intervention construct. These comments are an indication of the strong relationship between shared meaning, collaboration, and program outcomes. This is due to the observable positive behaviors occurring when there is a high level of shared meaning. Examples of the partners' comments referencing this refined theme follow.

Mom expressed to partners that couple therapy has been beneficial to family in working through their issues.

Another thing that has pleased me is that several of the kids that we have had in the program have been very difficult kids to work with. They have traditionally not been successful with interventions that have been tried previously. I have no doubt that what we provided will help them in the future.

School is pleasantly surprised with participant's progress.

Participant is doing well and is $100 \%$ for this week.

Participant is doing well and may have job at Waffle House.

The program strengths as a whole, we have helped a lot of kids overcome their substance dependency.

Participant continues to test negative on urinalysis.

Partners feel that family has made progress as a whole and the family continues to receive services at Morton Center. 
Participant is continuing to do well at school and with volunteer work at school; all reports are extremely positive even when he has been faced with adverse situations.

Grandmother reports that he is doing well. Partners identified that participant is $100 \%$ and received a 1 hour extension on his curfew, as long as it is approved by grandmother and scheduled ahead of time.

The construct of Intervention and the resulting themes are shown in the second building block of the new model (Table 4.3), and Table 4.4 provides supporting comments from the providers in response to open-ended questions on surveys.

\section{Table 4.3}

Intervention and Refined Themes

\begin{tabular}{|l|l|}
\hline $\begin{array}{l}\text { High levels of shared meaning on } \\
\text { this construct ... }\end{array}$ & $\ldots$ were refined into these themes \\
\hline Intervention & $\begin{array}{l}\text { Discussions } \\
\text { Decisions } \\
\text { Outcomes }\end{array}$ \\
\hline
\end{tabular}

Table 4.4

Content from Open-Ended Questions Relevant to Intervention Construct

\begin{tabular}{|l|l|}
\hline \multicolumn{1}{|c|}{ Content from March, 2010} & Content from October-December, 2010 \\
\hline $\begin{array}{l}\text { Treatment coordination, and the variety of } \\
\text { services offered }\end{array}$ & $\begin{array}{l}\text { Quality treatment coordination, and the availability } \\
\text { of services to juveniles }\end{array}$ \\
\hline
\end{tabular}

\section{The Roles Construct}

The construct of Roles also had a high number of references on which there was a high level of shared meaning among the partners. These comments were assigned to this construct because they spoke of the general knowledge and shared meaning of the various individuals who are participating within the collaboration, and their responsibilities to the JETS program. Within this construct two separate themes emerged-implied and actual. The theme of implied role suggests that the partners were familiar with one another's roles and shared the meanings about individuals' general duties, or responsibilities to the JETS 
Program, at least as defined by their roles in their employing agencies. Service

providers' comments referencing the theme of the partners' implied roles follow.

Seven Counties, Morton Center, Wellstone, they are actively participating and actively work to get referrals quickly and efficiently so that the kids and their families get into therapy really quickly

The case managers, they are supposed to be more of that modern trend piece, referring out to services and that type of thing.

The Administrative Office Courts and Department of Juvenile Justice each have specific workers that are with the court right now that are in primary kind of case coordinators for each case.

The public defender, where the youth obviously has to be represented to make sure nobody's rights are trampled on, so to speak, and overlooked, because some of these kids will be held in contempt of court, and then obviously, we see parents being held in contempt of court, so, you know, it goes across the board.

If there are any kids that Department of Juvenile Justice is internally involved with, whether it is a kid that's on probation and that is involved with JETS, then the Department of Juvenile Justice representative is there to provide progress on that kid. How the kid is doing on probation, what the kid's needs are, how is the family, are they cooperating?

The prosecutors address whatever particular situation there is as far as the allegation of the crime and then the purpose of the juvenile justice system is in the best interest of the child, what can be done to help that kid.

Court Designated Workers are there to monitor the diversion-track kids and there is also a volunteer that the judge has due to the volunteer's knowledge of the juivenile system.

Louisville Metro Youth Detention is represented for house arrest issues. The public defender is there to insure the youth's rights.

We have DCBS which is the Department of Community Based Services which is our child welfare agency, and they provide us information regarding the impact that these families have been involved or we need referral sources with child welfare.

Different from the theme of implied, is actual role. This particular theme, within

the construct of Role, is an indication of the shared meaning a specific team

member has regarding their responsibilities within the JETS Program. Examples

of the service providers' comments referencing the theme of actual role follow.

Role, more of a clinical advisor, whenever there are clinical related issues or decisions I typically get brought into the discussion.

One of the things I do is look up the child protection history on the youth coming in and bring that information to people and I contribute my thoughts about the things going on and some collaboration and brainstorming with the others about what path to take. 
I think l'm just counted on to help with making some decisions about understanding this population a little differently.

My role is I'm supervisor of the two Court Designated Workers. I'm also in charge of our end of the grant, making sure that all of our reports and all of our data are correct and submitting those reports to the parties that need to receive them. And then, also collaborating with our Grants Administrator in Frankfort and submitting reports to her too. And then of course there is being at every weekly staffing and providing support on that end as well.

I'm more of a private citizen who is a lawyer and who has some experience in the system.

I am a volunteer and I help the Judge coordinate things and kind of keep things going in the right direction.

I am the figurehead, I am the one who has the jurisdiction power to be able to say you have got to do this to the parents or to the children. I am the one who has the power to say, you have a week in the youth center if that is what it is going to take.

The Court Designated Workers, we are required to gather the information, be the paper holders.

My role is everything that comes through the hub. That would include obtaining the information on the kids, their behavior, school attendance, drug testing, and we present it to the team.

The resulting construct of Roles and the refined theme of implied and actual are shown in the third building block of the new model (Table 4.5).

\section{Table 4.5}

\section{Roles and Refined Themes}

\begin{tabular}{|l|l|}
\hline $\begin{array}{l}\text { High levels of shared meaning on this } \\
\text { construct ... }\end{array}$ & $\begin{array}{l}\ldots \text { were refined into these } \\
\text { themes }\end{array}$ \\
\hline Roles & $\begin{array}{l}\text { Implied } \\
\text { Actual }\end{array}$ \\
\hline
\end{tabular}

\section{The Program Structure Construct}

Program Structure is another construct with a high level of shared meaning among the partners of the JETS Program. These service providers' comments were assigned to this construct because they gave an indication of the general knowledge and shared meaning of the program's origins, goals, and actual structure amongst the collaborating partners. A high level of shared 
meaning on this construct reinforces the existence of a relationship between

shared meaning, collaboration, and program outcomes. In essence, a high level

of shared meaning on the construct of program structure indicates a solid

foundation for which positive program outcomes might be achieved. Examples of

service provider comments that reference the construct Program Structure and

the theme of program origins follow.

My understanding of the JETS Program is it originally started as an initiative to do a teen drug court program and when the state dissolved the Juvenile Drug Court Program, the Court Designated Workers obtained a grant to start a drug court for juveniles but this program was shut down across the state. But due to the fact that the Court Designated Workers had a grant they were able to keep a juvenile drug court program in place in Louisville, but they had to rename the program and in all essence that is how it became the JETS Program, the Juvenile Enhanced Treatment and Supervision Program. It used to be drug court; it is now an enhanced treatment docket.

It is my understanding that the Judge and the Administrative Office of the Court came together and apparently had some conversations prior to the rest of us coming on board. Apparently they had made some travels around the state observing other drug court groups around the state and pulled together a meeting of all the partners and the legal people involved and presented this program to us. Basically stating that the Administrative Office of the Court was going to file for a grant that would help pay for the incentives, drug testing, and whatnot. That is who was going to be applying for the grant, and we all pretty much signed off and said, yeah we'll do it whether we get the grant or not, because at the time we didn't know if we were going to get approval for the grant at that particular moment.

I think it started when several of us realized that we have a lot of kids that come through family court and juvenile court with pretty serious drug and alcohol problems. There seems to be a real gap in services, both locally and also statewide. Residential treatment is really, really very expensive and oftentimes, you know, cases involving drug problems come through court, and if the offense isn't serious enough it is handled in a way where there is just drug counseling referred, and there is no real serious intervention. So, I think the Judge and others wanted to create, we call it a court, but you know, that is using the term loosely I think, to call it a court. It is more akin to a social service agency, I think like the truancy court is not really a court, and this is the same sort of thing.

Program goals, another refined theme related to the construct of Program

Structure, pertains to service provider comments that referenced shared meaning around identified goals of the JETS Program. Recall that shared meaning around the primary goal of the program indicates a more solid foundation, and hence, greater likelihood of positive program outcomes (examples below). 
The primary goal is to help kids get better that have substance abuse problems, most of the time it is a family dynamic that's involved. So, unlike juvenile court and really unlike family court, even though family court is supposed to be more family-oriented, there is involvement with the families as well as the kid. We try to target, the specific behaviors and we try to make referrals to Morton Center, or whatever, and then every week the kids have to report, so we just sort of thought that that would be a good, new approach and really focus on improving the lot of the kid, because we realize that it really, really requires a lot of work on substance abuse. So, I think that was kind of the goal of setting up the JETS Program.

The primary purpose behind it is to help juveniles become clean and sober, those with substance related issues.

Well the mission was established because originally when we started, we were under the guidelines of the administrative office of courts and they already had a program designed that had a mission statement included and it was to identify and treat substance abuse issues so the kids could become productive.

The JETS program is aimed at focusing on kids that have drug and alcohol issues, providing treatment, finding resources for them and their family, and to make them accountable for their actions.

My understanding is that the main focus is substance abuse but they are also working with kids who have mental health issues as well, as other diagnosis besides drug addiction.

It is a collaboration that is between different agencies to work with youth who have substance abuse and mental health issues.

The JETS program is an enhanced supervision program primarily designed to assist juveniles who are currently having some type of substance abuse problem. It is a little bit more intensive, as far as wrap around services, than the traditional juvenile court, so it really allows and affords the juveniles and their families some services that they may not have been given if they were in the regular juvenile court setting. It provides counseling and a lot of support, as well as the other agencies. It is probably the largest collaborative effort as far as agencies that are designed to be able to affectively coordinate and identify any services that any of the juveniles and their families might need.

\section{Another theme that emerged from the construct of Program Structure was in}

\section{reference to the design of the JETS Program, and the shared meaning around}

\section{how services are structured (examples follow).}

The program is set up on a phase system. The kids come in, they are on phase 1 for so many weeks and then they go to phase 2, phase 3 and then there is like a graduation phase so that is basically an orientation, a learning, a progress and a graduation phase.

There are two different tracks, we have the diversion track which would be the kids who are coming through the Court Designated Worker Office, a lot of times they are going to be first offenders with some kind of substance related charge or they have indicated through the game short screener that there is a history of issues with substances. There is also a probation track which, the name of it is a little misleading, it is not necessarily that these kids are on probation as much as they are actually referred by a Juvenile Court Judge. Again the same thing, either on a substance related charge or there is some 
indication of substance use or abuse dependence. So once they get in the program we kind of get them hooked up with treatment, do random drug screens, and go from there.

They were the juveniles who qualify, identifying them as having either some kind of a substance abuse problem and in addition to some kind of mental health, and/or emotional health problems. So we call them kids with dual needs. It is a voluntary program to the extent that they come in and they sign into the program and their families sign in along with them.

It was styled after the adult drug court.

It was based on a drug court model, we had been looking into what kind of intervention or what kind of services can be helpful to adolescents in the Jefferson County area, the ones specifically that are getting referred for legal issues. There were a lot of kids that were having legal issues and trying to determine is this a criminal problem or is this a substance abuse problem or a mental health problem, what is the kind of foundation level problem, is legal charges just a symptom of other things going on? So we did some research into that and observed other city programs across the country. There were some successful drug courts and getting youth out of detention and really into treatment and in services and looking at their outcomes and thought that that would work well here.

The resulting construct of Program Structure and the refined themes are shown in the fourth building block of the new model (Table 4.6).

\section{Table 4.6}

\section{Program Structure and Refined Themes}

\begin{tabular}{|l|l|}
\hline $\begin{array}{l}\text { High levels of shared meaning on this } \\
\text { construct ... }\end{array}$ & $\ldots$ were refined into these themes \\
\hline Program Structure & $\begin{array}{l}\text { Origins } \\
\text { Goals } \\
\text { Design }\end{array}$ \\
\hline
\end{tabular}

These findings suggest that the partners of the JETS Program have a high level of shared meaning around the construct of Collaboration when exhibiting collaborative behaviors, identifying the appropriate professionals to participate with the JETS Program, having the ability to voice ideas or opinions and identifying the benefits of this type of collaborative partnership. Additionally, results indicate a high level of shared meaning around the construct of Intervention and the partners' ability to discuss possible intervention strategies, make decisions on which strategies are appropriate, and identify the positive 
outcomes resulting from those decisions. Regarding the construct of Role, findings suggest that service providers had a high degree of shared meaning around roles and responsibilities as they pertain to the various partners' employing agencies, and partially identifying their responsibilities as they pertain to the JETS Program. The final construct that produced significant references was Program Structure. Results indicate a high level of shared meaning around the origins, and goals of the JETS Program and a partial level of shared meaning around the actual design. The next section will discuss the constructs and refined themes where the service providers had low levels of shared meaning.

\section{Constructs and Refined Themes with Low Level of Shared Meanings The Collaboration Construct}

Similar to the high levels of shared meaning construct, Collaboration also had numerous references on which there was a low level of shared meaning among the partners. These comments were assigned to this particular construct because they spoke of the partners' disagreement with the other professionals involved in the collaboration, and their interactions. This construct, along with the refined themes, describes the ways in which shared meaning have not been achieved by the partners of the collaboration, and how members have felt disenfranchised within the collective of the JETS Program. Examples of comments referencing specific non-collaborative behaviors and lack of shared meaning follow.

I really don't know, I think that that is another issue that they should have addressed when they developed this program, they kind of had a broad view of what they wanted but they didn't necessarily involve all the different partners. 
Some people on the team are influenced by others in the decisions that they make or the opinions that they have or the options that they put out there. I think a lot of it is influenced by others. I don't think it is their opinions a lot of times.

Again, there seems to be problems with communication... within the partnership and within the agencies themselves.

The partnership is filled with "cliques" and if a partner is not affiliated with the "in cliques" their opinion is often overlooked.

It almost seems like there are a group of people who are like-minded that drive the bus.

I was outvoted and that's fine, you know, you ask for an honest feedback and opinion so I gave it, but what I understood from other participants who were there, before I got to the meeting my name was brought up and I was criticized for my position in that particular role. When I'm at the meeting nothing's said.

Service provider comments also reflect a low level of shared meaning and collaboration in terms of the partners not having shared responsibility and/or equality within the JETS Program. The refined theme of inequality indicates that many of the partners do not view the JETS Program as a true collaboration among the participating individuals and agencies. Examples of the comments for partner disagreement on the theme of equality follow.

They kind of developed the program and them came in and said this is the way it is going to run.

Sometimes I think they would like to lynch me. Sometimes I feel like the salmon swimming up the stream.

No. Our agency was brought in after the program had already started and was in place and had been running.

No, I don't feel like that there is equality in what anyone says.

I think some are more limited in what they say.

I made my effort to voice some concerns and in effect got shouted down, I'm not going to do that twice in a row.

Negative reactions constituted another refined theme from the Collaboration construct. Negative remarks about the partnership itself, as well as the resulting consequences, represent another indication of the problematic relationship between collaboration and shared meaning. This relationship is evident in the 
negative viewpoints expressed when there is a low level of shared meaning on

Collaboration between the partners.

I am very, in all honesty, I am very disappointed in the JETS program. I am very, very frustrated with the program.

I think the weakness of the program is that we don't feed off the strengths. We don't use what we have. We go the opposite direction.

I think the sad part is we all could have done something different, we all could have done something better, and none of us are perfect. We can all learn from our mistakes. What would it hurt to step back and say it hadn't been the best of year, so what can we do to fix it, because I think we could have all done something different, but I don't think you're going to get that.

I think people get frustrated because, I can see people feeling like they're not being validated.

There has been some conflict, there have been some disagreements. Some of the partners are obviously no longer at the table.

I think with all of that shifting and all those players, communication is something that is sporadic and inefficient. So, we're not really doing a real nice job exploring all of the communication options that might help with the consistency.

The resulting construct of Collaboration and the refined themes are shown in the sixth building block of the new model (Table 4.7), and Table 4.8 provides

supporting comments from the providers from open-ended questions on surveys.

\section{Table 4.7}

Collaboration and Refined Themes

\begin{tabular}{|l|l|}
\hline $\begin{array}{l}\text { Low levels of shared meaning on this } \\
\text { construct ... }\end{array}$ & $\begin{array}{l}\ldots \text { were refined into disagreement } \\
\text { on these themes }\end{array}$ \\
\hline Collaboration & $\begin{array}{l}\text { Non-collaborative behaviors } \\
\text { Inequality } \\
\text { Negative reactions }\end{array}$ \\
\hline
\end{tabular}

\section{Table 4.8}

\section{Content from Open-Ended Questions Relevant to Collaboration Construct}

\begin{tabular}{|l|}
\hline \multicolumn{1}{|c|}{ Content from March, 2010} \\
\hline $\begin{array}{l}\text { Better and increased communication } \\
\text { between the partners }\end{array}$ \\
\hline
\end{tabular}




\section{The Intervention Construct}

Intervention is another construct on which there were low levels of shared meaning among the partners. These comments were assigned to this construct because they spoke of the partners' limited knowledge on the chosen interventions, their frequency, and a lack of agreement on their results. The theme of limited knowledge is an indication of how shared meaning was not developed among the partners and gives an indication of how negative program outcomes can be partially attributed to a lack of knowledge by the partners.

Partners were confused about mother's participation in treatment group-family corrected court and stated that mother did attend.

Partners and parent (father) seemed to be confused about treatment group and missed session last night.

There is some questions regarding community service requirements and holding him accountable.

There is some discourse between the partners regarding community service hours.

Partners were unsure about whether he is in school, unsure about which Judge placed in detention and/or house arrest.

Several partners did not understand why client was not institutionalized if making "suicidal or homicidal" threats.

Team unsure who primary counselor is within program.

Mental health partners were unsure how long it would take to get juvenile and family into treatment.

Discussed control line of urinalysis being faulty.

Do I think the program is treating all of the issues with the family? No, I don't. I think we have done it well with some families, I don't think we have done it well with other families.

I don't feel like it is being done and I think some families get more services than they need and other families aren't getting what they should.

I think some kids in the program get more treatment, they get more services, they screw up more and she still excuses them while the other kids.

Negative outcomes for the intervention decisions constituted another refined theme from the intervention construct. These comments reference the 
relationship between shared meaning and program outcomes. This relationship seems to be aligned with observable negative behaviors (e.g., recidivism), especially when there is a lack of shared meaning on interventions, treatments, and readiness for sobriety.

No show for last court session, has not attended individual counseling, and is noncompliant for drug testing.

He has been missing for 6 days, and is refusing to participate in home-based services when therapist comes to home; mother has set cellular service to only receive services from home.

He is kicked out of ISAP (in-school suspension) due to smoking and is now suspended from school.

He has confessed to smoking pot.

Seven Counties expressed concern over parents and their lack of parenting skills; once court is over the family will digress.

The diversion staff is not drug checking their kids; there is also a problem with telephone checks. The partners, who are doing telephone check-ins, seem a little confused about what to be listening for during check-in.

As of Friday, urinalysis is still negative for TetraHydroCannabinol (THC). But he has admitted to using an over-the-counter cold medicine to get high.

TetraHydroCannabinol (THC) levels increasing and tested positive for benzodiazepines; he did not show up for the last urinalysis.

Last urinalysis was non-testable due to container leaking.

The resulting construct of Intervention and the refined themes are shown in the seventh building block of the new model (Table 4.9), and Table 4.10 provides supporting comments from the providers in response to open-ended questions on surveys.

Table 4.9

Intervention and Refined Themes

\begin{tabular}{|l|l|}
\hline $\begin{array}{l}\text { Low levels of shared meaning on this } \\
\text { construct ... }\end{array}$ & $\begin{array}{l}\ldots \text { were refined into disagreement } \\
\text { on these themes }\end{array}$ \\
\hline Intervention & $\begin{array}{l}\text { Limited knowledge } \\
\text { Negative outcomes }\end{array}$ \\
\hline
\end{tabular}


Table 4.10

Content from Open-Ended Questions Relevant to Intervention Construct

\begin{tabular}{|l|l|}
\hline \multicolumn{1}{|c|}{ Content from March, 2010 } & Content from October-December, 2010 \\
\hline $\begin{array}{l}\text { Getting payment for services if there is no } \\
\text { insurance, or family cannot afford }\end{array}$ & Increased informal pro-social activities \\
$\begin{array}{l}\text { Home incarceration as a form of } \\
\text { accountability }\end{array}$ & \\
\hline
\end{tabular}

The Role Construct

The construct of Role also had a high number of references on which there was a low level of shared meaning among the partners. These comments were assigned to this construct because they spoke of the lack of general knowledge and shared meaning of the various individuals who participated in the collaboration, and their responsibilities to the JETS program. Further, comments indicate there is a low level of shared meaning on the understanding of expected partner duties which can then contribute to poor service delivery and partner confusion.

I will do whatever you ask, if you define what my duties are.

Just everyone knowing their role and having that put into place.

The roles need to be more established. Everybody on the team needs to know what they are there for specifically and just not think that they are just somebody to come and sit to make the team look larger, that they actually have a role there. I think it needs to be more defined and they need to play that role.

I know there are some concerns about the Court Designated Workers doing the work of an Impact Plus worker. The Court Designated Workers are making all the contacts, they are overly involved with the family and that is what the impact plus worker is supposed to be doing. The Impact Plus workers are going into the home, dealing with the issues, working with the family and they are the ones who are supposed to be making those contacts and not the Court Designated Workers.

The judge's role is not clear.

I'm not really sure who's running it and who's supposed to be running the program. 
I think his email really reinforced to everyone how muddied the lines are and that that there are no clear roles.

Just totally define the roles, as far as each community partner. Okay, this is what this agency is going to provide and this is what this agency is going to provide. And then that way when we collaborate, everybody pretty much knows, what they're there for and what they are supposed to bring to the table.

Negative outcomes constituted another refined theme from the Role construct.

These comments give an indication of the relationship between shared meaning

and collaboration. This relationship can be illustrated with the negative

viewpoints on program outcomes that were expressed when there is a low level

of shared meaning around partner roles and responsibilities.

Yes, they are seeing that there is duplication in services and we even just spoke about this very issue last week; we need to have clear defined roles as to what everybody is supposed to be doing.

At this point I feel like the team is falling apart. Because of the lack of organization, nobody knows their particular roles; therefore they are just kind of sitting back waiting to see what everybody else is going to do. They are kind of confused as to what part they should be playing and it is kind of a little late in the game for them to stand up and now do the part that they were actually supposed to do, to now stand up and take their role and see it from their role instead of seeing it as a team partner.

I just find the process somewhat confusing. I know it is a work in progress and some things are being ironed out along the way, but I am not really sure that everybody does have a clear understanding of their roles and how it all meshes.

The resulting construct of Intervention and the refined themes are shown in the eighth building block of the new model (Table 4.11), and Table 4.12 provides supporting comments from the providers in response to open-ended questions on surveys.

Table 4.11

Roles and Refined Themes

\begin{tabular}{|l|l|}
\hline $\begin{array}{l}\text { Low levels of shared meaning on this } \\
\text { construct ... }\end{array}$ & $\begin{array}{l}\ldots \text { were refined into disagreement } \\
\text { on these themes }\end{array}$ \\
\hline Roles & $\begin{array}{l}\text { Expected partner duties } \\
\text { Negative outcomes }\end{array}$ \\
\hline
\end{tabular}


Table 4.12

Content from Open-Ended Questions Relevant to Role Construct

\begin{tabular}{|l|}
\hline \multicolumn{1}{|c|}{ Content from October-December, 2010} \\
\hline Clearer roles and expectations for each community partner \\
A designated person needs to be in charge \\
\hline
\end{tabular}

\section{The Program Structure Construct}

Program Structure is another construct with a low level of shared meaning among the partners of the JETS Program. These service providers' comments were assigned to this construct because they gave an indication of the lack of general knowledge and shared meaning on the program's consistency with providing services to participants and their families. Low levels of shared meaning on this construct indicate a less than solid foundation from which positive program outcomes can be achieved. Comments that reference the refined theme of inconsistency follow.

There is no consistency across the board as how we handle each case, even though they are done individually one kid will come in and have problems, then they want them out and another they will keep.

Weaknesses, just the lack of structure or steady flow of everything I think has really been challenging.

To be honest there are too many inconsistencies. We punish or hold youth accountable differently, some youth never come off of house arrest, never move up the phase system and then others with have a few violations and be removed from the program.

There needs to be a clearer process when a child is in JETS, what it takes to complete the program.

I think everybody needs to have a clear understanding of the expectations and the ground rules and what is going to happen.

There needs to be set standards of how things operate, that has been a huge part of the confusion here lately.

There are some discrepancies about the structure and about the flow of the program and how the kid gets in and then goes through the program. 
There are now three case managers, which I don't think l've quite understood why there are three case managers. Do we even have five kids right now? Why do we need three case managers for five kids? When we first started, when I first started into this program, we had a page and a half full of kids with two case managers and they managed that perfectly fine.

There seems to be some confusion between the partners regarding protocols and acceptance for kids from court along with releases.

Different from the refined themes previously discussed is the program design of

the JETS Program. This theme referenced the low level of shared meaning

around leadership, basic operations, and the formality of court proceedings.

I think you need that one person to say, okay, this is how it is supposed to run, this is what the roles are, so that everything kind of runs smoothly, and right now I don't think that happens.

The court is too informal with participants and their families; the Judge should be sitting behind the bench, with or without robes, making the proceedings seem more formal and the court process more credible; garnering more respect from participants and their families.

I think if we could work it the way it was originally started out to be, it would be a good program.

I just feel like it's not working the way that it was originally set up, as far as the type of kids that come into the program, or what we are supposed to be doing for the kids.

It definitely needs to be more structured. It needs to be more thought out as to the case management. There needs to be some type of records kept on these kids if they are going to be incarcerated, if their parents are going to be incarcerated. There needs to be some sort of records kept throughout their whole entire stay in the drug court process.

The program that you have seen today in my judgment, in my opinion, differs greatly from the way it was conceptualized and the way it was set up initially.

I think it needs to go back to the way it was first proposed, and I think it needs new leadership. I really do. The program needs somebody who has some training and has some formal training or education in the drug court, not self-taught.

Low shared meaning on the construct of Program Structure also gave rise to the refined theme of negative outcomes for the JETS Program. The negative comments made by service providers referenced a lack of shared meaning in program protocols and outcomes. This gave further indication of a relationship between shared meaning, collaboration, and program outcomes. 
I do think there are some frustrations with the way each session goes, in time and attendance and kind of spending too much time on one case and the frustrations. I think some of the workers are getting frustrated and they are not so sure that they want to stay involved.

I feel the court has become too enabling, by taking the responsibility away from the parent, or doing the parenting, which is not what we are supposed to be doing

I just don't think we are going in the right direction with a lot of the kids and it's a lot of my frustration that kind of pushes me from attending each week.

I think we've burnt quite a few bridges along the way. I think we've given people reasons to question what we've done, which, in a lot of ways is frustrating cause I don't want people to then think well, we can't trust those individuals anymore because look what they did with this kid.

I think that there is some confusion at the level of other judges. I think there is a lack of understanding of what we do in drug court.

I see some frustration and it comes down to the inconsistencies. Nobody ever set the foundation of what the program really was. Nobody sat down and said, well we probably should write up some type of a criteria and protocol and put it in to play so at least we have a foundation to start with.

Due to the lack of organization, and the miscommunication, it is causing a lot of confusion in other areas in other parts of the court system.

There are very, very good ground rules that are set up and this has been very successful in other places. Maybe we need to kind of start over from fresh a little bit and make sure that we all are aware of that so we can make this a successful program.

This is doing a disservice to the client because, if we're not clear on what we're supposed to do, how are we going to communicate to them what they're supposed to do.

There is a lack of follow-up. We do not really know what's being successful, what's not being successful, and I don't know how we'll get to that. How are we going to sell the program in the future, how are you going to know what is correct, or what to keep unless there is some way of measuring the outcomes?

The resulting construct of Program Structure and the refined themes are shown

in the ninth building block of the new model (Table 4.13), and Table 4.14

provides supporting comments from the providers in response to open-ended

questions on surveys. 
Table 4.13

Program Structure and Refined Themes

\begin{tabular}{|l|l|}
\hline $\begin{array}{l}\text { Low levels of shared meaning on this } \\
\text { construct... }\end{array}$ & $\begin{array}{l}\text {.. were refined into disagreement } \\
\text { on these themes }\end{array}$ \\
\hline Program Structure & $\begin{array}{l}\text { Inconsistency } \\
\text { Program design } \\
\text { Negative outcomes }\end{array}$ \\
\hline
\end{tabular}

Table 4.14

Content from Open-Ended Questions Relevant to Program Structure Construct

\begin{tabular}{|l|l|}
\hline \multicolumn{1}{|c|}{ Content from March, 2010 } & \multicolumn{1}{c|}{ Content from October-December, 2010 } \\
\hline $\begin{array}{l}\text { Lack of consistent procedures and the need } \\
\text { to work out the kinks between involved } \\
\text { parties, especially re whose case it is when } \\
\text { a youth fails to comply with the Drug Court }\end{array}$ & $\begin{array}{l}\text { Need written protocols, clarification of admission } \\
\text { criteria, and procedures in writing }\end{array}$ \\
$\begin{array}{l}\text { Not enough information about the youth is } \\
\text { available to staff }\end{array}$ & Staffing prior to court is too long \\
Staffing prior to court is too long & \\
\hline
\end{tabular}

\section{The Referral Construct}

Referral is a construct that did not formally materialize with a high degree of shared meaning but became evident in terms of low levels. In part, this can be attributed to the partners' lack of knowledge regarding the referral process, and the criteria for juvenile participation in the program. This lack of knowledge has contributed to low enrollment and an inability to assess the appropriateness of juveniles' participation in the JETS Program, thereby demonstrating another link between shared meaning and negative program outcomes. Comments referencing the theme of a service providers' lack of knowledge on the Referral construct follow. 
A specific referral form that if we want to bring a child in to the program, you complete a referral form, the case is then presented to the group. All the information is presented before you vote on them and take that kid into the program, get all the facts first. I think that that would really be good idea.

Referral process? What is the process? I don't know.

We are getting these kids referred that have never had a GAIN $Q$ done on that and that is one of the primary things that should be done prior to their acceptance into the program. I mean there is just, there needs to be a set process in place that is followed

Our intake process isn't really clear to everyone.

What is the system in place that identifies the youths for a diversion straight from the Court Designated Worker? What are the criteria for a diversion straight from the court system, what are the criteria?

There needs to be defined eligibility requirements for the kids.

When a child is presented, it seems like there is very little information about the child and we are being asked to vote, are they appropriate for the program? I don't know because I don't know the standard for appropriate.

There needs to be clearer guidelines about who is acceptable.

I think there are some kids that have been brought into juvenile court for JETS that shouldn't have been the kids that have been, they shouldn't have been there. I almost feel like they were penalized. If they had gone through the court track, they would have gotten five hours of community service and been right on their way. But instead they were made to participate with JETS. I think there needs to be a better process for how kids are brought into JETS.

It's interesting because I never really saw, and it may very well exist, but as far as the criteria of who's eligible and who's not.

Maybe we should step back and look at why we aren't getting referrals.

The resulting construct of Referral and the refined themes are shown in the tenth building block of the new model (Table 4.15), and Table 4.16 provides supporting comments from the providers in response to open-ended questions on surveys.

\section{Table 4.15}

\section{Referral and Refined Themes}

\begin{tabular}{|l|l|}
\hline $\begin{array}{l}\text { Low levels of shared meaning on this } \\
\text { Construct ... }\end{array}$ & $\begin{array}{l}\ldots \text { were refined into disagreement } \\
\text { on these themes }\end{array}$ \\
\hline Referral & \begin{tabular}{l} 
Lack of knowledge \\
\hline
\end{tabular} \\
\hline
\end{tabular}




\section{Table 4.16}

\section{Content from Open-Ended Questions Relevant to Referral Construct}

\begin{tabular}{|l|l|}
\hline \multicolumn{1}{|c|}{ Content from March, 2010 } & Content from October-December, 2010 \\
\hline $\begin{array}{l}\text { Stricter guidelines regarding type of drug } \\
\text { offense that can be accepted, and who } \\
\text { retains jurisdiction if juvenile is not compliant } \\
\text { with program }\end{array}$ & $\begin{array}{l}\text { A standardized process for referral is needed, as } \\
\text { well as clarification on referral criteria }\end{array}$ \\
\hline
\end{tabular}

These findings suggest that the partners of the JETS Program have low levels of shared meaning around the construct of Collaboration when respondents were speaking of their individual, or their agencies' involvement with the design, and their initial involvement with the implementation of the program. Further, the findings show that the partners have low levels of shared meaning on their ability to voice dissenting opinions within the collaboration, without fear of reprisal. There is also a lack of agreement among the partners, and an expressed dissatisfaction with how the program has been implemented.

Additional findings suggest there is a low level of agreement centered on the Intervention construct-there is an overall lack of knowledge of the services being offered to the individuals participating in the program and their progress. Several negative program outcomes were associated with this lack of shared meaning, including missed treatment appointments, lapses in sobriety, and ineffectual service delivery.

Other findings developed on the construct of Role, and the partners' lack of shared meaning regarding their responsibilities for service delivery, and the actual delivery of services to participants and their families. This low shared meaning around Role could have negatively affected program outcomes and 
resulted in a duplication of services, as well as feelings of confusion among the service providers. Program Structure is another construct that can be associated with poor program outcomes. Low shared meaning around this construct spoke of inconsistencies and ineffectiveness of service delivery, along with the partners' impression of participants not being treated equally, further illustrates the relationship between shared meaning, collaboration, and program outcomes.

Referral, the last construct, yielded a significant number of references in relation to a low level of shared meaning among the partners of the JETS Program. Results indicate that the partners have a low level of shared meaning on the actual referral process by which a juvenile should enter the program, and the criteria by which they are eligible for the program. This lack of knowledge and agreement on the referral process is another illustration of how a lack of shared meaning is related to program outcomes-if there is no shared meaning on how a youth is referred, the program will not be able to sustain enrollment, and eventually the program will terminate. Table 4.17 summarizes high and low levels of shared meaning with constructs and refined themes. The next section discusses the findings from the service provider surveys and the program evaluations; these are the quantitative data that were collected concurrently with the service provider interviews. 
Table 4.17

Summary of High and Low Levels of Shared Meaning with Constructs and

Refined Themes

\begin{tabular}{|c|c|c|}
\hline $\begin{array}{l}\text { High Levels of Shared Meaning } \\
\text { on these refined themes. . }\end{array}$ & CONSTRUCTS & $\begin{array}{l}\text { Low Levels of Shared Meaning } \\
\text { on these refined themes... }\end{array}$ \\
\hline $\begin{array}{l}\text { Communication } \\
\text { Appropriate professionals } \\
\text { Equality } \\
\text { Strengths }\end{array}$ & Collaboration & $\begin{array}{l}\text { Non-collaborative } \\
\text { behaviors } \\
\text { Inequality } \\
\text { Negative reactions }\end{array}$ \\
\hline $\begin{array}{l}\text { Discussions } \\
\text { Decisions } \\
\text { Outcomes }\end{array}$ & Intervention & $\begin{array}{l}\text { Limited knowledge } \\
\text { Negative outcomes }\end{array}$ \\
\hline $\begin{array}{l}\text { Implied } \\
\text { Actual }\end{array}$ & Role & $\begin{array}{l}\text { Expected partner duties } \\
\text { Negative outcomes }\end{array}$ \\
\hline $\begin{array}{l}\text { Origins } \\
\text { Goals } \\
\text { Design }\end{array}$ & $\begin{array}{l}\text { Program } \\
\text { Structure }\end{array}$ & $\begin{array}{l}\text { Inconsistency } \\
\text { Program design } \\
\text { Negative outcomes }\end{array}$ \\
\hline General & Referral & Lack of knowledge \\
\hline
\end{tabular}

\section{Quantitative Data}

\section{Service Provider Surveys}

The data and findings from the service provider surveys and the program evaluations support the results from the previously discussed service provider interviews. This section includes the findings from those service provider surveys and is followed by a discussion of the submitted program evaluations.

The service provider survey consisted of 11 Likert-style questions on which providers responded to each question from 1 (Not at all) to 5 (Very often). The 1-5 scales refer to the extent to which the providers believed that the key element in each question was true, or indicative of the collaboration. Hence, higher medians reflect more collaborative behaviors, with the exception of 
question \#7, which speaks of more conflict (Table 4.18) and was reversed scored

for consistency.

Table 4.18

Findings from the Service Provider Surveys

\begin{tabular}{|c|c|c|c|}
\hline & Question & Mode & Median \\
\hline 1 & $\begin{array}{l}\text { Rate the current level of coordination of services between service } \\
\text { providers who serve youth with multiple needs in your community. }\end{array}$ & 4 & 4 \\
\hline 2 & $\begin{array}{l}\text { Do providers make effective collaborative decisions regarding youth } \\
\text { with multiple needs and their families? }\end{array}$ & 4 & 4 \\
\hline 3 & Do families have meaningful input into their youth's plan of care? & 3 & 3 \\
\hline 4 & $\begin{array}{l}\text { Do providers function together as a unit to achieve common service } \\
\text { goals? }\end{array}$ & 3 & 3 \\
\hline 5 & $\begin{array}{l}\text { Are providers able to successfully deliver non-duplicated services to } \\
\text { families? }\end{array}$ & $3^{a}$ & 3 \\
\hline 6 & $\begin{array}{l}\text { Do providers consult with other providers when crisis decisions have to } \\
\text { be made about a child or family? }\end{array}$ & 4 & 4 \\
\hline 7 & $\begin{array}{l}\text { Are there conflicts between providers over who is responsible for } \\
\text { providing a given type or amount of service? (reversed scored) }\end{array}$ & $5^{a}$ & 4 \\
\hline 8 & $\begin{array}{l}\text { Do service providers agree about the type of services that are most } \\
\text { appropriate for serving youth and families? }\end{array}$ & 4 & 3 \\
\hline 9 & $\begin{array}{l}\text { Have there been opportunities for providers to learn about community } \\
\text { resources available to teams? }\end{array}$ & 4 & 3 \\
\hline 10 & $\begin{array}{l}\text { Has the LANScAT Juvenile Drug Court initiative in your community led } \\
\text { to improved coordination between service providers? }\end{array}$ & 4 & 3 \\
\hline 11 & $\begin{array}{l}\text { Do you feel youth with multiple needs and their families are more } \\
\text { effectively served through the LANScAT process than through the use } \\
\text { of independently operating providers? }\end{array}$ & 4 & 3 \\
\hline
\end{tabular}

a. Multiple modes exist.

\section{Program Outcomes}

The funding agency of the JETS program, the Bureau of Justice

Programs, requires quarterly evaluation reports that include, for example, the

numbers of youth served, recidivated, and who completed the program. In the 
spirit of concurrent nested methodology, therefore, two quarterly reports were

submitted during the tenure of the current study. The first, in October, 2010, was

9 to 12 months in the life of the program and spoke mainly of how hard the

providers were working to recruit youth into the program and provide services,

and was optimistic of gaining access to information and data for the next

quarterly report (Table 4.19).

Table 4.19

\section{Program Evaluation Findings from July - September 2010}

\begin{tabular}{|c|c|}
\hline Total number of government agency partners for this reporting period & 5 \\
\hline Total number of community service agency partners for this reporting period & 2 \\
\hline Total number of mental health advocacy agency partners for this reporting period & 5 \\
\hline Total number of consumer partners for this reporting period & 6 \\
\hline Total number of family member partners for this reporting period & 9 \\
\hline $\begin{array}{l}\text { Number of program participants supervised by a juvenile-based program who successfully } \\
\text { completed the program during the reporting period }\end{array}$ & 1 \\
\hline $\begin{array}{l}\text { Total number of program participants supervised by a juvenile-based program that left the } \\
\text { program (for any reason) during the reporting period }\end{array}$ & 2 \\
\hline $\begin{array}{l}\text { Number of current program participants who experienced one or more technical violations } \\
\text { of supervision during the reporting period }\end{array}$ & 1 \\
\hline $\begin{array}{l}\text { Number of current program participants who were terminated from the program during the } \\
\text { reporting period }\end{array}$ & 1 \\
\hline Total number of program participants during the reporting period & 6 \\
\hline $\begin{array}{l}\text { Number of current program participants who have a new arrest during the repo } \\
\text { period }\end{array}$ & 0 \\
\hline irticipants with a new arrest during the reporting period & 0 \\
\hline $\begin{array}{l}\text { Total number of program participants with a technical violation of probation or parole } \\
\text { during the reporting period }\end{array}$ & 2 \\
\hline $\begin{array}{l}\text { Total number of program participants with sanctions for non-compliance with conditions of } \\
\text { program experienced during the reporting period }\end{array}$ & 2 \\
\hline $\begin{array}{l}\text { Total number of program participants that completed a juvenile-based program within the } \\
\text { past year }\end{array}$ & 2 \\
\hline $\begin{array}{l}\text { Number of program participants for which referrals were made for mental health services } \\
\text { during the reporting period }\end{array}$ & 5 \\
\hline $\begin{array}{l}\text { Number of program participants for which referrals were made for substance abuse } \\
\text { service during the reporting period }\end{array}$ & 5 \\
\hline $\begin{array}{l}\text { Number of program participants for which referrals were made for co-occurring services } \\
\text { during the reporting period }\end{array}$ & 6 \\
\hline $\begin{array}{l}\text { Number of program participants for which referrals were made for education services } \\
\text { during the reporting period }\end{array}$ & 4 \\
\hline Total number of individuals released during the reporting period & 1 \\
\hline $\begin{array}{l}\text { Of the total, number of individuals who are released to the community with a discharge } \\
\text { plan that is written }\end{array}$ & 0 \\
\hline & 0 \\
\hline
\end{tabular}


The second quarterly report January, 2011, referred to a paucity of

information and data and was less optimistic about having data on a sufficient

number of youth to conduct any kind of quantitative analyses (Table 4.20). This

Table 4.20

\section{Program Evaluation Findings from October - December 2010}

\begin{tabular}{|c|c|}
\hline Total number of government agency partners for this reporti & \\
\hline Total number of community service agency partners for this reporting period & 2 \\
\hline Total number of mental health advocacy agency partners for this reporting period & 5 \\
\hline Total number of consumer partners for this reporting period & 10 \\
\hline Total number of family member partners for this reporting period & 13 \\
\hline $\begin{array}{l}\text { Number of program participants supervised by a juvenile-based program who successfully } \\
\text { completed the program during the reporting period }\end{array}$ & 0 \\
\hline $\begin{array}{l}\text { Total number of program participants supervised by a juvenile-based program that left the } \\
\text { program (for any reason) during the reporting period }\end{array}$ & 1 \\
\hline $\begin{array}{l}\text { Number of current program participants who experienced one or more technical violations } \\
\text { of supervision during the reporting period }\end{array}$ & 1 \\
\hline $\begin{array}{l}\text { Number of current program participants who were terminated from the program during the } \\
\text { reporting period }\end{array}$ & 0 \\
\hline Total number of program participants during the reporting period & 10 \\
\hline $\begin{array}{l}\text { Number of current program participants who have a new arrest during the reporting } \\
\text { period }\end{array}$ & 0 \\
\hline Number of program participants with a new arrest during the reporting period & 0 \\
\hline $\begin{array}{l}\text { Total number of program participants with a technical violation of probation or parole } \\
\text { during the reporting period }\end{array}$ & 0 \\
\hline $\begin{array}{l}\text { Total number of program participants with sanctions for non-compliance with conditions of } \\
\text { program experienced during the reporting period }\end{array}$ & 3 \\
\hline $\begin{array}{l}\text { Total number of program participants that completed a juvenile-based program within the } \\
\text { past year }\end{array}$ & 0 \\
\hline $\begin{array}{l}\text { Number of program participants for which referrals were made for mental health services } \\
\text { during the reporting period }\end{array}$ & 10 \\
\hline $\begin{array}{l}\text { Number of program participants for which referrals were made for substance abuse } \\
\text { service during the reporting period }\end{array}$ & 10 \\
\hline $\begin{array}{l}\text { Number of program participants for which referrals were made for co-occurring services } \\
\text { during the reporting period }\end{array}$ & 10 \\
\hline $\begin{array}{l}\text { Number of program participants for which referrals were made for education services } \\
\text { during the reporting period }\end{array}$ & 5 \\
\hline Total number of individuals released during the reporting period & 0 \\
\hline $\begin{array}{l}\text { Of the total, number of individuals who are released to the community with a discharge } \\
\text { plan that is written }\end{array}$ & 0 \\
\hline $\begin{array}{l}\text { Of the total, number of individuals who are discharged with care coordination/case } \\
\text { management }\end{array}$ & 0 \\
\hline
\end{tabular}


report did, however, applaud the rich qualitative data that were under analysis. In short, the evaluators were disappointed in the lack of meaningful numbers and the possibility of quantitative analyses, but were pleased to see meaningful qualitative data emerging from the program. These issues will be expanded upon in the recommendations section of Chapter V. 


\section{CHAPTER V}

\section{SUMMARY AND RECOMMENDATIONS}

Juvenile drug courts and diversion programs are designed as intensive treatment programs that provide specialized services for eligible drug involved juveniles and their families. These specialized services include an array of services such as substance abuse treatment, mental health services and family counseling, primary medical care, coordinated supervision of the juvenile, and continued education (Office of Juvenile Justice and Delinquency Prevention, 2001). The goal of the juvenile court diversion programs is to keep youth out of the court system when possible, hopefully preventing incarceration altogether, while also reducing the strain on the court system (Patrick \& Marsh, 2005). Combined juvenile drug courts and court diversion programs with community collaborations and comprehensive service planning have been shown to positively impact multiple domains (i.e., individual, parent, family, and community). Unfortunately, this progressive approach does not always have the desired outcomes (Pullman, Kerbs, Koroloff, Veach-White, Gaylor, \& Sieler, 2006). This chapter first discusses positive results from the concurrent nested design, and then the lessons learned that can lead to more collaborative partnerships. This chapter closes with recommendations for building more collaborative partnerships in dealing with juvenile substance abuse and/or mental 
health disorders within a juvenile court diversion program, and recommendations for future research.

\section{Positive Results}

Two main themes emerged as positive results: (a) the appropriate professional people were involved in the JETS program, and (b) the participants of the collaboration held a common goal—to provide services to youth with cooccurring mental health and substance abuse disorders so that they can lead healthy productive lives. These are discussed in terms of the data from the interviews with the service providers. However, the results may also prove useful in creating and evaluating other senvice collaborations.

\section{Appropriate Professionals at the Table}

The construct with a higher level of shared meaning around themes was Collaboration and the program is seen as a positive conduit for comprehensive services for youth. Example phrases include, we have the right people at the table to be able to do it and we're on the same team when we're in the JETS Program together-speaking to converting inputs to outcomes in systems theory.

An increase in the collaboration between the child welfare system, the judicial system, and the substance abuse/mental health treatment system is thought to be the key to timely access to appropriate treatment services, and assist with agencies communicating more effectively (Green, Rockhill, \& Burrus, 2008), and is supported by the results of this study. Additionally, successful collaborative approaches must be composed of all stakeholders from multiple system levels, including individuals or clients, family members, community 
supports, and mental health and governmental agencies, as well as policy makers (Barreira, Espey, Fishbein, Moran, \& Flannery, 2000). Service providers' comments reflected their agreement that the appropriate professionals were involved and that the partners share common goals for the JETS Program.

\section{Common Goals}

A major factor in building collaborative partnerships is for the partners to establish or share common goals (Barreira, Espey, Fishbein, Moran, \& Flannery, 2000). The construct of Program Structure and the refined theme of goals also had a high level of shared meaning among the service providers. Phrases that reflected the partners' agreement on sharing common goals include, the JETS program is aimed at focusing on kids who have drug and alcohol issues, providing treatment, finding resources for them and their families, and holding them accountable for their actions-speaking to the relativity of symbolic interactionism, or the importance of the right people sharing common goals for the collaboration to succeed. Recall Blumer's (1969) view that individuals' social reality depends upon their meaningful participation in their worlds, and their ability to adjust to ad hoc situations.

Congruent with Nissen, Merrigan, and Kraft (2005), respondents' comments reflect the struggle of support systems to positively intervene in the lives of these juveniles and their families. Respondents also mirrored these scholars' report of a lack of coordination and collaboration that further hinders the ability of these systems to support juvenile offenders with co-occurring substance abuse and mental health disorders. Green, Rockhill, and Burrus (2008) reported 
that when various systems operate under different, even conflicting, mandates and priorities, they are unable to come together with shared goals. However, the partners of the JETS program have been able to come from their respective silos (i.e., legal, mental health, and social support) and develop shared meaning around a common focus-providing intervention services to juvenile offenders with co-occurring substance abuse and mental health disorders. Although having the appropriate professionals at the table and a common goal provide a solid foundation on which to build a collaboration, there remained a lack of shared meaning among the JETS partners on equality, roles, program structure, and referrals.

\section{Lessons Learned}

Four themes emerged and became lessons learned for future collaborations: inequality, roles, program structure, and how youth are referred to the program. These are summarized here, following excerpts from respondents' remarks.

\section{Inequality}

They kind of developed the program and them came in and said this is the way it is going to run.

Sometimes I think they would like to lynch me. Sometimes I feel like the salmon swimming up the stream.

No, I don't feel like that there is equality in what anyone says.

Consider the position of Frost, Robinson, and Anning (2005) that traditional professionals must have the ability to mediate, liaise, and negotiate with other one another and if they cannot, team members can experience discomfort, anxiety, and anger-not positive traits for collaborations. This is reflected in the 
respondents' remarks above and can be attributed in part to the rapid pace in which collaborative teams often move from strategic planning to operational implementation. The excerpts above also speak to Frost, Robinson, and Anning's position that if team members have never had to work in teams, it may be a painful but necessary process if common goals are to be achieved.

\section{Roles}

I will do whatever you ask, if you define what my duties are.

The roles need to be more established. I think it needs to be more defined and they need to play that role.

These remarks reflect both symbolic interactionism and Morrione's (1988) assertion that individuals make their own interpretations of their experiences. According to symbolic interactionism, individuals act upon the definitions that they assign to people and events, and Morrione held that situations are always embedded in and shaped by larger contexts (i.e., culture, political, economic, and social). This can be problematic when all the partners in a collaboration interpret the same event or information in drastically different ways, thus creating a lapse or duplication in service, lack of accountability, and overall confusion.

\section{Program Structure}

There is no consistency across the board on how we handle each case.

There needs to be set standards on how things operate, that has been a huge part of the confusion here lately.

Applying symbolic interactionism to professional collaborations, Doyle (2008) might conclude that these remarks reflect a lack of the necessary ability, desire, or commitment to network with one another so that participants see solid program structure around their efforts. Clearly, if the standards are not clear or 
are applied inconsistently, there is little chance of effective implementation. While believing that collaborations can improve on service provision and better standards of care, Doyle held that a dedication of time, resources and a commitment for good communication and information sharing between agencies is essential for them to be effective.

\section{Referrals}

Referral process? What is the process? I don't know.

When a child is presented, it seems like there is very little information about the child and we are being asked to vote, are they appropriate for the program? I don't know because I don't know the standard for appropriate.

Maybe we should step back and look at why we aren't getting referrals.

While interagency/community teams can provide more comprehensive services, the whole process can become fragmented even when the goal is to streamline, if some of the key processes are not clear to everyone, e.g., the criteria for referrals and how youth are referred to the program. Lee, Morrissey, Thomas, Carter, and Ellis (2006) posited that this can be a major problem especially in the treatment of children and adolescents with co-occurring substance abuse and mental health disorders-sometimes adding to their confusion rather than alleviating it. Within such collaborations there are often conflicts in paradigms, communication patterns, organization and cognitive development (Duncker, 2001). Researchers and service providers viewing the JETS Program through a symbolic interactionism lens would attempt to make sense of this phenomenon by examining the extent to which the referral process is clear and the criteria consistently applied. Based on the findings, the next section includes recommendations for strengthening interagency/community collaborations for 
juveniles, as well as research to add to the empirical knowledge of strong partnerships.

\section{Programmatic Recommendations}

Three primary recommendations are suggested here to establish or strengthen collaborative efforts for juveniles with co-occurring substance abuse and mental health problems:

1. Early establishment of effective lines of communication,

2. Cross-training team members, and

3. Incorporating key components of the wrap-around model

\section{Effective Lines of Communication}

Service provider comments reflected the importance of establishing clear and effective lines of communication in the strategic planning at the beginning of any partnership (ex. Communication is something that is sporadic and inefficient, everyone knowing their role and having that put into place; Referral process? What is the process? I don't know, There is no consistency across the board as how we handle each case). This begins with the presence of strong leadership and includes the constructs and themes that emerged from the data, i.e., clarity of roles, criteria for and consistent application of admission criteria and making sure that all parties understand how the program is designed and expected to operate. Understanding the concepts of symbolic interactionism can help partners appreciate the importance of clear and consistent communication (Nissen, 2007), always delivered in a timely and collegial manner. For example, if 
the parties interpret their roles differentially (e.g., some see their roles as being paramount to others' roles), clear communication is likely to fail.

\section{Cross Training Team Members}

Symbolic interaction is again helpful to understanding the importance of team members' being able to perform one another's tasks. For example, by hearing an evaluation of a juvenile's problems from a judge's perspective, from a social worker's view, and from a therapist's view, heightens the possibility of a truly shared meaning of the complexity of the juvenile's life. Such depth of understanding cannot occur when partners remain isolated-the silo effect-very counter-productive to true team work. Such cross training requires more than court room interactions; team members need to freely discuss the information at hand, e.g., What are the legal implications? What does a score really mean? What does it mean to assess a juvenile-what goes into an assessment? What expertise is needed by the assessor? Such breadth of understanding may require more formal and purposive information sharing sessions (Barreira, Espey, Fishbein, Moran, \& Flannery, 2008; Doyle, 2000). This was reflected in service provider comments about the need for additional training including We have not done training as a JETS initiative; We need to have more training; We need formal training or education, more than self-taught.

\section{Wrap-around}

The JETS program utilizes the notion of wrap-around services by coordinating multiple services and 2 of the 10 key principles of the model are appropriate as recommendations to strengthen such collaborations. Service 
provider comments that reflected these needs include There needs to be a decision on what is important and what is the focus-school, community service, Alcoholics Anonymous, treatment services, papers for court, We need more providers at the table with us; Do we have outcomes to prove it, no; We are clearly running by the seat of our pants, making it up as we go along and I think that puts us in a dangerous position.

\section{The $2^{\text {nd }}$ Principle of the Wraparound Model: Team Based}

The main purpose of incorporating this concept as a recommendation is to recognize that the professional team is needed, but that juveniles are not with the team all of the time-that the best interests of the youth and their families call for the inclusion of informal, formal, and community support relationships (Bruns,Walker, Adams, Miles, Osher, Rast, \& VanDenBerg, 2004). The team may also need to develop more community supports, e.g., YMCA, tutoring, university resources, athletics, performing arts, restaurants and hotels, reflective of mezzo level supports from a systems perspective. Such efforts may also include helping the juveniles find part time employment and possibly even volunteer activities.

\section{The $10^{\text {th }}$ Principle of the Wraparound Model: Measureable Outcomes}

The necessity of measureable outcomes is clear and is first established at assessment. When a problem area is defined in the initial assessment it is accompanied by a measureable outcome. Bruns, Walker, Adams, Miles, Osher, Rasher, and VanDenBerg (2004), advised that treatment plans should be revised by the team and updated to reflect changing goals. Ongoing assessment of 
whether outcomes are being met becomes the basis for programmatic changes and the rationale for grant proposals for continued funding. The assessment speaks to symbolic interactionism via being sure that everyone is in agreement on the problem, the intervention, and desired outcomes; otherwise, there is no shared meaning.

\section{Recommendations for Research on Collaborations}

In addition to the JETS program's second year follow-up evaluations, evidence of longer tem effects of community collaborations is needed to determine whether such programs are cost effective and juvenile-effective. Unknown are whether juvenile graduates from such programs remain sober and free of the court system over time. Strategic planning may generate a way to incorporate comparison groups and cost/benefit analyses into program evaluation designs.

\section{Conclusion}

The collaborative efforts of the JETS program yielded both positive and negative results regarding just how collaborative were the efforts at collaborating to serve juvenile offenders with co-occurring substance abuse and mental health disorders. The positive outcomes were that respondents' felt that the right professionals were brought together with a common goal. Less positive were their responses about shared meaning of the equality of partners, their roles, understanding the program structure, and the criteria and consistency of their application to referrals. Limitations to evaluating just how collaborative was this collaboration were the lack of utilization of the initial six-month planning period, 
the absence of strong leadership, the lack of assessment throughout, and, therefore, the small number of juvenile participants.

Collaborations, networks, task forces, teams-these are the keys to real social work. These are the ways in which we work to get things done for clients, communities, and social justice. We must get them right. We must do them well and be effective. It is hoped that future studies of collaborations can advance the art of collaboration of human services. The Social Work profession and our clients deserve no less. 


\section{REFERENCES}

Anderson, R. E., Carter, I. E., \& Lowe, G. (1999). Human behavior in the social environment: $A$ social systems approach ( $5^{\text {th }}$ ed.). Piscataway, NJ: Transaction.

Annels, M. (2006). Triangulation of qualitative approaches: Hermeneutical phenomenology and grounded theory. Journal of Advanced Nursing, $56(1), 993-997$.

Austin, A. M., Macgowan, M. J., \& Wagner, E. F. (2005). Effective family-based interventions for adolescents with substance abuse problems: A systematic review. Research on Social Work Practice, 15(2), 67-83.

Austin, D. M. (1983). The Flexner myth and the history of social work. Social Service Review, 57, 1357-1377.

Aymer, C., \& Okitikpi, T. (2000). Epistemology, ontology, and methodology: What's that got to do with social work? Social Work Education, 19(1), 6775.

Azrin, N. H., Donohue, B., Besalel, V. A., Kogan, E. S., \& Acierno, R. (1994). Youth drug abuse treatment: A controlled outcome study. Journal of Child \& Adolescent Substance Abuse, 3(3), 1-16.

Bandura, A. (1977). Social learning theory. Englewood, NJ: Prentice Hall.

Barreira, P., Espey, B., Fishbein, R., Moran, D., \& Flannery, R. B. (2000). Linking substance abuse and serious mental illness service delivery systems: 
Initiating a statewide collaboration. The Journal of Behavioral Health Services \& Research, 27(1), 107-113.

Bengtson, V., \& Roberts, V. E. L. (1991). Intergenerational solidarity in aging families: An example of formal theory construction. Journal of Marriage and the Family, 53, 856-870.

Berger, C. R., \& Roloff, M. E. (1980). Social cognition, self-awareness, and interpersonal communication. Progress in communication sciences: 2. Dervin \& Voight (Eds.). Norwood, NJ: Ablex Publications.

Berkowitz, B. (2001). Studying the outcomes of community-based coalitions. American Journal of Community Psychology, 29, 213-227.

Bingham, C. R., \& Shope, J. T. (2004). Adolescent problem behavior and problem driving in young adulthood. Journal of Adolescent Research, 19(2), 205-223. DOI: 10.1177/0743558403258269.

Blau, P. M., \& Scott, W. R. (1962). Formal organizations: A comparative approach. San Francisco, CA: Chandler Publishing.

Blumer, H. (1969). Symbolic interactionism: Perspective and method. Berkeley, CA: University of California Press.

Broderick, C. B. (1993). Understanding family process: Basics of family systems theory. Thousand Oaks, CA: Sage Publications

Brown, T. A., Henggeler, S. W., Schoenwald, S. K., Brondino, M. J., \& Pickrel, S. G. (1999). Multisystemic treatment of substance abusing and dependent juvenile delinquents: Effects on school attendance at posttreatment and 6- 
month follow-up. Children's Services: Social Policy, Research, and Practice, 2(2), 81-93.

Brunier, D. (2005). Making it meaning full: Postmodern public administration and symbolic interactionism. Administrative Theory \& Praxis, 27(3), 498-516.

Bruns, E. J., Walker, J. S., Adams, J., Miles, P., Osher, T. W., Rast, J., \& VanDenBerg, J. D., \& National Wraparound Initiative Advisory Group. (2004). Ten principles of the wraparound process. National Wraparound Initiative, Research and Training Center on Family Support and Children's Mental Health, Portland State University. Retrieved from http://www.rtc.pdx.edu/PDF/TenPrincWAProcess.pdf

Bureau of Justice Assistance. (1994). Defining drug courts: The key components. Retrieved from http://www.ojp.usdoj.gov/BJA/grant/DrugCourts/DefiningDC.pdf

Burns, N., \& Grove, S. K. (2005). The practice of nursing research: Conduct, critique and utilization. St. Louis, MO: Elsevier Saunders.

Caldwell, C. L., Home, A. M., Davidson, B., \& Quinn, W. H. (2007). Effectiveness of a multiple family group intervention for juvenile first offenders in reducing parent stress. Journal of Child and Family Studies, 16, 443-459.

Calhoun, G. B., Glaser, B. A., \& Bartolomucci, C. L. (2001). The juvenile counseling and assessment model and program: A conceptualization and intervention for juvenile delinquency. Journal of Counseling \& Development, 79, 131-141. 
California Legislative Analyst's Office. (1995). Juvenile Crime-Part I. Retrieved from http://www.lao.ca.gov/1995/050195 juv crime/kkpart1.aspx

Cavanagh, S. (1997). Content analysis: Concepts, methods and applications. Nurse Researcher, 4, 5-16.

Centers for Disease Control. (2008). Retrieved from http://www.cdc.gov/hiv/topics/surveillance/basic.htm\#aidsage

Church, W. T., MacNeil, G., Martin, S. S., \& Nelson-Gardell, D. (2009). What do you mean my child is in custody? A qualitative study of parental response to the detention of their child. Journal of Family Social Work, 12(1), 9-24.

Clarke, D. J. (2009). Using qualitative observational methods in rehabilitation research: Part two. International Journal of Therapy and Rehabilitation, 16(8), 413-419.

Cohen, M., \& Piquero, A. (2009). New evidence on the monetary value of saving a high risk youth. Journal of Quantitative Criminology, 25(1), 25-49.

Cole, F. L. (1988). Content analysis: Process and application. Clinical Nurse Specialist, 2(1), 53-57.

Cook, K. S., \& Emerson, R. M. (1978). Power equity and commitment in exchange networks. American Sociological Review, 43, 721-739.

Corbin, J., \& Strauss, A. (2008). Basics of Qualitative Research (3rd ed.). Thousands Oak, CA: Sage Publications.

Coser, L. A. (1971). Masters of sociological thought: Ideas in historical and social context. New York, NY: Harcourt Brace Jovanovich. 
Cox, R. G., Zhang, L., Johnson, W. D., \& Bender, D. R. (2007). Academic performance and substance use: Findings from a state survey of public high school students. Journal of School Health, 77(3), 109-115.

Crabtree, B. F., \& Miller, W. L. (1992). Doing qualitative research. Newbury Park, CA: Sage.

Creswell, J. W. (2007). Qualitative inquiry \& research design: Choosing among five approaches (2nd ed.). Thousand Oaks, CA: Sage Publications.

Crotty, M. (1998). The foundations of social research: Meaning and perspective in the research process. London: Sage.

Dean, R. G., \& Fenby, B. L. (1989). Exploring epistemologies: Social work action as a reflection of philosophical assumptions. Journal of Social Work Education, 25(1), 46-54.

Dembo, R., \& Walters, W. (2003). Innovative approaches to identifying and responding to the needs of high risk youth. Substance Use \& Misuse, 38(11-13), 1713-1738.

Denzin, N. K. (1989). The research art: $A$ theoretical introduction to sociological methods ( $3^{\text {rd }}$ ed.). Chicago, IL: Aldine.

Denzin, N. K., \& Lincoln, Y. S. (Eds.). (2008). Strategies of qualitative inquiry ( $3^{\text {rd }}$ ed). Thousands Oak, CA: Sage Publications.

Department of Human Services Division of Substance Abuse. (2001). Utah drug courts: An inventory of judicially monitored substance abuse treatment programs. Retrieved from http://www.usaav.utah.gov/Interventions/DrugCourtInventory.pdf 
Donohue, B., \& Azrin, N. (2001). Family behavior therapy. In Wagner \& Waldron (Eds.), Innovations in adolescent substance abuse interventions $\left(1^{\text {st }}\right.$ ed., pp. 205-224). New York, NY: Pergamon.

Downe-Wamboldt, B. (1992). Content analysis: Method, application and issues. Health Care for Women International, 13, 313-321.

Doyle, J. (2008). Barriers and facilitators of multidisciplinary team working: A review. Pediatric Nursing, 20(2), 26-30.

Duncker, E. (2001). Symbolic communication in multidisciplinary cooperations. Science, Technology, \& Human Values, 26(3), 349-386.

Elo, S., \& Kyngas, H. (2008). The qualitative content analysis process. Journal of Advanced Nursing, 62(1), 107-115.

Egbert, S. C., Church, W. T., \& Byrnes, E. C. (2006). Justice and treatment collaboration: A process evaluation of a drug court. Best Practices in Mental Health, 2(1), 74-91.

Evans, M. E., Armstrong, M. I., Beckstead, J. W., \& Lee, J. (2006). Examining the impact of policy on collaboration in systems of care. Journal of Child and Family Studies, 16, 567-576.

Fass, S. M., \& Chung-Ron, P. (2002). Getting tough on juvenile crime: An analysis of costs and benefits. Journal of Research in Crime and Delinquency, 39(4), 363-399.

Fellin, P. (2001). The community and the social worker ( $3^{\text {rd }}$ ed). Itasca, IL: Peacock. 
Fishbein, D. H., \& Perez, D. M. (2000). A regional study of risk factors for drug abuse and delinquency: Sex and racial differences. Journal of Child and Family Studies, 9(4), 461-479.

Flash, K. (2003). Treatment strategies for juvenile delinquency: Alternative solutions. Child and Adolescent Social Work Journal, 2O(6), 509-527.

Foster-Fishman, P. G., Berkowitz, S. L., Lounsbury, D. W., Jacobson, S., \& Allen, N. A. (2001). Building collaborative capacity in community coalitions: A review and integrative framework. American Journal of Community Psychology, 29, 241-261.

Freid, B. J., \& Rundall, T. G. (1994). Managing groups and teams. In S. M. Shortell \& A. D. Kaluzny (Eds.). Health Care Management: Organization, Design, and Behavior (pp. 137-163). Albany, NY: Delmar.

Frost, N., Robinson, M., \& Anning, A. (2005). Social workers in multidisciplinary teams: Issues and dilemmas for professional practice. Child and Family Social Work, 10, 187-196.

Gambrill, E. (1999). Evidence-based practice: An alternative to authority-based practice. Families in Society: The Journal of Contemporary Human Services, 80(4), 341-350.

Gergen, K. (1999). An invitation to social construction. Thousand Oaks, CA: Sage.

Gibbs, L. E. (2003). Evidence-based practice for the helping profession-A practical guide with integrated multimedia. Pacific Grove, CA: Brooks/Cole. 
Gray, B. (1989). Collaborating: Finding common ground for multiparty problems $\left(1^{\text {st }}\right.$ ed.). San Francisco, CA: Jossey-Bass.

Green, B. L., Rockhill, A., \& Burrus, S. (2008). The role of interagency collaboration for substance-abusing families involved with child welfare. Child Welfare, 87(1), 29-61.

Guba, E. G., \& Lincoln, Y. S. (1989). Fourth generation evaluation. Thousand Oaks, CA: Sage

Gyamfi, P., Keens-Douglas, A., \& Medin, E. (2007). Youth and youth coordinators' perspectives on youth involvement in systems of care. Journal of Behavioral Health Services \& Research, 34(4), 382-394.

Halfors, D., Hyunsan, C., Livert, D., \& Kadushin, C. (2002). Fighting back against substance abuse. Are community coalitions winning? American Journal of Preventive Medicine, 23(4), 237-245.

Hamilton, Z. K., Sullivan, C. J., Veysey, B. M., \& Grillo, M. (2007). Diverting multiproblem youth from juvenile justice: Investigating the importance of community influence on placement and recidivism. Behavioral Sciences and the Law, 25, 137-158. DOI: 10.1002/bsl.720

Hatch, J. A. (2002). Doing qualitative research in educational settings. Albany, NY: State University of New York Press.

Haworth, G. O. (1991). My paradigm can beat your paradigm: Some reflections on knowledge conflicts. Journal of Sociology and Social Welfare, 18(4), 35-50. 
Henderson, C. E., Rowe, C. L., Dakof, G. A., Hawes, S. W., \& Liddle, H. A. (2009). Parenting practices as mediators of treatment effects in an earlyintervention trial of multidimensional family therapy. American Journal of Drug and Alcohol Abuse, 35(4), 220-226.

Henggeler, S. W. Schowenwald, S. K., Bourdin, C. M., Rowland, M. D., \& Cunningham, P. B. (1998). Multisystemic treatment of antisocial behavior in children and adolescents. New York, NY:Guilford.

Hesse, M. L., Hesse, M., \& Lawrence, R. (2009). Juvenile justice: The essentials. Thousand Oaks, CA: Sage Publications.

Hesse-Biber, S. (2010). Qualitative approaches to mixed methods practice. Qualitative Inquiry, 16(6), 455-468.

Holmes, R. (1986). The knower and the known. Sociological Forum, 4(1), 610631. DOI: $10.1007 / \mathrm{BF} 01107339$

Homans, G. C. (1958). Social behavior as exchange. American Journal of Sociology, 63(6), 597-606.

Homans, G. C. (1961). Social behavior: Its elementary forms. New York, NY: Harcourt, Brace \& World, Inc.

Hopkins, K. M. (2002). Organizational citizenship in social service agencies. Administration in Social Work, 26(2), 1-15.

Hull, C. L. (1929). A functional interpretation of the conditioned reflex. Psychological Review, 36, 498-511.

Hull, C. L. (1930). Knowledge and purpose as habit mechanisms. Psychological Review, 37, 511-525. 
Hull, C. L. (1937). Mind, mechanism, and adaptive behavior. Psychological Review, 44, 1-42.

Hull, C. L. (1943). Principles of behavior: An introduction to behavior theory. New York: Appleton-Century-Crofts.

Hyde, K. F. (2000). Recognising deductive processes in qualitative research. Qualitative Market Research: An International Journal, 3(2), 82-90. doi: $10.1108 / 13522750010322089$

Izquierdo, T. G., Healy, T., Rinderle, M., \& Matthew, T. (2005). The prevalence of mental health disorders among juveniles in northern Kentucky's regional juvenile detention center. Journal for Juvenile Justice Services, 20(1), 35-

57.

Johnson, D. P. (2008). Contemporary sociological theory: An integrated multilevel approach. New York, NY: Springer Science+Business Media.

Jones, G. (2009). Organizational theory, design and change $\left(6^{\text {th }}\right.$ ed.) Upper Saddle River, NJ: Prentice Hall.

Kadushin, C., Lindholm, M., Ryan, D., Brodsky, A., \& Saxe, L. (September 2005). Why is it so difficult to form effective community coalitions. City \& Community, 4(3), 255-275.

Kentucky Division of Substance Abuse. (2004). Adolescent Substance Abuse in Kentucky: A report prepared for the HB 843 children's workgroup. Retrieved from http://www.mhmr.ky.gov/mhsas/files/AdolescentSA.pdf Kentucky Justice and Public Safety Cabinet. (2008).Sourcebook of Criminal Justice Statistics in the Commonwealth. Retrieved from 
http://www.justice.ky.gov/NR/rdonlyres/15878C81-10EF-443A-B3C3FD386219B5A1/239379/KYSourcebook2008FINAL.pdf

Kentucky State Police. (2009). Crime in Kentucky. Retrieved from http://www.kentuckystatepolice.org/pdf/cik 2009.pdf

Kumpfer, K. L., Alvarado, R., \& Whiteside, H. O. (2003). Family-based interventions for substance use and misuse. Substance Use \& Misuse, $38(11-13), 1759-1787$.

Krippendorff, K. (1980). Content analysis: An introduction to its methodology. Newbury Park, CA: Sage Publications.

Lasker, R. D., and Committee on Medicine and Public Health. (1997). Medicine and public health: The power of collaboration. Chicago, IL: Health Administration Press.

Lasker, R. D., Weiss, E. S., \& Miller, R. (2001). Partnership synergy: A practical framework for studying and strengthening the collaborative advantage. The Milbank Quarterly, 79(2), 179-205.

Lee, S. D., Morrisey, J. P., Thomas, K. C., Carter, W. C., \& Ellis, A. R. (2006). Assessing the service linkages of substance abuse agencies with mental health and primary care organizations. The American Journal of Drug and Alcohol Abuse, 32, 69-86. DOI: 10.1080/00952990500328620

leSage, L., \& deRuyter, D. (2008). Criminal parental responsibility: Blaming parents on the basis of their duty to control versus their duty to morally educate their children. Educational Philosophy \& Theory, 40(6), 789-802. 
Levine, R. (1988). Ethics and the regulation of clinical research $\left(2^{\text {nd }}\right.$ ed.). New Haven, CT: Yale University Press.

Levi-Strauss, C. (1963). Structural anthropology. Translated by C. Jacobson and B. Grundfest. New York, NY: Doubleday Anchor Books.

Liddle, H. A. (1999). Theory development in a family-based therapy for adolescent drug abuse, Journal of Clinical Child Psychology, 28(4), 521532.

Liddle, H. A., Dakof, G. A., Parker, K., Diamond, G. S., Barrett, K., \& Tejeda, M. (2001). Multidimensional family therapy for adolescent drug abuse: Results of a randomized clinical trial. American Journal of Drug and Alcohol Abuse, 27(4), 651-688.

Likert, R. (1932). A technique for the measurement of attitudes. Archives of Psychology, 140, 1-55.

Lincoln, Y. S., \& Guba, E. G. (1985). Naturalistic inquiry. Newbury Park, CA: Sage Publications.

Louisville Metro Police Department. (2005). Youth Needs Assessment Report. Louisville and Jefferson County Seventeenth Annual Drug, Alcohol, and Violent Crime Database. Retrieved from http://www.louisvilleky.gov/NR/rdonlyres/2F16A5BD-C953-4A11BF4917121FE4F31B/0/17thAnnualDrugAlcoholandViolentCrimeDatabase Report.pdf

Malinowski, B. (1922). Argonauts of Western Pacific: An account of native enterprise and adventure in the archipelagoes of Melanesian New Guinea. 
London School of Economics and Political Science Studies, No. 65.

London, England: Routledge and Kegan Paul (Republished 1984 by Waveland Press).

Malysiak, R. (1998). Deciphering the tower of Babel: Examining the theory base for wraparound fidelity. Journal of Child and Family Studies, 7(1), 11-25.

Mattessich, P. W., Murray-Close, M., Monsey, B. R., \& Wilder Research Center. (2001). Collaboration: What makes it work ( $2^{\text {nd }}$ ed.). St. Paul, MN:

Fieldstone Alliance.

Mayo, M. (1997). Partnerships for regeneration and community development. Critical Social Policy, 17, 3-26.

McCollister, K., French, M., Sheidow, A., Henggeler, S., \& Halliday-Boykings, C. (2009). Journal of Behavioral Health Services and Research, 36(1), 111126.

Mead, G. H. (1934). Mind, self and society. Chicago, IL: University of Chicago Press.

Metro Louisville Operating Budget. (2009-2010). Retrieved from http://www.louisvilleky.gov/NR/rdonlyres/7ACA3038-3761-4A45-9DFB4A8A56635633/0/eYouthDetentionCenter.pdf

Mooney, J. D., \& Reiley, A. C. (1931). Onward industry. New York, NY: Harper and Row.

Morrione, T. J. (1988). Herbert G. Blumer (1900-1987): A legacy of concepts, criticisms, and contributions. Symbolic Interaction, 11(1), 1-12. DOI. 10.1525/si.1988.11.1.1 
Morse, J. M. (1991). Approaches to qualitative-quantitative methodological triangulation. Nursing Research, 40, 120-123.

Morse, J. M. (2003). Principles of mixed methods and multimethod research design. In A. Tashakkori, \& C. Teddlie (Eds.), Handbook of mixed methods in social and behavioral research, 189-208. Thousand Oaks, CA: Sage Publications.

Munro, E. (2002). The role of theory in social work research: A further contribution to the debate. Journal of Social Work Education, 38(3), 461470.

National Center on Addiction and Substance Abuse at Columbia University. (2004). Criminal Neglect: Substance abuse, juvenile justice, and the children left behind. Retrieved from http://www.casacolumbia.org/templates/publicationsreports.aspx?keyword

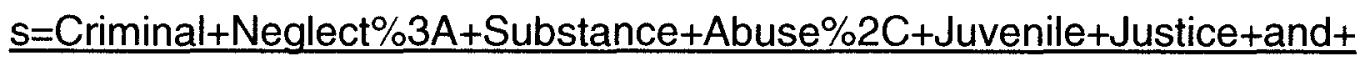
The+Children+Left+Behind

Nissen, L. B. (2007). Reclaiming futures: Communities helping teens overcome drugs, alcohol and crime: A new practice framework for juvenile justice. Journal of Psychoactive Drugs, 39(1), 51-58.

Nissen, L. B., Merrigan, D. M., \& Kraft, M. K. (2005). Moving mountains together: Strategic community leadership and systems change. Child Welfare League of America, 136(2), 123-140.

Office of Justice Programs. (1997). Office of Justice Programs Annual Report. Retrieved from http://www.ncjrs.gov/pdffiles1/170090.pdf 
Office of Juvenile Justice and Delinquency Prevention. (2001). Juvenile accountability incentive block grants program. Retrieved from http://www.ncirs.gov/pdffiles1/oijdp/184744.pdf

Office of the State Budget Director. Commonwealth of Kentucky Operating Budget 2010-2012. Retrieved from http://www.osbd.ky.gov/

Ozechowski, T. J., \& Liddle, H. A. (2000). Family-based therapy for adolescent drug abuse: Knowns and unknowns. Clinical Child and Family Psychology Review, 4(3), 269-298.

Ozechowski, T. J., \& Liddle, H. A. (2002). Family-based therapy. Substance abuse and dependence in adolescence: Epidemiology, risk factors, and treatment. Essau (Ed.) East Sussex, UK: Brunner-Routledge.

Parens, E., \& Johnston, J. (2008). Mental health in children and Adolescents. From Birth to Death and Bench to Clinic: The Hastings Center Bioethics Briefing Book for Journalists, Policymakers, and Campaigns. Garrison, NY: The Hastings Center.

Parker, J. S., \& Benson, M. J. (2004). Parent-adolescent relations and adolescent functioning: Self-esteem, substance abuse, and delinquency. Adolescence, 39(155), 519-530.

Patrick, S., \& Marsh, R. (2005). Juvenile diversion: Results of a 3-year Experimental study. Criminal Justice Policy Review, 59(16), 59-75. DOI: $10.1177 / 0887403404266584$

Patton, M. Q. (1990). Qualitative evaluation and research methods. Newbury Park, CA: Sage Publications. 
Payne, M. (1997). Modern social work theory: A critical introduction. Chicago, IL: Lyceum Books.

Pincus, A., \& Minahan, A. (1973). Social work practice: Model and method. Itasca, IL: F.E. Peacock.

Plancherel, B., Bolognini, M., Stephan, P., Laget, J., Chinet, L., Bernard, M., \& Halfon, O. (2005). Adolescents' beliefs about marijuana use: A comparison of regular users, past users and never/occasional users. Journal of Drug Education, 35(2), 131-146.

Plano Clark, V. L. (2010). The adoption and practice of mixed methodologies:

U.S. trends in federally funded health-related research. Qualitative Inquiry, 16(6), 428-440. DOI: 10.1177/1077800410364609

Plano Clark, V. L., \& Creswell, J. W. (2008). The mixed methods reader. Thousand Oaks, CA: Sage Publications.

Pullman, M. D., Kerbs, J., Koroloff, N., Veach-White, E., Gaylor, R., \& Sieler, D. (2006). Juvenile offenders with mental health needs: Reducing recidivism using wraparound. Crime Delinquency, 52(3), 375-397. DOI:

$10.1177 / 0011128705278632$

Poggenpoel, M., Myburgh, C. P. H., \& van der Linde, C. H. (2001). Qualitative research strategies as prerequisite for quantitative strategies. Education, 122(2), 408-413.

Richardson, W. C., \& Allegrante, J. P. (2000). Shaping the future of health through global partnerships. In C. E. Koop, C. E. Pearson, \& M. R. 
Schwarz (Eds.), Critical Issues in Global Health (pp. 375-383). San

Francisco, CA: Jossey-Bass.

Robbins, M. S., \& Szapocznik, J. (2000). Office of Juvenile Justice and Delinquency Prevention. Brief Strategic Family Therapy, Retrieved from http://www.ojidp.ncjrs.org/pubs/alpha.html

Robbins, S. P., Chatterjee, P., \& Canda, E. R. (2006). Contemporary human behavior theory: A critical perspective for social work ( $2^{\text {nd }}$ ed.). Boston, MA: Pearson Education.

Roberts, M. (2000). Rethinking the postmodern perspective: Excavating the Kantian system to rebuild social theory. The Sociological Quarterly, 41(4), 681-698.

Robertson, A. A., Dill, P. L., Husain, J., \& Undesser, C. (2004). Prevalence of mental illness and substance abuse disorders among incarcerated offenders in Mississippi. Child Psychiatry \& Human Development, 35(1), $55-74$.

Rotter, J. B. (1966). Generalized expectancies for internal vs. external control of reinforcements. Psychological Monographs, 80, 1-28.

Rotter, J. B. (1975). Some problems and misconceptions related to the construct of internal versus external control of reinforcements. Journal of Consulting and Clinical Psychology, 43, 56-67.

Rowe, C. L., Wang, W., Greenbaum, P., \& Liddle, H. A. (2008). Predicting HIV/STD risk level and substance use disorders among incarcerated adolescents. Journal of Psychoactive Drugs, 40(4), 503-512. 
Rubin, A., \& Babbie, E. R. (2005). Research methods for social work ( $5^{\text {th }}$ ed). Belmont, CA: Brooks/Cole-Thomson Learning.

Sabatelli, R. M., \& Shehan, C. L. (1993). Exchange and resource theories. Sourcebook of family theories and methods: $A$ contextual approach. Boss, Doherty, LaRossa, Schuman, \& Steinmetz (Eds.). New York, NY: Springer.

Saleebey, D. (1991). Technological fix: Altering the consciousness of social work profession. Journal of Sociology and Social Welfare, 18(4), 51-67.

Sandelowski, M. (1995). Qualitative analysis: What it is and how to begin. Research in Nursing \& Health, 18, 371-375.

Schwendt, T. (1996). Farewell to criteriology. Qual Inquiry, 2(1), 58-72.

Sexton, T. L., \& Alexander, J. F. (2000). Office of Juvenile Justice and Delinquency Prevention. Functional Family Therapy. Retrieved from http://www.oijdp.ncirs.org/pubs/allpha.html

Sheehan, D., Robertson, L., \& Ormond, T. (2007). Comparison of language used and patterns of communication in interprofessional and multidisciplinary teams. Journal of Interprofessional Care, 21(1), 17-30. DOI:

$10.1080 / 13561820601025336$

Shufelt, J. L., \& Cocozza, J. J. (2006). Youth with mental health disorders in the juvenile justice system: Results from a multi-state prevalence study. National Center for Mental Health and Juvenile Justice. Retrieved from http://www.ncmhij.com/pdfs/publications/PrevalenceRPB.pdf

Skinner, B. F. (1974). About behaviorism. New York, NY: Vintage. 
Skowyra, K. R., \& Cocozza, J. J. (2006). Blueprint for change: A comprehensive model for the identification and treatment of youth with mental health needs in contact with the juvenile justice system. National Center for Mental Health and Juvenile Justice. Retrieved from http://www.ncmhii.com/Blueprint/pdfs/ProgramBrief_06 06.pdf

Substance Abuse and Mental Health Services Administration. (2005). The DASIS Report: Adolescents with co-occurring psychiatric disorders: 2003. Retrieved from http://www.oas.samhsa.gov/2k5/youthMH/youthMH.pdf Substance Abuse and Mental Health Services Administration. (2008). Cooccurring mental and substance abuse disorders: A guide for mental health planning + advisory councils. Retrieved from http://download.ncadi.samhsa.gov/ken/pdf/NMH03-0146/NMH03-0146.pdf

Tashakkori, A. \& Teddlie, C. (2003). Handbook of mixed methods in social and behavioral research. Thousand Oaks, CA: Sage Publications.

Taylor, F. W. (1911). The principles of scientific management. New York, NY: Harper and Row.

Taylor-Powell, E., Rossing, B., \& Geran, J. (1998). Evaluating collaborative:

Reaching the potential. Madison, WI: University of Wisconsin-Cooperative Extension.

Tooley, M. (2007). Epistemology lecture notes. Retrieved from http://spot.Colorado.EDU/ tooley/LectureNotes.html.

Thyer, B. A. (2002). Popper, positivism, and practice research. Journal of Social Work Education, 38(3), 471-474. 
Wade, T. J., \& Pevalin, D. J. (2005, October). Adolescent delinquency and health. Canadian Journal of Criminology and Criminal Justice, 619-654.

Waldron, H. B., Slesnick, N., Brody, J. L., Turner, C. W., \& Peterson, T. R. (2001). Treatment outcomes for adolescent substance abuse at 4- and 7month assessments. Journal of Consulting and Clinical Psychology, 69(5), 802-813.

Waldron, H. B., \& Turner, C. W. (2008). Evidence-based psychosocial treatments for adolescent substance abuse. Journal of Clinical Child \& Adolescent Psychology, 37(1), 238-261.

Wandersman, A., \& Florin, P. (2003). Community science: Bridging the gap between science and practice with community-centered models. American Journal of Community Psychology, 31, 227-253.

Weber, M. (1947). The theory of social and economic organization. Translation by A. Henderson and T. Parsons. New York, NY: Oxford University Press.

Weber, M., Heinrich, G., \& Turner, B. S. (1948). From Max Weber: Essays in sociology. England: Routledge.

Weber, R. P. (1990). Basic content analysis. Newburry Park, CA: Sage Publications.

Weick, A. (1991). The place of science in social work. Journal of Sociology and Social Welfare, 18(4), 13-34.

Weiss, C. H. (1998). Evaluation: Methods for studying programs and policies ( $2^{\text {nd }}$ ed.). Upper Saddle River, NJ: Prentice Hall. 
Williams, J. H., Davis, L. E., Johnson, S. D., Williams, T. R., Saunders, J. A., \& Nebbitt, V. E. (2007). Substance use and academic performance among African American high school students. National Association of Social Workers, 31(3), 151-161.

Wisconsin Collaborative. (2008). Children come first advisory committee 2008 annual report. Retrieved from www.wicollaborative.org/downloads/2008 Annual Report Final.pdf

Wolf, J., Gibson, O. M., Watson, D. D., \& Leukefeld, C. G. (2005). Kentucky Needs Assessment Project Adolescent Household Survey Report. University of Kentucky, Center on Drug \& Alcohol Research. Retrieved from http://cdar.uky.edu/knap/05AdolescentReport/05AdolReportPdfs/2005\%20 Adol\%20Report\%20FINAL.pdf

Wolf, T. (2001). A practitioner's guide to successful coalitions. American Journal of Psychology, 29(2), 173-191.

Zastrow, C. H., \& Kirst-Ashman, K. K. (2010). Understanding human behavior and the social environment. Belmont, CA: Brooks/Cole. 


\section{Appendix A:}

Service Provider Survey and Questionnaire 


\section{Louisville Adolescent Network for Substance Abuse \& Co-Occurring Treatment (LANSCAT)}

\section{$\underline{\text { Service Provider Evaluation }}$}

In order to help us evaluate the effectiveness of the ESSAY Program in the future, but not identify you personally, please start by creating a unique code that only you will know, using the initial of your first name, the initial of your mother's maiden name and the last four digits of your home phone number. For example, if your name was John Smith, your mother's maiden name was Jones, and your phone number is (859)555-1234, your unique code would be: JJ1234.

Participant Code:

What is your job title? (optional)

What primary service do you provide $\mathrm{Ml} / \mathrm{COD}$ youth?

Date:

Please respond to the following questions by circling the number that best represents your response (1=low/not at all, 5=high/very often).

All responses refer to providers who serve youth with multiple needs (i.e., needs related to mental health, and/or education, and/or child welfare, and/or alcohol \& other drug abuse)

1. Rate the current level of coordination of services

$\begin{array}{ccccc}\begin{array}{c}\text { Not at All } \\ \text { low }\end{array} & & & \begin{array}{c}\text { Very Often } \\ \text { high }\end{array} \\ 1 & 2 & 3 & 4 & 5\end{array}$
between service providers who serve MI/COD youth with multiple needs in your community.

2. Do providers make effective collaborative decisions $1 \begin{array}{llllll}1 & 2 & 3 & 4 & 5\end{array}$ regarding youth with multiple needs and their families?

3. Do families have meaningful input into their youth's $\begin{array}{llllll}1 & 2 & 3 & 4 & 5\end{array}$ plan of care? 
4. Do providers function together as a unit to achieve $\begin{array}{llllll}1 & 2 & 3 & 4 & 5\end{array}$ common service goals?

5. Are providers able to successfully deliver nonduplicated services to families?

6. Do providers consult with other providers when crisis decisions have to be made about a child or family?

7. Are there conflicts between providers over who is responsible for providing a given type or amount of service?

8. Are there conflicts between providers over who is responsible to pay for a given type or amount of service?

9. Do service providers agree about the types of services that are most appropriate for serving youth and families?

10. Have there been opportunities for providers to learn $\begin{array}{llllll}1 & 2 & 3 & 4 & 5\end{array}$ about community resources available to teams?

11. Has the LANSCAT Juvenile Drug Court initiative in $\begin{array}{llllll}1 & 2 & 3 & 4 & 5\end{array}$ your community led to improved coordination between service providers?

12. Do you feel youth with multiple needs and their families are more effectively served through the LANScat process than through the use of independently operating providers?

$\begin{array}{lllll}1 & 2 & 3 & 4\end{array}$

$\begin{array}{lllll}1 & 2 & 3 & 4 & 5\end{array}$

$\begin{array}{lllll}1 & 2 & 3 & 4 & 5\end{array}$

$\begin{array}{lllll}1 & 2 & 3 & 4 & 5\end{array}$

$\begin{array}{lllll}1 & 2 & 3 & 4 & 5\end{array}$

12345


2. What areas need the most improvement in the LANSCAT Juvenile Drug Court initiative and how would you improve them?

3. What are the greatest benefits to you in having the LANSCAT initiative available in Jefferson County?

Questions about the survey? Contact: Ramie Martin-Galijatovic, Research Manager (502852-3230) 
Appendix B:

Service Provider Informed Consent 


\section{punioversitrof}

Kent School of Social Work

\section{Subject Informed Consent Document} Evaluation of ESSAY Program

\section{IRB assigned number: $10 / 0073$ Investigator(s) name \& address:} Principal Investigator: Dr. Crystal Collins-Camargo, Kent School of Soci University of Louisville, Louisville, KY 40292

Research Staff: Jay Dickerson, MSW and Ramie Martin-Galijatovic, MSSW, University of Louisville, Louisville, KY 40292

Site(s) where study is to be conducted:

Administrative Office of the Courts Offices and Juvenile Drug Court Rooms

Phone number for subjects to call for questions: 502-852-3174

\section{Introduction and Background Information}

You are being invited to participate in an interview because a youth in your family is participating in this program through the Jefferson County Court System. Your ideas are very important to this study. Family members of approximately 100 youth will be asked to participate in an interview.

\section{Purpose}

The purpose of this study is to gather information regarding the experience your family has had with the ESSA Y Program, your ideas regarding how it might have affected the youth who was participating and your family, and to identify any recommendations you might have for improving the program.

\section{Procedures}

You will be asked to participate in an interview either alone or with family members of other youth completing the program at around the same time. An interviewer from the University of Loujsville will ask a series of questions and record notes of your responses. Responses will be recorded without names or identifying information. Interviews may be recorded on audiotape or digital tape so that the research team can review it to make sure the notes taken accurately describe your ideas. You may decline to answer any questions that make you feel uncomfortable.

\section{Potential Risks}

It is not believed that there are any risks related to your participating in the interview other than possible discomfort in answering personal questions, although some may be unforeseeable.

\section{Benefits}

The possible benefits of this study include helping to show how this program may or may not assist youth and their families to avoid further involvement with the court system, and providing information that may be used to improve the program in the future. The information collected may not benefit you directly, but may be helpful to others participating in the program in the future.

\section{Compensation}

You will not be compensated for your participation in this study.

\section{Confidentiality}

No information identifying you or what you say in the interview will be recorded, and the interview will be conducted without anyone involved in the program being present. Reports will summarize themes identified from interviewing many different families. Court or other program staff will not be provided with information 
connecting what was said in the interview to you or your family. If the results from this study are published, your name will not be made public. However, total confidentiality cannot be guaranteed. Your privacy will be protected to the extent permitted by law. While unlikely, the following may look at the study records:

The sponsor and companies hired by the sponsor to oversee the study

The University of Louisville Institutional Review Board, Human Subjects Protection Program Office

Office for Human Research Protections (OHRP)

\section{Voluntary Participation}

Taking part in this interview is voluntary. You may choose not to take part at all. If you decide to be in this study you may stop taking part at any time. If you decide not to be in this study or if you stop taking part at any time, you will not lose any benefits for which you may qualify.

\section{Research Subject's Rights, Questions, Concerns, and Complaints}

If you have any concerns or complaints about the study or the study staff, you have three options. You may contact the principal investigator Dr. Crystal Collins-Camargo at 502-852-3174. If you have any questions about your rights as a study subject, questions, concerns or complaints, you may call the Human Subjects Protection Program Office (HSPPO) (502) 852-5188. You may discuss any questions about your rights as a subject, in secret, with a member of the Institutional Review Board (IRB) or the HSPPO staff. The IRB is an independent committee composed of members of the University community, staff of the institutions, as well as lay members of the community not connected with these institutions. The IRB has reviewed this study.

If you want to speak to a person outside the University, you may call 1-877-852-1167. You will be given the chance to talk about any questions, concerns or complaints in secret. This is a 24 hour hot line answered by people who do not work at the University of Louisville.

This paper tells you what will happen during the study if you choose to take part. Your signature means that this study has been discussed with you, that your questions have been answered, and that you will take part in the study. This informed consent document is not a contract. You are not giving up any legal rights by signing this informed consent document. You will be given a signed copy of this paper to keep for your records.

PRINCIPAL INVESTIGATOR

Dr. Crystal Collins-Camargo
PHONE NUMBER

502-852-3174
Fo IRB Approval Stamp
UNMERSITY OF LOUISVLLE
WSTITUTKONAL REVEW BOARD

Date Approved 0446/2010 Valid Thru 2M15/2011 


\section{CURRICULUM VITA}




\author{
James G. Dickerson, MSW, LSW \\ 1911 Harvard Drive \\ Louisville, KY 40205 \\ (812) $789-3803$ \\ James.dickerson@louisville.edu
}

\title{
Education
}

\author{
Since 2008 Kent School of Social Work $-3^{\text {rd }}$ Year in Doctoral Program \\ University of Louisville-Louisville, Kentucky \\ $2007 \quad$ Master of Social Work \\ University of Southern Indiana-Evansville, Indiana \\ $2003 \quad$ Bachelor of Arts, Psychology \\ Indiana University-Bloomington, Indiana
}

\section{Research Interests}

During my clinical practice with children, adolescents and their families, I have assisted many families who were involved with the Juvenile Justice system and who were encountering substance abuse issues. These individuals and families have been facing ever-increasing complex and diverse issues, such as addiction, recidivism and multi-agency involvements. Due to these issues and the evolving collaboration of community support agencies, with more agencies combining resources and information, I am interested in the affects on children and their families. Specifically, my research interest is with juvenile court diversion programs and the collaboration between community support agencies.

\section{Work Experience}

August, 2008 Present
Graduate Assistant

Office of the President, University of Louisville Louisville, KY

Responsible for University President's research on speech materials and presentation development to University affiliates and community partners. Scheduling meetings and assisting in agenda development for University Leadership Team. Providing University communication and meeting schedules for Board of Trustees and affiliated Board of Trustee Committees. Assisting outside auditing firm with communication between University President, Vice Presidents, and Deans on grant procurement and fund management. 
April 2004-July 2008 Good Samaritan Hospital, Samaritan Center

Vincennes, IN

2006-2008

Intensive Youth Service Wraparound/Case Manager Coordinator

Was responsible for completing comprehensive

assessments of families, working in full partnership with the children and family team members to develop plans of care. Assured that care was delivered in a manner consistent with strength-based, family centered, and culturally competent values, offered consultation and education to all providers regarding the values of the model, monitored progress toward treatment goals, and assured that all necessary data for evaluation were gathered and recorded.

2004-2006

Intensive Youth Service Case Manager

Provided home-based mental health services to children, adolescents and their families. Services included counseling, home visits and the facilitating communication between patients, families, educational providers, state/judicial agencies and community based service providers in conjunction with mental health services provided by the Samaritan Center.

\section{9/2002 - 3/2004 Coleman Farms, Property Administrator}

Managed daily operations of 500 -acre family owned business; including negotiation of land, oil and mineral rights. Oversaw and monitored rental property and farmland leasing.

1/1999 - 11/2002 Century 21 POSMAK Realty, Realtor

Assisted clients in all aspects of acquiring and disposing of real property; including contract negotiation and property inspection.

$6 / 1990-11 / 1998$

Associated Marine Institutes, Executive Director Duties included case management, counseling, and education of students and families. Oversaw annual budgeting, payroll, and accounts payable and receivable. Utilized performance contracts and periodic reviews to 
manage the supervision of all personnel. Accountable for Quality Assurance in compliance with state and district guidelines associated with Department of Juvenile Justice. Facilitated the Volunteer Board of Directors, including the coordination of fund and community support. Worked with charitable organizations to secure grants, such as United Way, Publix Foundation, Children Services Council, MacArthur Foundation, and Quantum Foundation.

\section{Management Trainee/Aquatic Coordinator} Assisted Director of Operations with daily activities. Taught water safety, marine science, first aid and CPR to students and staff. Assisted in development of case treatments and goals. Functioned as trainer for facilities throughout the company.

\section{Teaching Experience}

Fall, 2009

Human Behavior Social Environment I

Kent School of Social Work, University of Louisville

Spring, 2010

Human Behavior Social Environment II

Kent School of Social Work, University of Louisville

Service

2009 - Present Kent School of Social Work, Faculty Meetings

Doctoral Representative, University of Louisville 
2008 - Present

$2006-2007$

2007

Since 2008

Since 2008

Since 2007

1997

1995

$2001-2002$

1998
Institutional Review Board

Doctoral Representative, University of Louisville

\section{Academic Affiliations}

Phi Alpha Academic Honor Society

Vice-President, University of Southern Indiana

Student Affairs Committee

Graduate Representative, University of Southern Indiana

\section{Certifications / Licensures}

Health Insurance Portability and Accountability Act (HIPAA) and Research Training

University of Louisville

Human Subject Protections Training/Collaborative Institutional Training Institute or "CITI"

University of Louisville

Licensed Social Worker

Professional Licensing Board, Indiana

Certified Peer Reviewer

Department of Juvenile Justice, Florida

United States Power Squadron

United States Coast Guard, South Carolina

\section{Civic Service}

Board of Adjustments

City of Oakland Park, Florida

Leadership Delray Beach

Greater Delray Beach, Florida 
Social Work and Research Organizations

Since 2008

Since 2008

Since 2006
Society for Social Work and Research (SSWR)

Active-member, University of Louisville

Public Responsibility in Medicine and Research (PRIM\&R)

Active-member, University of Louisville

National Association of Social Workers (NASW)

Active-member, University of Louisville \& University of Southern Indiana 